\title{
NUEVOS DATOS SOBRE ALGUNAS ESPECIES DE CRISÓPIDOS DE LA PENÍNSULA IBÉRICA, ISLAS BALEARES E ISLAS CANARIAS (INSECTA, NEUROPTERA, CHRYSOPIDAE)
}

\author{
Víctor J. Monserrat*, Fernando Acevedo** \& Roberto A. Pantaleoni*** \\ *** Departamento de Zoología y Antropología Física, Facultad de Biología, Universidad Complutense, \\ José Antonio Novais, 12. 28040 Madrid (España) \\ * artmad@bio.ucm.es - urn:Isid:zoobank.org:author:9D6FB187-2230-42DE-A754-20BE8A8BEB2A \\ ${ }^{* *}$ facevedoramos@gmail.com - urn:Isid:zoobank.org:author:322876C8-5F79-41DA-A479-838A86BA41D7 \\ *** Dipartimento di Agraria, Università degli Studi, via Enrico De Nicola, 07100 Sassari (Italia). r.pantaleoni@uniss.it \\ urn:Isid:zoobank.org:author:C9B155BB-E98D-45F7-AAB8-753E771B738B
}

\section{RESUMEN}

Se aportan nuevos datos de 41 especies de crisópidos de las Faunas Ibérica, Balear y Canaria. Se redescribe la morfología externa y genital de Chrysopa nigricostata Brauer, 1850 y se corrigen sus citas erróneas de España y Portugal, que mayoritariamente se asignan a Cunctochrysa cosmia (Navás, 1918). Se revalida la especie Chrysopa cosmia Navás, 1918 estatus válido restaurado (antes sinónima posterior de Chrysopa nigricostata) y se transfiere al género Cunctochrysa, proponiéndose una nueva combinación: Cunctochrysa cosmia (Navás, 1918) n. comb., y una nueva sinonimia: Cunctochrysa cosmia (Navás, 1918)=(Cunctochrysa bellifontensis Leraut, 1988) n. sin. Sobre el único ejemplar hasta ahora conocido de Cunctochrysa cosmia y el nuevo material ahora a ella asignado, se redescribe su morfología externa y genital, aportándose una clave de identificación para las tres especies europeas del género Cunctochrysa, anotándose nuevos datos para diferenciarlas tanto entre sí, como de otras especies europeas de similar morfología y coloración (Pseudomallada flavifrons, Chrysopa viridana y especialmente $C$. nigricostata). Por estas similitudes, se detectan algunos errores en la identificación de estas especies, se llama la atención sobre la posible confusión entre estas especies, y se sugiere revisar la autenticidad de sus sinonimias propuestas. Se establecen dos nuevas combinaciones: Pseudomallada subcostalis (McLachlan, 1882) n. comb. y Pseudomallada fortunatus (McLachlan, 1882) n. comb.

Palabras clave: Insecta; Neuroptera; Chrysopidae; faunística; biología; fenología; Península lbérica; Islas Baleares; Islas Canarias; Paleártico.

\section{ABSTRACT}

New data on some Iberian, Balearic and Canarian green lacewing species (Insecta, Neuroptera, Chrysopidae)

New data on 41 green-lacewings species belonging to the lberian, Balearic and Canarian faunas are given. The external morphology and genitalia of Chrysopa nigricostata Brauer, 1850 are re-described, and the erroneous citations given for Spain and Portugal, mostly assigned now to Cunctochrysa cosmia (Navás, 1918), are corrected. The species Chrysopa cosmia Navás, 1918 is confirmed, and its valid status reinstated (previously a later synonymous of Chrysopa nigricostata), and it is transferred to the genus Cunctochrysa, proposing a new combination: Cunctochrysa cosmia (Navás, 1918) n. comb., and a new synonymy: Cunctochrysa cosmia (Navás, 1918) $=($ Cunctochrysa bellifontensis Leraut, 1988 n. syn.) is now proposed. Based on the single known of Cunctochrysa cosmia and on the material now assigned to this species, its external and genital morphology are re-described, giving an identification key for the three European species of the genus Cunctochrysa, underscoring certain elements to differentiate them from one another, as well from other European species with a similar morphology and coloration (Pseudomallada flavifrons, Chrysopa viridana and specially C. nigricostata). Because of these similarities, some errors in the identification of these European species are detected. This paper draws attention on the possible confusion among these species, and it suggests checking the authenticity of its proposed synonyms. Two new combinations: Pseudomallada subcostalis (McLachlan, 1882) n. comb., and Pseudomallada fortunatus (McLachlan, 1882) n. comb. are proposed. 
Key words: Insecta; Neuroptera; Chrysopidae; Faunistics; Biology; Phaenology; Iberian Peninsula; Balearic Islands; Canary Islands; Palaearctic.

\section{Recibido/Received: 1/08/2013; Aceptado/Accepted: 14/02/2014; Publicado en línea/Published online: 29/08/2014}

Como citar este artículo/Citation: Monserrat, V. J., Acevedo, F. \& Pantaleoni, R. A., 2014. Nuevos datos sobre algunas especies de crisópidos de la Península lbérica, Islas Baleares e Islas Canarias (Insecta, Neuroptera, Chrysopidae). Graellsia, 70(1): e002. http://dx.doi.org/10.3989/graellsia.2014.v70.100

Copyright: (C) 2014 SAM y CSIC. Salvo indicación contraria, todos los contenidos de la edición electrónica de Graellsia se distribuyen bajo licencia de uso y distribución Creative Commons Reconocimiento no Comercial 3.0. España (cc-by-nc).

\section{Introducción}

La familia Chrysopidae es, sin duda, la mejor estudiada dentro del Orden Neuroptera s.str. Con una distribución cosmopolita (salvo la Antártida y zonas particularmente elevadas y frías), y mayoritariamente abundante y frecuente en zonas tropicales y templadas, está constituida por unas 1200 especies agrupadas en 86 géneros (Aspöck et al., 1980; Brooks \& Barnard, 1990), cifras que han venido incrementándose desde entonces (Aspöck et al., 2001). La familia fue revisada a nivel genérico por Brooks \& Barnard (1990), siendo resaltables algunas interesantes aportaciones generales (Canard et al., 1984; McEwen et al., 2001, etc.).

No sólo se trata de una de las familias del orden Neuroptera más extensas en cuanto al número de especies, sino también de una de las más importantes por su conocido interés aplicado/económico, pues muchas especies de esta familia son aliados agentes espontáneos sobre nuestros intereses en agricultura/ silvicultura, y son utilizadas en programas de control biológico contra plagas de pequeños fitófagos, especialmente áfidos, cóccidos y aleyródidos, ya que sus estadios larvarios, y también los imagos de algunos de sus géneros, depredan activamente sobre estos insectos, y por su labor como agentes espontáneos de control o por su empleo y cultivo por el hombre con el fin de combatir estas plagas, es una familia sobradamente reconocida (Canard et al., 1984; Principi \& Canard, 1984; Brooks \& Barnard, 1990; McEwen et al., 2001; Monserrat et al., 2001).

Muchas especies de esta familia son bien conocidas, en especial de las Regiones Paleártica y Neártica, cuyas faunas son las mejor estudiadas, si bien el límite real de distribución de muchas de sus especies es, con frecuencia, impreciso o incompleto, y en ocasiones los datos sobre su biología son escasos y fragmentarios, y el nivel de conocimiento de las faunas de muchos países, incluso en zonas relativamente bien estudiadas de Europa y Estados Unidos es aún poco satisfactorio. Este hecho se evidencia particularmente dentro algunos géneros, como Chrysopa, Pseudomallada, Chrysoperla o Cunctochrysa, géneros en los que la situación taxonómica definitiva de alguna de sus especies/ subespecies está aún por aclarar, bien por la falta de revisiones que pongan al día la información existente, o porque debido a diferencias halladas en la morfología o los sonidos de reclamo sexual entre diferentes poblaciones, nuevas especies y formas siguen apareciendo o revalidándose (ver datos más adelante al tratar estos géneros). Para los estadios juveniles de la mayoría de los taxa europeos y norteamericanos pueden consultarse Díaz-Aranda \& Monserrat (1995), Díaz-Aranda et al. (2001) y Monserrat \& Díaz-Aranda (2012).

En lo que respecta a las faunas de otros continentes, $\mathrm{y}$ aunque a nivel de género han sido revisadas (Brooks \& Barnard, 1990), mayoritariamente faltan multitud de datos, muchas de sus especies han sido escasamente citadas, y desconocemos su distribución real y la biología de muchas de ellas, y especialmente los estados larvarios son en su mayoría desconocidos (Díaz-Aranda et al., 2001), y todavía están por definirse numerosas especies que aún no han sido adecuadamente redescritas, por lo que el nivel de conocimiento es francamente incompleto.

En relación a la Fauna Ibero-Balear mencionemos que, a las especies de esta familia más comunes y habituales que históricamente fueron descritas o iban siendo conocidas en la Península Ibérica, se han venido añadiendo, más recientemente, nuevas opiniones y nuevos elementos (Brinckochrysa nachoi, Suarius iberiensis, S. walsinghami, S. tigridis, Chrysoperla mutata, Ch. mediterranea, Ch. ankylopteryformis, Ch. lucasina, Ch. pallida, Ch. agilis, Cunctochrysa baetica, Pseudomallada zelleri, Chrysopa abbreviata, C. dubitans, C. walkeri, etc.) (Hölzel \& Ohm, 1972; Hölzel, 1972a, b, 1974; Monserrat, 1977b, 1978a, 1984a, b, 1985, 1986; Aspöck et al., 1980; Díaz Aranda \& Monserrat, 1988a, b; Monserrat \& Díaz Aranda, 1989a, b, c; Monserrat \& Rodrigo, 1992; Monserrat et al., 1994; Henry et al., 2002, 2003, 2013; Fernández, 2003; Duelli et al., 2014, etc.).

Sobre la biología de las especies ibéricas, Monserrat \& Marín $(1994,2001)$ compendian toda la información existente hasta entonces sobre su preferencia de sustrato vegetal, y la recopilación de todos los datos existentes sobre la biología, fenología y distribución de las especies ibéricas ha sido recientemente anotada por Monserrat \& Díaz-Aranda (2012), quienes también describen en detalle los estadios larvarios de la mayoría de ellas. 
Desde el punto de vista taxonómico, las especies europeas/ibero-baleares fueron mayoritariamente revisadas por Hölzel \& Ohm (1972), Hölzel (1973) y Aspöck et al. (1980, 2001), existiendo un sinfín de nuevas aportaciones posteriores que afectan a la fauna que nos ocupa. Recientemente Monserrat (2008, $2010,2012,2013)$ anota nuevos elementos, resuelve la posición taxonómica de alguna especie, y corrige algunas citas que resultaban dudosas o cuestionables. Por último, Monserrat \& Triviño (2013) aportan un listado de todas las sinonimias y combinaciones nomenclatoriales bajo las cuales estas especies ibéricas/baleares han sido citadas en la bibliografía, anotando la problemática respecto a las citas antiguas de esta familia dadas en la Fauna Ibero-Balear, y también ponen en cuestión la validez de algunas citas más recientes: Chrysopa abbreviata Curtis, 1834, Chrysopa dubitans (McLachlan, 1887) y Chrysopa walkeri McLachlan, 1893, ofreciendo un cartografiado de la distribución de las especies ibero-baleares hasta entonces conocida.

Dada la multitud de artículos faunísticos y de otra índole que han aportado numerosos datos sobre la taxonomía, la morfología, la corología, los estadios larvarios y la biología de las especies ibero-baleares, puede indicarse que en el caso de la Fauna Ibérica, han acabado por conformar una de las familias más ricas en especies dentro de la Fauna Europea, representando la fauna más abundante y diversa del Continente Europeo, ya que en ella están representados todos los géneros conocidos del continente europeo (Hölzel \& Ohm, 1972; Aspöck et al., 1980, 2001; Aspöck, 1992; Monserrat \& Díaz-Aranda, 2012), y en ella están presentes 49 de las 52 especies europeas hasta ahora conocidas. La cifra alcanza las 50 de las 52 especies europeas, ya que ahora añadimos Chrysopa cosmia Navás, 1918 estatus válido restaurado, especie anteriormente considerada como sinónima posterior de Chrysopa nigricostata Brauer, 1850, y que transferimos al género Cunctochrysa, redescribiendo su morfología y su genitalia, proponiéndose una nueva combinación: Cunctochrysa cosmia (Navás, 1918) n. comb., y proponemos una nueva sinonimia: Cunctochrysa cosmia (Navás, 1918) $=$ Cunctochrysa bellifontensis Leraut, 1988 n. sin.

Con respecto a la fauna de crisópidos de las Islas Baleares, hasta el momento son conocidas 15 especies (Monserrat, 2005) de las que ahora aportamos algunas novedades, y ahora citamos Chrysoperla lucasina en Menorca; y sobre la fauna de las Islas Canarias, donde también se ha citado alguna reciente novedad taxonómica o invasora (Chrysoperla nigrinervis, Chrysoperla lucasina, Chrysopa pallens, Pseudomallada flavifrons, Cunctochrysa albolineata), son conocidas 11 especies (Ohm \& Báez, 2004; Monserrat, 2008; Báez \& Oromí, 2010), y también ahora anotamos interesantes novedades sobre su fauna de crisopas. La morfología larvaria de algunas especies canarias fue estudiada por Monserrat (1978a, 1982).

A pesar de todo este enorme acervo de información que recientemente se ha venido aportando sobre la fauna de crisópidos ibero-balear y canaria, aún existen multitud de lagunas y enormes áreas completamente inexploradas sobre este grupo dentro del solar ibéricobalear (Monserrat \& Triviño, 2013) y/o canario, y nuevas prospecciones y aporte de datos taxonómicos, morfológicos, faunísticos y biológicos son necesarios para ir alcanzando un nivel de conocimiento suficientemente satisfactorio. Prueba de todo lo que aún cabe esperar sobre ello son las novedades taxonómicas y faunísticas anotadas en la presente contribución.

En ella anotamos nuevos datos sobre la distribución geográfica, la biología, la fenología, la taxonomía, la morfología y/o los estadios larvarios de 41 especies pertenecientes a esta familia que citamos de la Península Ibérica, Islas Baleares e Islas Canarias (6 de ellas de la fauna balear y 5 de la canaria), alguna de ellas muy poco citadas con anterioridad en alguna de estas zonas. De entre ellas, y como se ha indicado, se redescribe la morfología externa y la genitalia de Chrysopa nigricostata Brauer, 1850, y se corrigen y rectifican las numerosas citas erróneas que se habían dado sobre esta especie de España y Portugal, y que ahora han sido mayoritariamente asignadas a Cunctochrysa cosmia (Navás, 1918) n. comb., redescribiendo esta especie y anotándose ciertos elementos sobre su morfología y su biología que ayuden a diferenciarlas tanto entre sí, como de otras especies europeas de estos u otros géneros que poseen similar morfología y coloración externa (Chrysopa viridana, Pseudomallada flavifrons, Cunctochrysa baetica y Cunctochrysa albolineata). Debido a estas similitudes, se han detectado y se corrigen algunos errores en la identificación de ejemplares relacionados con estas especies europeas, se llama la atención sobre la posible confusión en las identificaciones de material europeo pertenecientes a estas especies, y se comentan y se sugiere revisar la autenticidad de sus sinonimias anteriormente propuestas y comúnmente aceptadas.

También se establecen dos nuevas combinaciones: Pseudomallada subcostalis (McLachlan, 1882) n. comb. y Pseudomallada fortunatus (McLachlan, 1882) n. comb.

\section{Material y métodos}

La mayoría de los ejemplares que se citan pertenecen a la colección de V. J. Monserrat (Madrid), sin embargo, otro material estudiado pertenece a diferentes instituciones y colecciones que a continuación listamos, anotando las siglas empleadas, sólo en estos casos, para indicar la pertenencia del material que se cita:

(DV): Colección Daniel Ventura (Menorca, España).

(MCNB): Museu de Ciències Naturals (Barcelona, España). 
(MCNT): Museo de Ciencias Naturales de Tenerife (Tenerife, España).

(MCT): Colección M. Carles-Tolrá (Barcelona, España). (MNCN): Museo Nacional de Ciencias Naturales (Madrid, España). (RP): Colección Roberto A. Pantaleoni (Sassari, Italia). (UL): Universidad de León (León, España).

Las especies se mencionan siguiendo la sistemática y la terminología general de Brooks \& Barnard (1990), y para la información sobre su distribución general se sigue a Aspöck et al. $(1980,2001)$. De cada una de las 41 especies citadas en esta contribución anotamos una breve sinopsis de su distribución general conocida, de sus preferencias ecológicas y de sustrato vegetal en la zona de estudio, actualizando lo anotado para las especies ibero-baleares por Monserrat \& Marín $(1994,2001)$ y Monserrat \& Díaz-Aranda (2012), así como de los datos más significativos que merezcan citarse en relación al nuevo material ahora aportado.

Para la exposición del material estudiado, los datos se citan ordenados alfabética- y cronológicamente, siguiendo la siguiente secuencia: país, provincia - archipiélago - isla, localidad de captura, fecha de

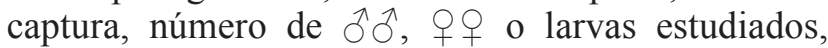
datos de biología/planta sustrato sobre el que los nuevos ejemplares han sido capturados, recolector e institución a la que dicho material pertenece, según las siglas anteriormente anotadas. Para no reiterar en esta exposición datos del país, provincia, isla, localidad, fecha de captura, etc., los datos se separan por comas o puntos según se haya citado, o no, parte de la información (país, provincia, isla, localidad, fecha de captura, etc.) de los ejemplares mencionados inmediatamente antes de los que se exponen, y para no hacer cansina la repetición del sustrato vegetal sobre el que los ejemplares se han capturado o de los recolectores del material citado, se apocopará el género de la planta sustrato una vez citada dentro del material de cada especie ahora mencionada, y solo se anotarán los recolectores cuando estos no hayan sido los autores de esta contribución. Para la información que porta el material tipo estudiado, se separan por barras (/) la que corresponde a cada una de las diferentes etiquetas que cada ejemplar porta. La relación de las coordenadas UTM y altitud s. n. m. de las localidades ibero-baleares y canarias citadas se adjunta en el Apéndice 1.

De cada especie anotamos los datos altitudinales (se ha considerado $10 \mathrm{~m}$ como el de nivel mar) y los fenológicos existentes sobre la captura de imagos en la península y Baleares, incluyendo los datos del nuevo material ahora citado (se excluyen los datos de los ejemplares adultos obtenidos ex ovo o ex larva cultivadas en condiciones de laboratorio). Para esta información, y salvo las especies de Rexa, Hypochrysa, Italochrysa, Chrysotropia y Nothochrysa, no se han considerado los datos existentes en la bibliografía dados por autores anteriores, salvo aquellos de reconocida solvencia, o correspondientes a material revisado por nosotros o por estos autores.

Cuando ha sido necesario, para acceder a sus estructuras y genitalia internas, el abdomen de los imagos era previamente reblandecido en agua y tratado con ácido láctico templado hasta aclararlas y, ocasionalmente, se ha empleado negro de clorazenol para acceder a las estructuras internas menos visibles. Las medidas fueron tomadas con un calibre automático con ayuda de un micrométrico, y se tomó como medida la distancia alar desde la base del ala hasta el extremo distal, tanto de las alas derechas / izquierdas, como anteriores / posteriores.

Para las observación, identificación y descripción de la mayoría de los ejemplares estudiados se utilizó una lupa ZEISS ${ }^{\circledR}$ STEMI-SV8 con cámara clara de dibujo incorporada (Figs. 1-9). La mayor parte de las fotografías del aspecto general y detalles de los adultos (Figs. 10-21) fueron tomadas con una lupa Olympus ${ }^{\circledR}$ SZX7, con cámara Olympus ${ }^{\circledR}$ S-C-30 integrada, utilizando para su proceso el software analySIS getIT. En otras fotografías de otro material estudiado (Figs. 22-27), un estereomicroscopio Leica ${ }^{\circledR}$ MZ9.5 se utilizó para las observaciones morfológicas, mientras que un estereomicroscopio Leica ${ }^{\circledR}$ MZ16 equipado con una cámara digital DFC320 fue utilizado tanto para las mediciones morfológicas como para realizar las fotografías que fueron posteriormente retocadas con el software LAS (Leica Application Suite) Versión 2.5.0 R1. El software Adobe Photoshop CS5 Extended Version 12.0 fue utilizado para el procesamiento de todas las imágenes.

Los mapas de distribución en la Península Ibérica de alguna de las especies de crisopas citadas (Figs. 29, 30) han sido realizados con el programa informático de libre distribución DIVA-GIS. Este, junto a las capas con los límites administrativos de los países y sus provincias o distritos que constituyen la Península Ibérica, ha sido obtenido a través de la web de DIVA-GIS (http:// www.diva-gis.org), y están proyectadas en coordenadas de longitud y latitud geográficas. Las coordenadas de los puntos que reflejan los registros que disponemos (Figs. 29, 30) se encuentran en coordenadas UTM con precisión de $10 \mathrm{~km}^{2}$ (MGRS), y estas coordenadas están transformadas a geográficas a través de Geotrans (http://earth-info.nga.mil/GandG/geotrans).

\section{Resultados y Discusión}

Nothochrysinae Navás, 1910

\section{Hypochrysa elegans (Burmeister, 1839)}

Especie europea extra-mediterránea, extendida hasta Anatolia e Irán. En la península es local y de biología poco conocida. En ocasiones los datos citados para esta especie coinciden con lo conocido en otras partes de Europa, aunque en otras ocasiones estos datos no parecen coincidir (Aspöck et al., 1980; Pantaleoni, 1996). En la península parece estar 
asociada tanto a coníferas (Abies) como a planifolios (Fagus, Quercus, Crataegus), generalmente en zonas montanas y húmedas, y se circunscribe a su zona septentrional eurosiberiana. En la península se ha recolectado entre V y VIII, en altitudes que oscilan entre 150 y $1400 \mathrm{~m}$.

Material estudiado: ESPAÑA: Gerona, Molló, 21.VIII.1999, $1 \hat{\jmath}, \mathrm{G}$. Bonet.

Chrysopinae Schneider, 1851

Belopterygini Navás, 1913

Italochrysa italica (Rossi, 1790)

Especie holomediterránea expansiva, extendida hasta Irak. En la península es conocida de Portugal y España (incluyendo Baleares). Fuertemente asociada a medios térmicos mediterráneos, y citada sobre diversa vegetación arbórea (Pinus, Quercus, Ceratonia, Ulmus, Olea, Eucaliptus). Sus estadios larvarios se desarrollan a expensas de hormigueros de Crematogaster scutelaris (Olivier, 1791). En la península se ha recolectado entre VI y IX, en altitudes que oscilan entre 10 y $2000 \mathrm{~m}$.

Material estudiado: ESPAÑA: Barcelona, Cabrils, 24.VII.2000, 1 đ̂ a la luz, M. Carles-Tolrá (MCT). Granada, El Dornajo, 10.VII.2012, 1 q sobre Platanus acerifolia. Este ejemplar realizó una puesta (el 13.VII.2012) formada por nueve huevos de color blanquecino y de aspecto característico (Principi, 1946; Monserrat \& Díaz-Aranda, 2012), de los que emergieron las larvas neonatas (el 21.VII.2012). Con gran actividad iniciaron la realización de su capa de camuflaje, sin que parecieran estar interesadas por las pupas de Plagiolepis pygmaea (Latreille, 1798) que se les proporcionaron [similar comportamiento fue observado por Monserrat \& Díaz-Aranda, 2012 en larvas neonatas de Italochrysa stigmatica (Rambur, 1842), quienes ofrecieron larvas de hormigas por las que, es este estadio, no prestaron el más mínimo interés], por lo que parece que esta especie de hormiga no debe ser considerada como potencial alimento de sus larvas, al menos en este estadio, a diferencia de Crematogaster scutellaris (Olivier, 1792), con la que Principi (1946) obtuvo éxito en el desarrollo de sus estadios larvarios. Zaragoza, Perdiguera, 29.VIII.2013, 1 q, C. Escuer.

\section{Italochrysa stigmatica (Rambur, 1842)}

Especie eremial expansiva, conocida desde España (incluyendo Baleares), Marruecos y norte de África, a Arabia Saudí e Irán. Asociada a medios térmicos de carácter mediterráneo, con cierta frecuencia hallada sobre gramíneas (Stipa) y otros fanerófitos y herbáceas (Retama, Vicia). En la península se ha recolectado entre $\mathrm{V}$ y $\mathrm{X}$, en altitudes que oscilan entre $10 \mathrm{y}$ $1500 \mathrm{~m}$.

Material estudiado: ESPAÑA: Almería, Almerimar, 11.IX.2011, 1 §ै, M. A. Dionisio, Rambla del Agua, 29.VI.2011, 1 §, Retamar, Rambla del Retamar, 20.VII.2011, 1 今 a la luz. Cádiz, Puerto del Boyar, 22.VI.2012, 1 + sobre Ceratonia siliqua. Huelva, Patrás, 19.VI.2012, 1 \& sobre Erica terminalis.

\section{Italochrysa sp.}

Merced a la información proporcionada por Arp Kruithof y que está expuesta en el foro que anotamos: http://www.flickr.com/photos/lagrimon/5587572138/ in/set-72157625678841053/, han aparecido interesantes citas de especies de crisópidos que han sido fotografiadas en diferentes localidades de las Islas Canarias y que consideramos interesante contribuir a difundir, a la espera de que la recolecta de ejemplares confirme las identificaciones que ahora anotamos sobre alguna de ellas. Entre ellas es destacable un ejemplar de Italochrysa sp., que representaría la primera cita de este género en las Islas Canarias. El género posee una amplia distribución en Europa, Asia, Australia y África (Brooks \& Barnard, 1990). En la Macaronesia sólo es conocida I. lobini Hölzel \& Ohm, 1982 citada de Cabo Verde, Argelia, Senegal y Nigeria (Aspöck et al., 2001), especie a la que podría pertenecer el ejemplar que ahora mencionamos.

Material anotado en la citada web: ESPAÑA: Islas Canarias, Gran Canaria, Sardina, 3.IV.2011, 1 ㅇ, D. Marquina.

Chrysopini Schneider, 1851

Nineta flava (Scopoli, 1763)

Especie europea extra-mediterránea expansiva, extendida hasta Anatolia, Cáucaso e Irán. Mayoritariamente asociada a planifolios en zonas húmedas y montanas. En la península es conocida de su mitad septentrional en estos medios. Se ha recolectado entre VI y VIII, en altitudes que oscilan entre 400 y $2250 \mathrm{~m}$.

Material estudiado: ESPAÑA: Gerona, Molló, 21.VIII.1999, $2 \lesssim \widehat{\partial}$, G. Bonet.

\section{Nineta guadarramensis (Pictet, 1865)}

Especie atlantomediterránea, conocida de la Península Ibérica y Marruecos. Está asociada a planifolios (especialmente Quercus spp. marcescentes) en zonas húmedas y montanas de carácter mediterráneo. En la península se ha recolectado entre $\mathrm{V}$ y X, en altitudes que oscilan entre 15 y $2000 \mathrm{~m}$.

Material estudiado: ESPaÑa: Cádiz, Estación de la Almoraima, 21.VI.2012, 1 đิ sobre Quercus canariensis.

\section{Peyerimhoffina gracilis (Schneider, 1851)}

Especie europea expansiva, extendida hasta Marruecos, Argelia, Anatolia y Cáucaso. Generalmente local, poco frecuente, y mayoritariamente asociada a coníferas. En la península se circunscribe mayoritariamente a la región pirenaica, y se ha recolectado entre VI y IX, en altitudes que oscilan entre 1070 y $1340 \mathrm{~m}$.

Material estudiado: ESPAÑA: Gerona, Molló, 21.VIII.1999, 2

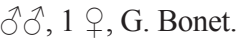

\section{Chrysotropia ciliata (Wesmael, 1841)}

Especie eurosiberiana. Asociada a planifolios en medios húmedos y montanos. En la península se circunscribe al tercio septentrional, donde se ha recolectado entre IV y IX, en altitudes que oscilan entre $30 \mathrm{y}$ $1470 \mathrm{~m}$.

Material estudiado: ESPAÑA: Gerona, Molló, 21.VIII.1999, 1 o, 1 \&, G. Bonet. 


\section{Chrysopa perla (Linnaeus, 1758)}

Especie eurosiberiana asociada a vegetación de rivera, herbácea y a matorrales en medios húmedos. En la península se circunscribe a su región septentrional eurosiberiana y se ha recolectado entre V y VIII, en altitudes que oscilan entre 650 y $1890 \mathrm{~m}$.

Material estudiado: ESPAÑA: Huesca, San Juan de Plan, 17.VIII.1982, 1 § sobre hierba.

\section{Chrysopa pallens (Rambur, 1838)}

Especie paleártica, extendida por acción humana a otras zonas (Mauricio, Taiwán y Camboya). Marcadamente eurioica y generalmente asociada a medios arbóreos abiertos y soleados. Conocida de toda la península y Baleares (Mallorca y Menorca). Se ha recolectado entre IV y IX, en altitudes que oscilan entre 10 y $1340 \mathrm{~m}$.

Material estudiado: ESPAÑA: Granada, La Herradura, Punta de la Mona, 26.VII.2010, 2 q $q$ a la luz, 16.VIII.2011, 1 đ a la luz, 21.VIII.2011, 1 q a la luz, 11.VII.2012, 1 + a la luz, 10.VIII.2012, 1 a la luz. Guadalajara, Brihuega, 11.VII.2010, 1 a la luz. Madrid, San Fernando de Henares, 19.VII.2010, 1 o, 29.V.2011, 1 §, J. I. López Colón.

\section{Chrysopa dorsalis Burmeister, 1839}

Especie pontomediterránea, ampliamente citada en Europa, y en Asia, desde Georgia, Anatolia e Israel a Kazakhstán. Conocida de toda la península, posee una cierta tendencia orófila y una marcada preferencia por las coníferas (especialmente Pinus y Juniperus). El estudio del ejemplar tipo de Chrysopa regalis Navás, 1915 confirma la sinonimia entre esta especie y la ahora que tratamos, que ya propuso Monserrat (2008). En la península se ha recolectado entre V y IX, en altitudes que oscilan entre 90 y $1350 \mathrm{~m}$.

Material estudiado: ESPAÑA: Barcelona, Cabrils, Can Tolrá, 25.VII.1996, 1 a la luz, M. Carles-Tolrá. Tarragona, / Arnes (T) 28.VIII.13 (1913) / Typus / Chrysopa regalis Nav. Navás S. J. / 1 o (MCNB).

\section{Chrysopa phyllochroma Wesmael, 1841}

Especie ampliamente distribuida en Europa, muy escasamente citada en la fauna ibérica (Granada, Lérida, Almería), existiendo identificaciones, no siempre incuestionables, de escasos ejemplares: Navás (1915, 1924 a, 1925a); Vidal \& López (1943); Hölzel (1964); Hölzel \& Ohm (1972); Aspöck et al. (1980); Monserrat (1987); Monserrat \& DíazAranda (1989 a). Tenemos ciertas dudas sobre la autenticidad en la asignación a esta especie de los ejemplares ibéricos en medios meridionales térmicos, ya que se trata de una especie marcadamente montana, y sólo cabría ser correcta, si acaso, la cita de Lérida. En cualquier caso, hasta no recolectar algún ejemplar macho, mantenemos esta situación a la espera de que pueda ser resuelta. En la península se ha citado entre VI y VII, en altitudes que oscilan entre 10 y $1000 \mathrm{~m}$.
Material estudiado: ESPAÑA: Almería, San José, Playa de Mónsul, 14.VI.2012, 1 q sobre Nerium holeander.

\section{Chrysopa flaviceps (Brullé, 1839)}

Especie endémica de las islas occidentales de Canarias (El Hierro, La Palma, La Gomera, Tenerife, Gran Canaria). Aparentemente euroica y con una cierta tendencia orófila.

Material estudiado: ESPAÑA: Islas Canarias, Tenerife, Cumbres de Arafo, 7.VI.1990, $2 \widehat{\jmath} \widehat{\jmath}$, G. Ortega (MCNT), Las Cañadas, 14.VI.1979, 1 +, M. Báez (MCNT).

\section{Chrysopa viridana Schneider, 1845}

Especie holomediterránea expansiva hacia el Cáucaso, Irán, Afganistán y Turkmenistán, asociada a medios mediterráneos, mayoritariamente hallada sobre Quercus spp. esclerófilos en estos medios mediterráneos, y también recolectada sobre una amplia gama de sustratos vegetales (oleáceas, salicáceas, sapindáceas, coníferas, cultivos, jardines, etc.). Ampliamente citada en la península entre $\mathrm{V}$ y $\mathrm{X}$, en altitudes que oscilan entre 10 y $2250 \mathrm{~m}$.

La posición taxonómica de esta especie dentro del género Chrysopa dista de ser satisfactoria, ya que numerosos estudios destacan sus particularidades frente a otras especies del género. Iniciando el comentario sobre estas diferencias con sus estadios larvarios, y siguiendo la terminología larvaria de Monserrat \& Díaz-Aranda (2012), ha de indicarse que estos autores la citan como permanente excepción en los caracteres que definen las larvas de este género: $C$. viridana es la única especie de este género que posee seta cefálica S-12, elemento que para esta especie ya había sido registrado por Principi (1954), y la ausencia o presencia de dicha seta es un dato definitoriamente característico a nivel de género dentro de las larvas de esta familia, manteniéndose siempre como un carácter constante en todas las especies europeas estudiadas dentro de cada uno de los géneros que han sido descritos hasta el presente. La presencia de seta S-12 en las larvas de esta especie, junto al escaso desarrollo de los tubérculos laterodorsales del abdomen y a la longitud, relativamente corta, de las setas de sus tubérculos dorsales y laterales, hacen que esta especie se separe marcadamente de las restantes del género (Principi, 1954; Monserrat \& DíazAranda, 2012).

Por otra parte, y en relación con la morfología y genitalia de sus imagos, Brooks \& Barnard (1990) anotan numerosos caracteres morfológicos y genitales que diferencian a $C$. viridana de las restantes especies del género analizadas, como es su pigmentación cefálica, solo con tenues manchas rojizas y pardas sobre las genas, pero sin abundantes puntos, manchas o bandas negras sobre el vértex, coloración característica de otras especies del género, y ausencia de gonocoristae en la genitalia masculina, que caracteriza a las restantes especies del género (ver como ejemplo figs. 7-8 para C. nigricostata). También 
Canard et al. (1990) y Canard (2001) anotan significativas diferencias en los diámetros de los troncos traqueales de esta especie (excepcionalmente grandes) en comparación a las restantes especies consideradas del género Chrysopa, hecho que también sugiere distintos hábitos alimenticios. También Günsten (com. per.) indica que esta especie posee glándulas torácicas diferentes a otras especies de este género.

Con relación a otro tipo de estudios, Bullini et al. $(1983,1984)$ y Bullini \& Cianchi (1984), mediante la realización de estudios electroforéticos de enzimas, también anotan que $C$. viridana es una especie genéticamente muy diferente a las otras especies del género Chrysopa estudiadas en dichos trabajos, y recientes estudios han demostrado nuevas vías moleculares aplicables a la taxonomía y sistemática de la familia Chrysopidae, y entre ellos, Cadena et al. (2007) sostienen la presencia de especies y géneros morfológicamente muy semejantes que requieren un examen más cuidadoso, y Haruyama et al. (2008), y en lo que respecta a esta especie, anotan que $C$. viridana se separa en un exclusivo cluster respecto a las restantes especies de este género por ellos consideradas.

Todos estos hechos alejan a esta especie de su posición taxonómica actual habitualmente aceptada, y prueban, una vez más, la necesaria revisión a fondo del género Chrysopa, hecho que ya ha sido sugerido por numerosos autores (Naville \& Beaumont, 1933, 1936; Killington, 1937; Adams, 1975; Principi, 1977; New, 1984; Séméria, 1984a; Brooks \& Barnard, 1990; Cadena et al., 2007, etc.).

Material estudiado: ESPAÑA: Cádiz, Bolonia, 21.VI.2012, 1 Ĵ, 2 우우 sobre Pistacea lentiscus, Estación de la Almoraima, 21.VI.2012, 1 ô sobre Quercus canariensis, Pinsapar de Grazalema, 22.VI.2012, 1 \& sobre Q. rotundifolia. Ciudad Real, Navas de Estena, 7.VII.2012, 3 ôे sobre Q. ilex. Granada, Dehesa del Camarate, 19.VII.2011, 3 우 우 sobre Q. pyrenaica, Dúdar, VIIVIII.2005, 1 §, A. Tinaut, El Dornajo, 10.VII.2013, 1 क sobre Q. rotundifolia, Lugros, 19.VII.2011, 1 त sobre Q. pyrenaica. Huelva, La Corte, 19.VI.2012, 2 ठิ $\widehat{~}$ sobre Q. rotundifolia. Madrid, Alpedrete, 14.VII.1976, 1 \&, Embalse de la Pedrezuela, 12.VIII.2010, 1 ऊे sobre Q. faginea, San Fernando de Henares, 8.IX.2011, 2 우, 9.IX.2011, 1 , J. I. López Colón, 10.IX.2011, 2 우, J. I. López Colón.

\section{Chrysopa formosa Brauer, 1850}

Especie paleártica, marcadamente eurioica. Ampliamente citada en toda la península y Baleares, donde se ha recolectado entre IV y $\mathrm{X}$, en altitudes que oscilan entre 10 y $1750 \mathrm{~m}$.

Material estudiado: ESPAÑA: Almería, El Toyo, Rambla del Agua, 6.V.2011, 1 ㅇ sobre Tamarix sp., 2 ठ추, 1 ㅇ sobre Atriplex halinus, Rambla del Retamar, 14.I.2012, 1 ㅇ a la luz, Tabernas, 18.VII.2011, 1 q sobre Tamarix gallica. Baleares, Ibiza, Santa Eulalia, 16.VII.2010, 1 \& a la luz. Cádiz, Barbate, 24.V.2012, 1 q a la luz. Ciudad Real, Navas de Estena, 7.VII.2012, 1 \& sobre Quercus ilex. Granada, La Herradura, Punta de la Mona, 8.VII.2013, 1 q a la luz. Huelva, Punta Umbría, 23.V.2012, 1 q a la luz, 20.VI.2012,

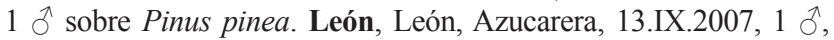
M. C. Delgado (UL). Madrid, Alcorcón, 7.IX.2010, 1 ㅇ a la luz,
San Fernando de Henares, 19.VII.2010, 3 $\widehat{\jmath}, 1$ ㅇ, J. I. López Colón, 22.VII.2010, 1 ðૈ, J. I. López Colón, 24.VII.2010, 1 q, J. I. López Colón. Salamanca, Berruecopardo, 31.V.2009, 1 q sobre $Q$. rotundifolia.

\section{Chrysopa nigricostata Brauer, 1850}

Especie holomediterránea expansiva hacia Anatolia, el Cáucaso, Armenia, Irak, Irán, Afganistán, Turkmenistán, Azerbaiyán, Tadschikistán, Kirguistán, Tayikistán y Kazakstán. Marcadamente estenotópica y frecuentemente citada en la bibliografía asociada a choperas y a pinares en medios mediterráneos. También más escasamente citada en bosques de galería, de robles y encinas, etc.

En la Península Ibérica esta especie está citada con cierta frecuencia desde principios del pasado siglo por Navás (1901, 1904, 1905, 1908, 1914a, 1915, 1917, 1918, 1924a, 1925a, 1931) de Aragón (Zaragoza, Veruela, Hecho, "Pirineos"), Castilla (Burgos) y Madrid (Chamartín), bien como Chrysopa nigricostata Brauer, 1850, como Chrysopa nigricostata ataresi Navás, 1914, como Chrysopa nigricostata marginata Navás, 1904, e indirectamente como Chrysopa cosmia Navás, 1918, pues más adelante, esta especie será sinonimizada a Chrysopa nigricostata por Hölzel (1973), y ahora haremos algún comentario sobre estas citas. Estas referencias han generado alguna reseña a España en la distribución general de esta especie (Hölzel, 1965; Sengonca, 1980; Séméria, 1984b, etc.) sin que sepamos, se haya aportado nuevo material de la zona por estos u otros autores, salvo el nuevo material ahora citado, y únicamente Hölzel \& Ohm (1972) y Hölzel (1973) anotan la presencia de esta especie en España y Portugal en base al material tipo de Chrysopa cosmia de Hecho (Huesca), ya citado por Navás $(1917,1918,1924 a)$ y a nuevo material recolectado en Portugal, Manteigas (Serra da Estrêla).

Nosotros hemos estudiado el material citado por Navás como Chrysopa nigricostata marginata Navás, 1904 y Chrysopa nigricostata ataresi Navás, 1914, comprobando la ausencia de interés taxonómico como tales variedades, que simplemente pertenecen a Chrysopa nigricostata Brauer, 1850, confirmando pues su presencia en Aragón (Zaragoza, Veruela), Castilla (Burgos) y Madrid (Chamartín), y así lo anotamos en el material ahora estudiado (Fig. 29), mientras que la cita basada en el ejemplar de Hecho, "Pirineos", citado por Navás (1918), Hölzel \& Ohm (1972) y Hölzel (1973) (material tipo de Chrysopa cosmia que citamos en el material estudiado de esta especie) no deben considerarse, ya que, en realidad, no pertenece a Chrysopa nigricostata, sino a Cunctochrysa cosmia (Navás, 1918) n. comb., y que, como veremos, son dos especies diferentes (Figs. 1-15, 16-23).

Hemos pues estudiado la mayoría de los ejemplares citados por L. Navás como Chrysopa nigricostata, y uno de los dos ejemplares estudiados por $\mathrm{H}$. Hölzel, y aunque no sabemos con seguridad si la cita de Portugal: Manteigas (Serra da Estrêla) (Hölzel \& 


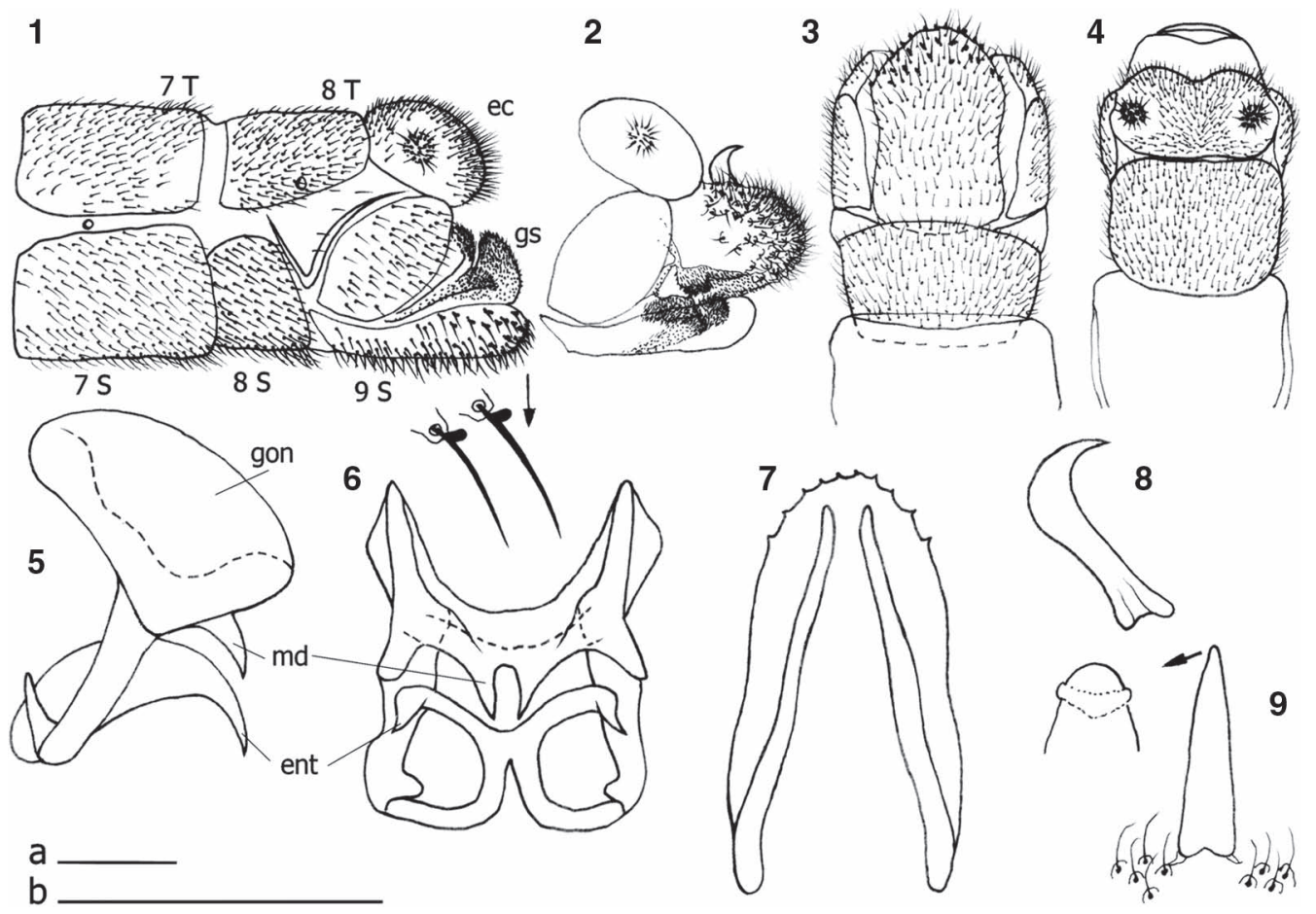

Figs. 1-9.- Chrysopa nigricostata, ô 1) Extremo abdominal, vista lateral (aumentadas dos setas). 2) Ídem, con gonosaco evaginado. 3) Ídem, vista ventral. 4) Ídem, vista dorsal. 5) Complejo gonarco-mediuncos-entoprocesos, vista lateral. 6) Ídem, vista caudal. 7) Apodemas del noveno esternito, vista interior dorsal. 8) Arceso, vista lateral. 9) İ́dem, vista dorsal (aumentado el ápice). ec: ectoprocto, ent: entoproceso, gon: gonarco, gs: gonosaco, md: mediunco, s: esternito, t: terguito. Escalas 0,5 mm, a: $1-4$, b: 5-9.

Figs. 1-9.- Chrysopa nigricostata, ô 1) Abdominal apex, lateral view (two magnified setae). 2) Ditto, with gonosacus evaginated. 3) Ditto, ventral view. 4) Ditto, dorsal view. 5) Complex gonarcus-mediuncus-entoprocessus, lateral view. 6) Ditto, caudal view. 7) Apodemes of ninth sternite, dorsal interior view. 8) Arcessus, lateral view. 9) Ditto, dorsal view (magnified apex). ec: ectoproct, ent: entoprocessus, gon: gonarcus, gs: gonosacus, md: mediuncus, s: esternite, t: terguite. Scale bar 0.5 mm, a: 1-4, b: 5-9.

Ohm, 1972; Hölzel, 1973) corresponde en realidad a Chrysopa nigricostata, por considerar este autor ambas especies como sinónimas, pero por la altitud $(850 \mathrm{~m})$ y la ubicación de la cita, nos inclinamos a considerar que, también en este caso, se trata de Cunctochrysa cosmia, que ahora citamos y confirmamos su presencia en Portugal (Fig. 30) (ver más adelante diferencias anotadas en la biología de ambas especies). No podemos asegurar si otras citas antiguas se corresponden con la realidad taxonómica de la especie que ahora tratamos, quizás excepción hecha de las correspondientes a Chrysopa nigricostata marginata Navás, 1904, que sí parece ajustarse plenamente a lo que ahora consideramos como verdadera Chrysopa nigricostata.

Ahondando en la confusión entre ambas especies, y sobre las numerosas citas de material ibérico que en las últimas décadas nosotros hemos venido dando bajo el nombre de Chrysopa nigricostata, adelantamos que también hemos detectado una casi generalizada confusión entre lo que considerábamos como ejemplares pertenecientes a esta especie y lo que ahora conocemos sobre Chrysopa cosmia Navás, 1918 [ver más adelante Cunctochrysa cosmia (Navás, 1918) n. comb.] a la que corresponden la mayoría de los ejemplares que anteriormente habíamos citado como Chrysopa nigricostata, y corregiremos estos errores más adelante al tratar esta especie. Definir incuestionablemente estos dos taxones es uno de los principales motivos de esta contribución.

Conocida esta problemática, y para hacer aún más compleja la situación, también es conocida (y ahora lo hemos corroborado) la enorme similitud morfológica entre estas dos especies y otras especies europeas de morfología y pigmentación externa muy similar (Chrysopa viridana, Pseudomallada flavifrons, Cunctochrysa albolineata o Cunctochrysa baetica), hecho del que ahora hablaremos y trataremos también de contribuir a dilucidar, aportando nuevos datos diagnósticos que ayuden a diferenciarlas. Por todo ello mantenemos ciertas reservas sobre la veracidad/ autenticidad o posible confusión entre estas especies de morfología externa bastante similar, y de hecho, citamos algunas confusiones en el material (no solamente ibérico) ahora estudiado (ver material citado de Chrysopa viridana, Pseudomallada flavifrons, Cunctochrysa albolineata, Cunctochrysa baetica o Cunctochrysa cosmia). 
En el caso de las abundantes citas ibéricas existentes en la bibliografía no corroboradas por nosotros, y ante la posibilidad de mezclar información de varias especies, las citas antiguas de estas especies no fueron consideradas en el cartografiado que sobre la distribución de estas especies hemos recientemente aportado (Monserrat \& Triviño, 2013). En cualquier caso ahí queda sin resolver esta cuestión a la espera de que se localicen y/o revisen las identificaciones del restante material ibérico que pueda haberse conservado (Hölzel \& Ohm, 1972), y que estos datos se sumen a los recientes datos derivados del estudio de parte del material que ya ha sido revisado. Veamos las causas de estas posibles confusiones.

Dado que la mayor parte de las especies europeas/ ibéricas de esta familia poseen caracteres de morfología y pigmentación externa que permiten su diferenciación específica, mayoritariamente se recurre, por comodidad, a estos caracteres para identificar la mayoría de sus especies, en particular dentro de los géneros Chrysopa, Chrysoperla, Pseudomallada, Hypochrysa, Nothochrysa, Italochrysa, Peyerimhoffina, Chrysotropia, Rexa o Suarius, y así se recoge en la mayoría de las claves existentes en la bibliografía, donde como veremos poniendo como ejemplo la especie que ahora tratamos, se ha dado poca o muy poca importancia a la genitalia en las especies europeas de esta familia, en comparación con otras familias (Raphidioptera: Raphidiidae, Inocelliidae; Megaloptera: Sialidae; Neuroptera: Coniopterygidae, Hemerobiidae, Sisyridae, Nevrorthidae, Dilaridae, etc.) en las que, mayoritariamente, se recurre a la genitalia para las identificaciones. Ha de citarse como excepción a Principi, 1949, 1954, 1956, 1977; Kis et al., 1970; Hölzel \& Ohm, 1972; Hölzel, 1973, etc., que han tratado profusamente el tema en algunas especies europeas/ibéricas e italianas, aunque pocas veces se recoge su labor sobre estos caracteres y, consecuentemente, la genitalia de las especies de crisopas europeas ha sido muy poco utilizada a la hora de efectuar claves de identificación. En especies de otros géneros de esta familia (Brinckochrysa, Cunctochrysa, y en particular Nineta) es más habitual recurrir a la genitalia masculina para corroborar las identificaciones. En el caso de la especie que nos ocupa, la negra y recia setación del pronoto (Figs. 13, 14) es el carácter que habitualmente se utiliza para su identificación, y también así se recoge en la mayoría de las claves existentes en la bibliografía.

Sin embargo, y como hemos anotado, esta especie posee caracteres de morfología externa con enormes similitudes en su aspecto externo con otras especies, incluso de diferentes géneros, y en particular Chrysopa nigricostata ha sido desde antiguo confundida o advertida como muy similar en su morfología y aspecto externo a algunas especies, concretamente de los géneros Chrysopa ( $C$. viridana), Pseudomallada (P. flavifrons) o Cunctochrysa (C. albolineata, C. baetica) (Schoch, 1885; Bakker,
1943; Hölzel, 1965; Kis, 1968; Geijskes, 1972; Aspöck et al., 1980, 2001; Czechowska, 1986; Popov, 1993; Hölzel, 1998, etc.), y la genitalia masculina, de ser utilizada, sería resolutiva en la mayoría de las identificaciones. A esta posibilidad de confusión añadimos ahora Cunctochrysa cosmia (Navás, 1918) n. comb., con varios errores en la identificación entre estas dos especies, que ahora citamos y rectificamos. Detectada esta posible (y probablemente frecuente) confusión llamamos la atención sobre la necesidad de revisar el correspondiente material europeo asignado a estas especies y, en el caso de Chrysopa nigricostata aseverar su posible confusión con Cunctochrysa cosmia (Navás, 1918) n. comb., especie a la que podrían pertenecer más de un ejemplar europeo citado como Chrysopa nigricostata.

En relación al material ibérico, y como hemos indicado anteriormente, más recientemente esta especie (Chrysopa nigricostata) ha sido frecuentemente citada por nosotros, y también en este caso demostramos la confusión de estas identificaciones, ya que parte de este material pertenece en realidad a Cunctochrysa cosmia (Navás, 1918) n. comb., y de ello hablaremos ahora y también haremos referencia de ello más adelante al referirnos a esta especie, donde citaremos esta confusión, y anotaremos el material asignado ahora a Cunctochrysa cosmia.

Pues bien, en relación a estas confusiones en la identificación de numerosos ejemplares de esta especie y en lo que nos compete y con respecto a las citas de Chrysopa nigricostata que en la fauna de la Península Ibérica (España y Portugal) nosotros hemos venido dando en las cuatro últimas décadas: Monserrat, 1977a: 107-109, 1978a: 178, 1980: 186, 1984a: 37, 1984b: 156, 1996: 14, 2008: 181, 2013: 291; Marín \& Monserrat, 1995: 116; Díaz-Aranda et al., 1986: 1139; Díaz-Aranda \& Monserrat, 1988a: 223, 1988b: 220; Monserrat \& Díaz-Aranda, 1989a: 256; Monserrat \& Rodrigo, 1992: 127; Canard et al., 1992: 96; Monserrat \& Marín 1994a: 122; Monserrat \& Triviño, 2013: 75 (part.), es el momento de revisarlas y, en su caso, confirmarlas o descartarlas. Para ello, hemos vuelto a estudiar todo el material citado existente en nuestras colecciones, y en este caso incorporando el estudio de la genitalia masculina, y no sólo los caracteres de su morfología externa que ha generado todos estos errores.

El motivo y la necesidad de este empeño era doble. Por un lado, ya empezamos a tener dudas sobre la correcta identificación de estos ejemplares (hasta ahora asignados y considerados como pertenecientes a Chrysopa nigricostata) al estudiar sus estadios preimaginales (Monserrat \& Díaz-Aranda, 2012), ya que, sorprendentemente, sus larvas presentaban caracteres inequívocos del género Cunctochrysa, y no de Chrysopa, hecho que urgía a una necesaria revisión de nuestros datos. Por otra parte, el nuevo material ahora citado de Chrysopa nigricostata, es similar en 
su aspecto externo (coloración y setación del pronoto) (Figs. 13, 14, 19, 20) a lo que hasta ahora habíamos considerado como Chrysopa nigricostata (tal como se conoce en la mayor parte de la bibliografía y claves sobre esta especie/género), pero un estudio en mayor detalle de estas y otras características externas y en especial de su genitalia masculina nos demuestran que son especies completamente distintas (Figs. 1-15, 16-23), y estos nuevos ejemplares, junto a material no ibérico ahora también estudiado, nos permiten la revisión comparativa y más a fondo del anterior material, sea perteneciente a esta especie (Chrysopa nigricostata) o erróneamente asignado a ella y ahora mayoritariamente adjudicado a Cunctochrysa cosmia, hecho que ahora subsanamos y que será tratado y discutido más adelante al ocuparnos del género Cunctochrysa. Tras estas rectificaciones, la distribución real de ambas especies (Chrysopa nigricostata y Cunctochrysa cosmia) en la Península Ibérica en base a la información ahora rectificada y corroborada se anota en las figuras 29 y 30.

Anunciada esta situación, y volviendo ya a Chrysopa nigricostata, y ahondando en lo anteriormente indicado sobre la escasa importancia que se suele dar a la genitalia entre las especies europeas de esta familia, comentemos que de las 183 referencias bibliográficas que conocemos en las que se trata esta especie bajo diferentes aspectos (descartadas y sin contabilizar las citas correspondientes a Chrysopa cosmia Navás, 1918 que ahora revalorizamos como especie válida en esta contribución), bien citada como tal o bajo sus distintas variedades descritas o combinaciones nomenclatoriales o bien de sus sinonimias conocidas y habitualmente aceptadas (Hölzel, 1973; Aspöck et al., 1980, 2001): [Chrysopa heydenii Schneider, 1851; Chrysopa nigrovenosa Pongrácz, 1912; Chrysopa fastigiata Navás, 1914; Chrysopa laburdensis Lacroix, 1924; Chrysopa mediata (Navás, 1924); Chrysopa neuralis (Navás, 1924) o Chrysopa ingens Steinman, 1964], solo cuatro de estas 183 referencias aportan algún dato de su genitalia (Hölzel, 1965; Kis, 1968; Kis et al., 1970; Sengonca, 1980), a veces reiterativos $\mathrm{o}$, en ocasiones, excesivamente esquemáticos. El resto de lo que mayoritariamente conocemos sobre esta especie versa sobre puntuales datos de su taxonomía, morfología externa, biología, faunística, fenología o estadios larvarios, a veces reiterativos, a veces contradictorios $y$, en cualquier caso, particularmente escasos en relación a las otras especies del género. Ya Hölzel (1998) llamaba la atención sobre la sorprendente falta de datos que desde su descripción original (Brauer, 1850) ilustraran la morfología de esta especie. Por ello, y a pesar de estar abundantemente citada, en realidad, es una especie de identidad muy poco conocida en profundidad.

Detectada esta posible (y probablemente frecuente) confusión, llamamos la atención sobre la necesidad de revisar el correspondiente material tipo de estas especies a ella sinonimizadas, y aseverar las sinonimias, especialmente su relación con Chrysopa cosmia Navás, 1918, especie a la que podrían pertenecer más de un ejemplar tipo citado como sinónimo de Chrysopa nigricostata, ya que esta confusión entre ambas especies también podría afectar a sus sinonimias, que en más de una ocasión podrían haber sido propuestas sin haber considerado la validez de Cunctochrysa cosmia (Navás, 1918) n. comb. como especie diferente. Comentemos sobre ello algunas de nuestras opiniones.

Sobre las numerosas sinonimias propuestas para esta especie (Chrysopa nigricostata), pensamos que, desde nuestro punto de vista, así se corresponde en el caso de Chrysopa heydenii, descrita por Schneider (1851) de Alemania, y que fue considerada como sinónima de Chrysopa nigricostata por Brauer (1856). Esta sinonimia fue corroborada por Brauer (1876), Heyden (1896), Ohm \& Remane (1968), Aspöck, et al. (1980, 2001) y Brooks \& Barnard (1990), y así lo consideramos. Sobre esta especie conviene citar que Hagen (1858) la considera probable sinónima de Chrysopa angustipennis, descrita de Inglaterra por Stephens (1836), y que indirectamente la relacionaría con la especie que tratamos (Chrysopa nigricostata). Los datos aportados por Stephens (1836), Evans (1848), Walker (1853) o Hagen (1858) no permiten una clara diagnosis de esta especie, y Killington (1937), en su revisión de las especies británicas, estudia el supuesto ejemplar tipo de esta especie inglesa, citando que su morfología no se correspondía con lo anotado en la descripción original [el ejemplar por él estudiado pertenecía a $C$. septempunctata Wesmael, 1841=C. pallens (Rambur, 1838)], sugiriendo un posible cambio en las etiquetas originales del ejemplar y, consecuentemente, haciendo inviable el aclarar la situación taxonómica de esta especie. Más recientemente Aspöck et al. $(1980,2001)$ asumen como probable esta sinonimia con C. septempunctata, que sin poder aclararse su estatus, permanece como nomina dubia, y no es considerada por Brooks \& Barnard (1990).

Chrysopa nigrovenosa fue descrita de Hungría por Pongrácz (1912), y sinonimizada por Pongrácz (1913). Navás (1915) recoge su morfología. Nos parece muy probable la sinonimia propuesta. No existen más datos que la sinonimia recogida por Aspöck et al. $(1980,2001)$ y Brooks \& Barnard (1990).

Chrysopa fastigiata fue descrita de Issyk-kul (Kirguistán) por Navás (1914b) y sinonimizada por Hölzel (1973). Nos parece muy probable la sinonimia propuesta (Navás, 1914b: "margine postico flavo; venulis gradatis in utraque ala fere $8 / 9 \ldots$, in regione stigmatica pluribus venulis, 7-8 instructa"). No conocemos más datos que la sinonimia recogida por Aspöck et al. $(1980,2001)$ y Brooks \& Barnard (1990).

Chrysopa neuralis (Navás, 1924) fue descrita dentro del género Cintameva por Navás, 1924b de Asia Central, Tscherdschui (Turkestán) y sinonimizada por 

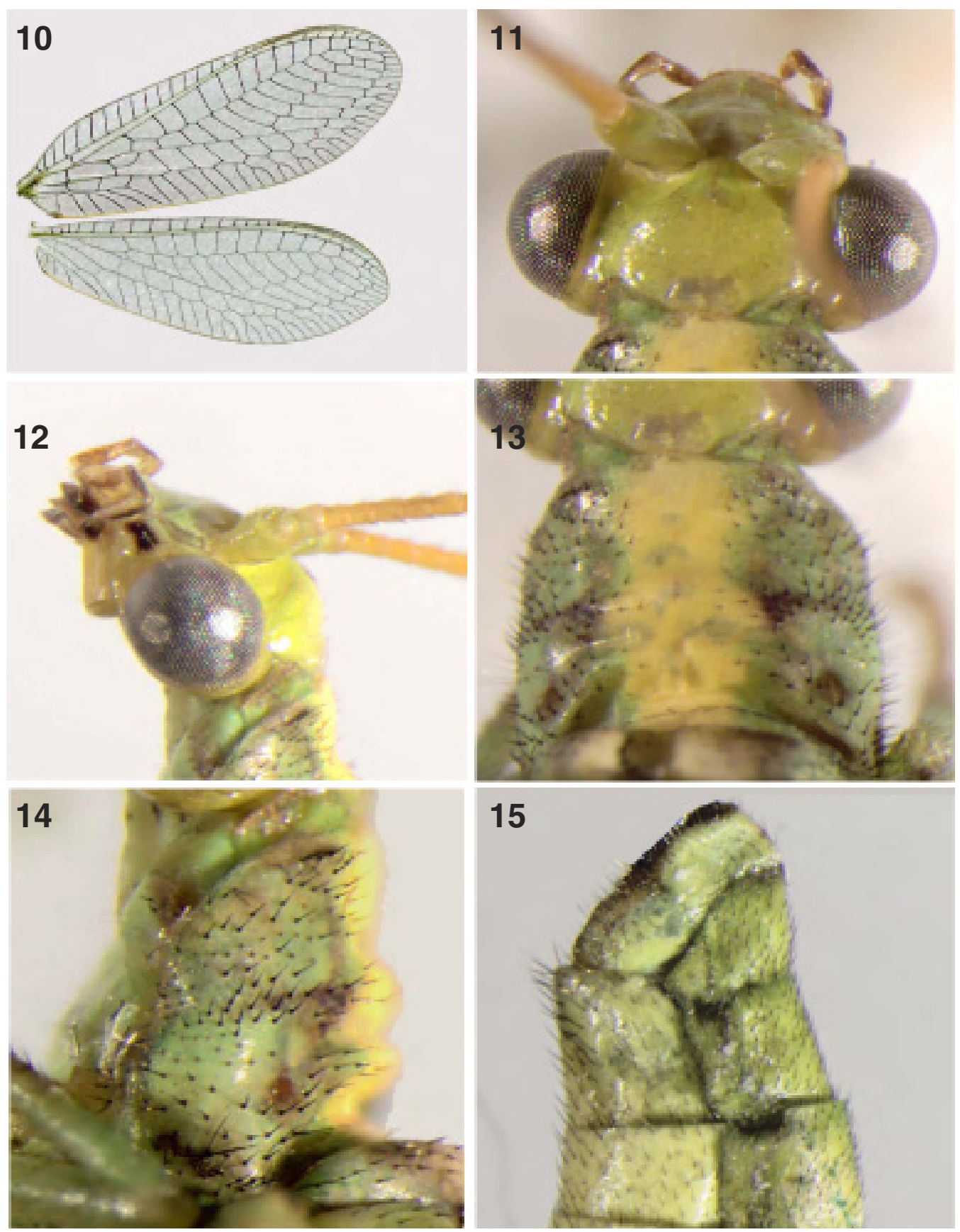

Figs. 10-15.- Chrysopa nigricostata. 10) Alas. 11) Cabeza, vista dorsal. 12) Ídem, vista lateral. 13) Pronoto, vista dorsal. 14) Ídem, vista lateral. 15) Extremo del abdomen, vista lateral.

Figs. 10-15.- Chrysopa nigricostata. 10) Wings. 11) Head, dorsal view. 12) Ditto, lateral view. 13) Pronotus, dorsal view. 14) Ditto lateral view. 15) Abdomen apex, lateral view.

Aspöck et al. (1980). Nos parece muy probable la sinonimia propuesta (Navás, 1924b: "stigmate venulis pluribus, 6-7 in area subcostali. Ala anterior venulis gradatis fere 7/8 fuscis"). No existen más datos que la sinonimia recogida por Brooks \& Barnard (1990) y Aspöck et al. (2001).

Chrysopa mediata (Navás, 1924) fue descrita dentro del género Cintameva por Navás (1924b) de Asia Central, también de Tscherdschui (Turkestán) y fue sinonimizada por Aspöck et al. (1980). Nos parece muy probable la sinonimia propuesta (Navás, 1924b: "venulis gradatis $4 / 8$ vel $5 / 7$ "). No existen más datos que la sinonimia recogida por Brooks \& Barnard (1990) y Aspöck et al. (2001).

Chrysopa laburdensis fue descrita de los Pirineos Atlánticos (Ustaritz, Francia) por Lacroix, 1924a (y no por Lacroix, 1924b, como algunos autores citan: Aspöck et al., 1980; Leraut, 1988, etc.). Leraut (1988) estudió el decolorado holotipo y no define su estatus en relación con Cunctochrysa albolineata o 
16

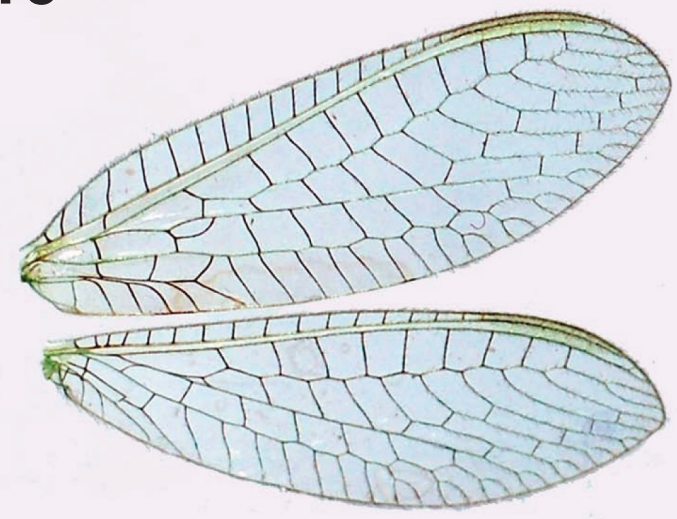

\section{8}
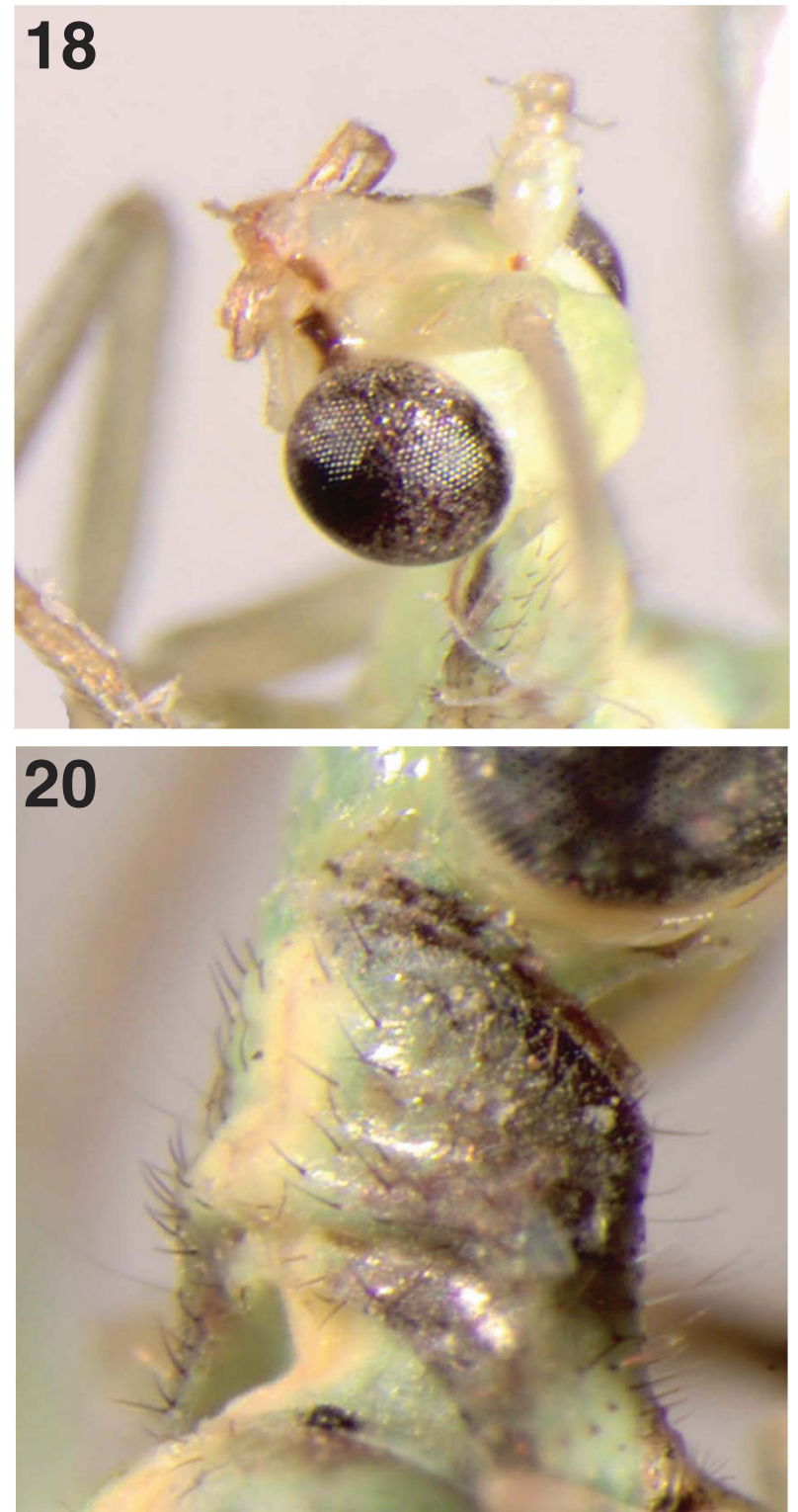
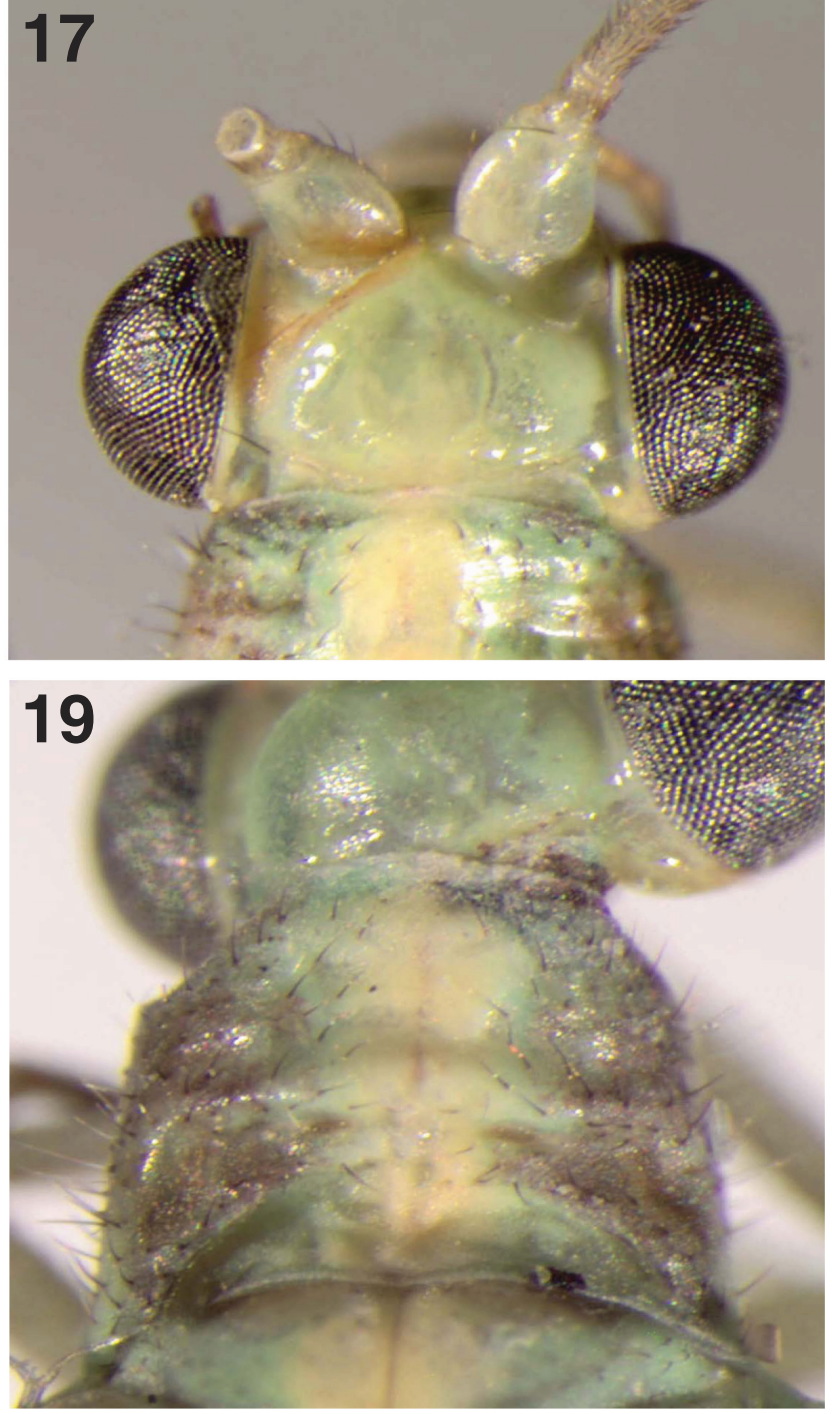

21

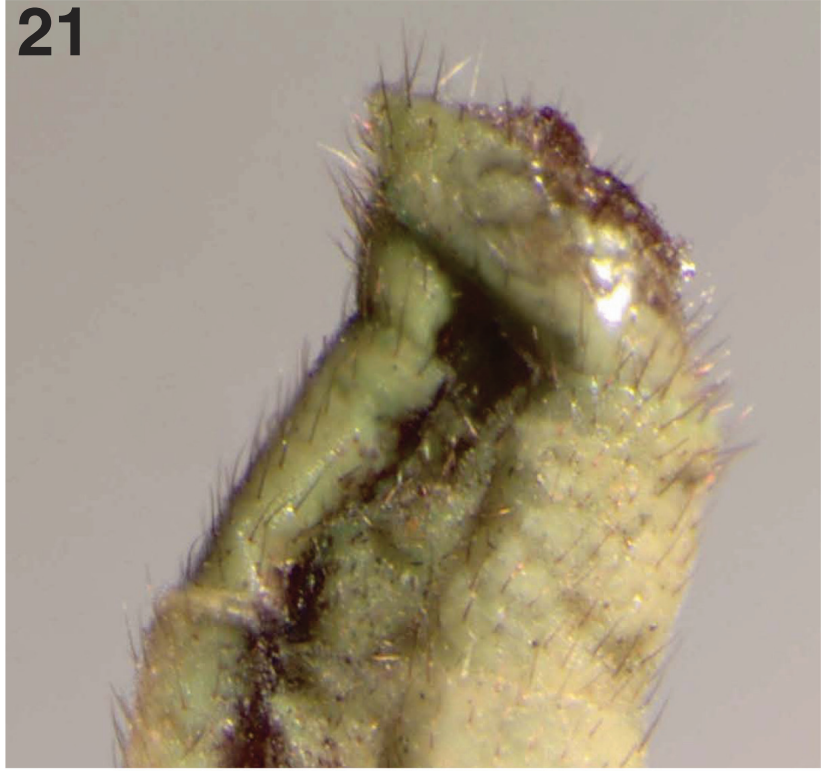

Figs. 16-21.- Cunctochrysa cosmia n. comb. 16) Alas. 17) Cabeza, vista dorsal. 18) Ídem, vista lateral. 19) Pronoto, vista dorsal. 20) Ídem, vista lateral. 21) Extremo del abdomen, vista lateral.

Figs. 16-21.- Cunctochrysa cosmia n. comb. 16) Wings. 17) Head, dorsal view. 18) Ditto, lateral view. 19) Pronotus, dorsal view. 20) Ditto lateral view. 21) Abdomen apex, lateral view. 
C. bellifontensis, pero advierte sobre el posible error entre la sinonimia de esta especie con $C$. nigricostata propuesta por Aspöck et al., 1980. Por los datos de su descripción original (Lacroix, 1924a), no nos parece correcta su relación con Chrysopa nigricostata, a esta especie sinonimizada por Aspöck et al. (1980) y así es recogido por Brooks \& Barnard (1990), debido a algunos elementos de su descripción: "Aile supérieure avec les $2^{e}, 3^{e}$ et $4^{e}$ nervules costales brunes aux extrémités; la $1^{\text {re }}$ nervule costale entièrement verdâtre". Por el contrario, a nosotros se nos antoja muy similar a Cunctochrysa albolineata, aunque nos soprende "Uniformément vert in vivo, sans bande jaune longitudinale et dorsale". La identidad de esta especie no la consideramos definitivamente resuelta, y podría afectar a Cunctochrysa albolineata (Killington, 1935) o C. baetica (Hölzel, 1972) por el principio de prioridad.

Por último, Chrysopa ingens fue descrita de Hungría por Steinmann (1964) y sinonimizada por Hölzel (1973). Mantenemos ciertas reservas sobre esta sinonimia (Steinmann, 1964: "Venation of wings green, except for ochreous basal section of radius"). No existen más datos que la sinonimia recogida por Aspöck et al. (1980, 2001) y Brooks \& Barnard (1990).

También debemos indicar que, muy probablemente, puedan resultar nuevas sinonimias de Chrysopa nigricostata alguna de las numerosas especies descritas en la zona asignada a su distribución potencial (Fig. 28), en particular alguna de las descritas de la zona ribereña del norte de África y/o de Oriente Medio y Próximo Oriente.

Dejando al margen la taxonomía, y ya en relación a la "supuesta" biología, faunística y corología asignada para esta especie, debemos anotar también que de los numerosos datos citados sobre ella, parece desprenderse la posible generalizada confusión entre Chrysopa nigricostata y Cunctochrysa cosmia, pues llama poderosamente la atención de que la mayoría de las citas existentes en la bibliografía sobre Chrysopa nigricostata se segreguen significativamente en dos tipos de medios y plantas completamente diferentes: unas sobre chopos en zonas bajas, y otras sobre pinos/ coníferas en zonas elevadas. Ya Pantaleoni (1982) anotaba estas disparidades, y Szentkirályi (2001) apuntaba estas mismas cuestiones planteadas sobre la discrepancia en las opiniones dadas sobre su biología por numerosos autores (baja vegetación, zonas arenosas, caducifolios, pinos, etc.) y concluye mencionando: "It is probable that $\mathrm{C}$. nigricostata lives in both types of forest" [en esta información se recogían los datos ibéricos de Chrysopa nigricostata sobre pinos a partir de información aportada por Monserrat \& Marín (1994, 2001), datos que mayoritariamente ahora adscribimos a Cunctochrysa cosmia]. En cualquier caso, y al margen de esta reseña sobre esta información ibérica, toda la información existente sobre esta especie sugiere una mezcla generalizada de información sobre la biología de, al menos, estas dos especies (Chrysopa nigricostata y Cunctochrysa cosmia) (e incluso con más de un dato perteneciente a Pseudomallada flavifrons, Chrysopa viridana o Cunctochrysa albolineata, como anotamos en el material estudiado de estas especies), confusiones que en este artículo tratamos de contribuir a aclarar y resolver.

Es seguro, o al menos muy probable, que ambas especies estén mezcladas y confundidas en la identificación correspondiente a la multitud de citas existentes sobre Chrysopa nigricostata, hecho que explicaría esta disparidad en los datos sobre su biología. A nivel general, muy probablemente las citas dadas en zonas esteparias de mediana o baja cota, y especialmente las dadas sobre Populus spp. (al que sin duda acompaña en su distribución espontanea) en zonas que se distribuyan por el Paleártico occidental (Fig. 28), pertenezcan realmente a Chrysopa nigricostata (así lo hemos comprobado personalmente y así consta en el material ahora citado de esta especie), mientras que las citas de Chrysopa nigricostata dadas en zonas elevadas, y especialmente las dadas sobre Pinus spp. y otras coníferas, y especialmente en zonas montanas de mayor influencia atlanto-mediterránea (Península Ibérica, Francia, Islas Británicas, este y centroEuropa, y quizás Marruecos) pertenezcan, en realidad, a Cunctochrysa cosmia, como también así lo hemos comprobado personalmente (ver material estudiado de esta especie), y así consta en el material ibérico de ella ahora citado, ya que, como hemos comprobado, eran erróneas nuestras identificaciones, según más adelante anotaremos al tratar esta especie.

También es muy probable que alguna de las citas de Cunctochrysa, en particular las dadas sobre ejemplares recolectados sobre coníferas (Pinus sp., $P$. sylvestris) desde el sur de Francia y Bélgica a Gran Bretaña (Séméria, 1978; Leraut, 1988; Plant, 1993; San Martin, 2004; Canard et al., 2010, 2014), también se correspondan con lo que ahora citamos como Cunctochrysa cosmia (Navás, 1918) n. comb. (especie anteriormente no considerada por haber sido sinonimizada), por lo que una mayor distribución de la que ahora anotamos es más que probable, y de hecho hemos estudiado algún ejemplar de Rumanía identificado erróneamente y asignable a esta especie (ver material estudiado de $C$. cosmia), por lo que una mayor distribución y una cierta generalizada confusión en las identificaciones parece confirmarse.

Por todo ello, y en base a este nuevo material ibérico, consideramos necesario anotar nuevos y más precisos datos que definan incuestionablemente esta especie, y sobre todo describir su genitalia de forma más completa y definitiva (Figs. 1-9), así como aportar nuevos datos diferenciales respecto a otras especies similares ( $C$. viridana o $P$. flavifrons) y en especial Cunctochrysa cosmia, con quien, como hemos indicado, posee enormes similitudes en su morfología externa (Figs. 10-15, 16-27). 


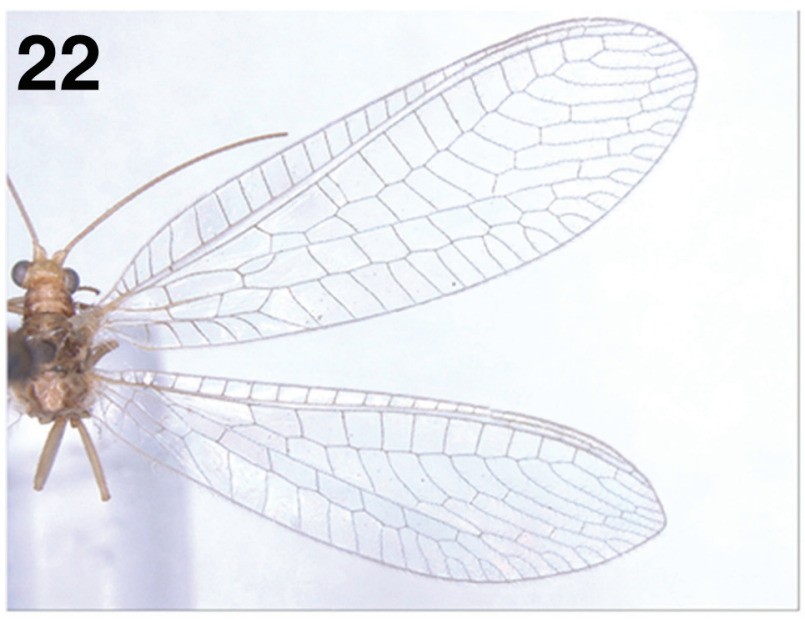

24
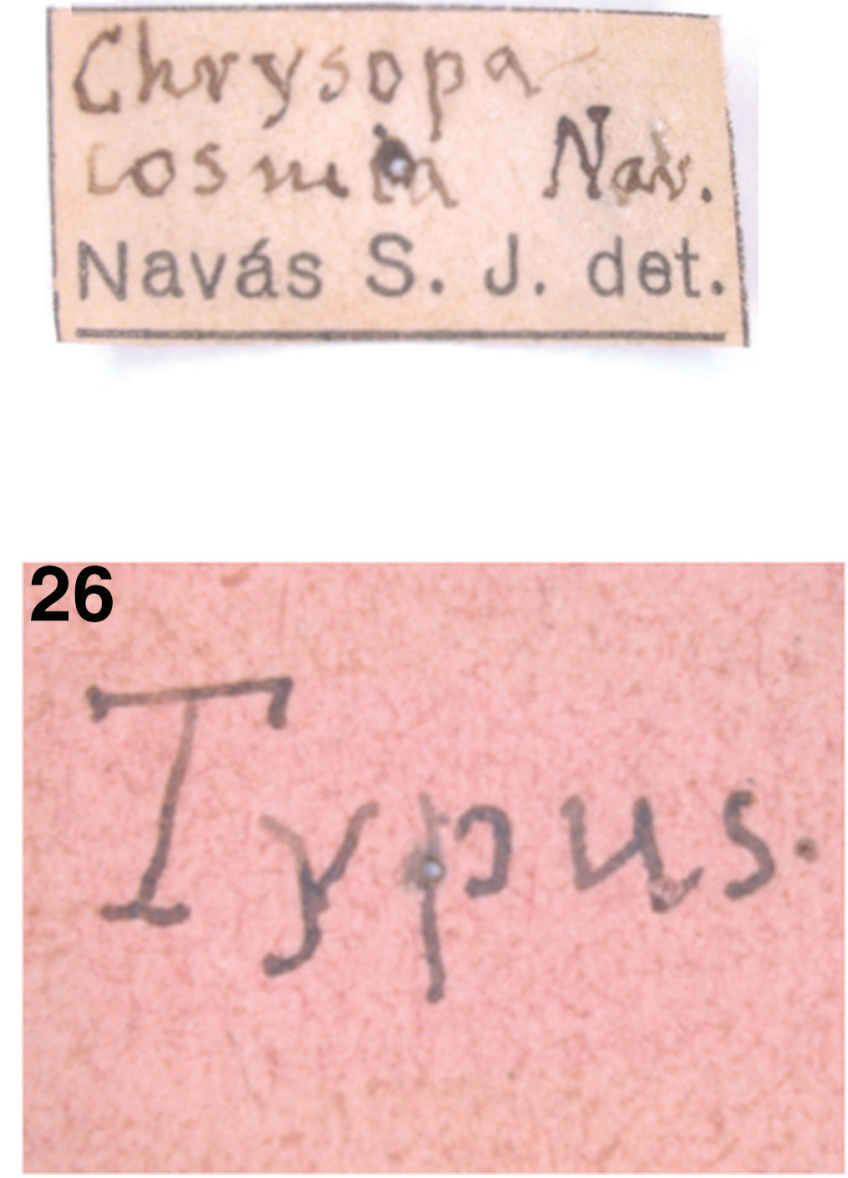

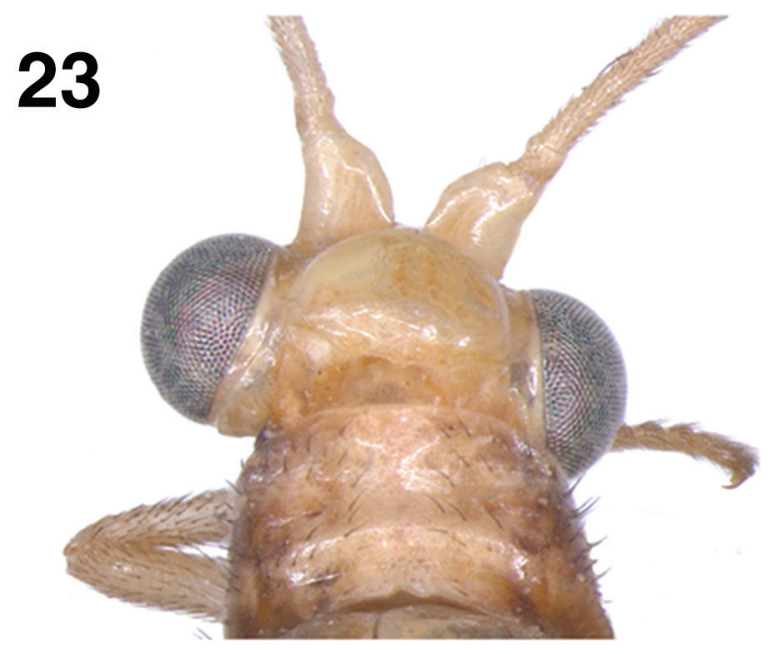

25

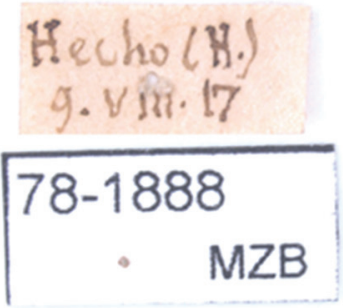

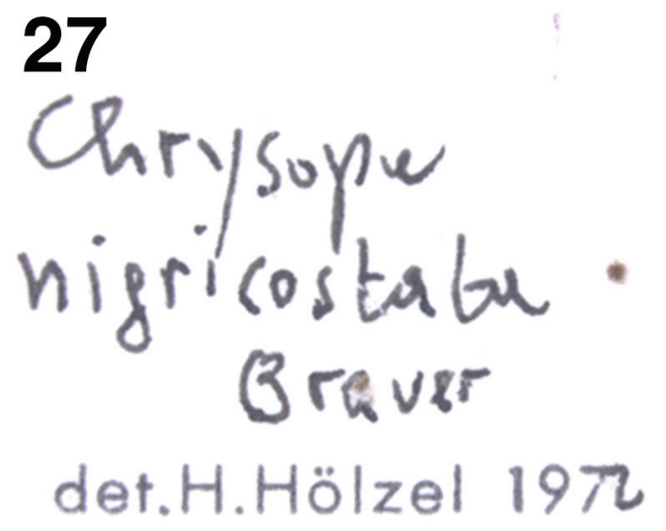

Figs. 22-27.- Ejemplar tipo de Chrysopa cosmia = Cunctochrysa cosmia n. comb. 22) Aspecto general, vista dorsal. 23) Cabeza y pronoto, vista dorsal. 24-27) etiquetas.

Figs. 22-27.- Type of Chrysopa cosmia = Cunctochrysa cosmia n. comb. 22) Habitus, dorsal view. 23) Head and pronotus, dorsal view. 24-27) Labels.

Morfología externa: Cabeza verde, con vertex algo más amarillento y dos manchas negras en las genas y el clípeo, ésta última de menor tamaño (Figs. 11, 12). Antenas con escapo y pedicelo verdes, flagelo pardo, progresivamente algo más oscuro hacia el final. Palpos labiales pardo-pálidos y palpos maxilares más oscuros en su cara externa (Figs. 11, 12).

Tórax verde con una banda amarilla central ancha y bien delimitada (Fig. 13). Pronoto con abundantes setas a ambos lados, robustas, cortas y negras, algo 
más largas las más externas (Figs. 13, 14), sobre su margen latero-posterior existe una mancha circular parda oscura, y otra central en el margen lateral de mayor tamaño (Figs. 13, 14). Meso- y metanoto con pequeñas setas negras laterales (Fig. 14). Patas verdes, las anteriores con porción distal de la tibia parda, igual que los tarsos, que son pardos con último tarsómero triangular-fusiforme, muy desarrollado. Uñas pardas fuertemente dilatadas y acodadas en su base. Patas medias similares a las patas anteriores, y las patas posteriores algo más pardas en su mitad ventral. Alas (Fig. 10) con membrana muy iridiscente. Alas anteriores con vena costal verde en su recorrido, salvo en la región mediana, cubital y anal donde es llamativamente amarilla, vena subcostal, vena radial, sector del radio, pseudomediana, pseudocubital, cubital posterior, cubital anterior y anal 3 verdes, anal 1 y 2 verdes en su base. Venas transversales del campo costal, subcostal y radial negras, venas gradadas negras, las existentes entre las dos series de venas gradadas (internas y externas) verdes con algunas venillas suplementarias entre ellas hacia el ápice. Venas entre radial y pseudomediana negras, venas entre el sector del radio y las gradadas negras las tres basales, verdes en su porción central, pardas en los extremos las medias, y verdes las que conectan con las gradiformes, venas entre gradadas externas y/o horquillas marginales verdes, horquillas marginales negras salvo zona de unión con la costal. Venas del campo medial y cubital negras. Órgano timpánico en la base de R (y aparentemente de M) bien desarrollado y de color pardo el primero y verde el segundo. Entre la vena $\mathrm{A}_{3}$ y el margen alar se dispone una enorme concentración de microtriquias que tiñen de pardo esta zona de la membrana en ambos sexos, estando marcadamente dilatada esta zona de la vena costal, y que sin duda posee naturaleza sensorial (Fig. 10). Alas posteriores con vena costal verde, más amarillenta en el campo medial cubital y anal. Venas longitudinales verdes, venas transversales del campo costal pardas, más pálidas las perostigmáticas, venas transversales entre el radio y su sector y gradadas externas negras, venas transversales entre sector del radio y pseudomediana verdes, entre pseudomediana y pseudocubital verdes, venas entre gradadas externas e internas y entre mediana posterior 2 y costal verdes. Horquillas marginales verdes, venillas entre el campo medial y anal verdes. Cubital anterior y posterior verdes, anales verdes en su base y negras hacia la subcostal (Fig. 10).

Abdomen dorsalmente verde, con los terguitos algo más oscuros en su parte lateral, con abundantes setas cortas y negras. Región pleural verde oscura formando dos bandas longitudinales (Fig. 15). Esternitos más amarillentos con abundantes setas cortas y negras. No se han visualizado estructuras estriduladoras. En los machos (Figs. 1-4) los terguitos y esternitos con abundante pilosidad. Terguitos rectangulares, más largos que anchos, octavo terguito trapecial, no fusionado con el noveno terguito, existiendo entre ambos un fuerte apodema (Fig. 1), en la región ventral este apodema se continúa dorsalmente por el límite anterior del octavo esternito, y caudalmente con los apodemas laterales del noveno esternito. Esternitos cuadrangulares, algo más anchos que largos, octavo esternito trapecial, no fusionado con el noveno esternito (Figs. 1, 3). Noveno esternito espatulado en vista ventral, con dos fuertes apodemas internos a ambos lados (Figs. 3, 7), y sobre su margen latero-caudal posee setas curvas y con una dilatación lateral cerca de su base (Figs. 1, 3). Ectoprocto ovoide, callo cercal elipsoide con 34 tricobotrias en todos los ejemplares $\hat{\partial} \hat{O}$ contabilizados $(n=4)$, ectoproctos fusionados dorsalmente (Fig. 4). En las hembras los terguitos son rectangulares, con abundante pilosidad. Esternitos trapeciales algo más anchos que largos. Octavo terguito trapecial, y margen caudal del noveno terguito redondeado, fuertemente acodado sobre la línea media ventral, dejando un amplio espacio medio donde se ubica la placa subgenital. Ectoprocto y noveno terguito parcialmente fusionados, el ectoprocto es cuadrangular, callo cercal elipsoide con 35 tricobotrias en todos los ejemplares 오 우 contabilizados $(\mathrm{n}=2)$. Gonapófisis laterales elipsoides en vista caudal.

Morfología GENITAL INTERna: En la genitalia interna masculina, entre el noveno terguito y el noveno esternito se encuentra un complejo gonosaco evaginable, que en posición de reposo está formado por diferentes membranas replegadas que portan abundantes microtriquias (gonocoristae) (Fig. 1), y en posición evaginada este gonosaco se muestra como un proceso membranoso globoso con multitud de gonosetas (Fig. 2) y sobre el que se dispone un fuertemente esclerificado arceso/pseudopene, potentemente recurvado en vista lateral y de aspecto cónico en vista dorsal (Figs. 2, 8-9). Gonarco ancho en su parte media y formando dos expansiones planas laterales y ovoides (Figs. 1, 2). Sobre la línea media caudal del gonarco surge un mediumco formado por dos dientes sub-paralelos en vista caudal, y recurvados hacia abajo en vista lateral (Figs. 5, 6). Entoprocesos complejos, con un dentículo caudal recurvado hacia abajo que se continúa anteriormente hacia delante y hacia la región dorsal asociando ambos entoprocesos, y ventralmente se recurva hacia delante y hacia arriba para llegar a la cara interna de los procesos laterales del gonarco (Figs. 5, 6). Hipandrio no visualizado.

La genitalia interna femenina posee espermateca esclerificada, circular en vista ventral, con una vela bien desarrollada que deja un espacio circular en el centro, ducto sinuoso y corto, con porción terminal no esclerificada y de aspecto piloso, algo más corto que el ducto esclerificado. Placa subgenital 


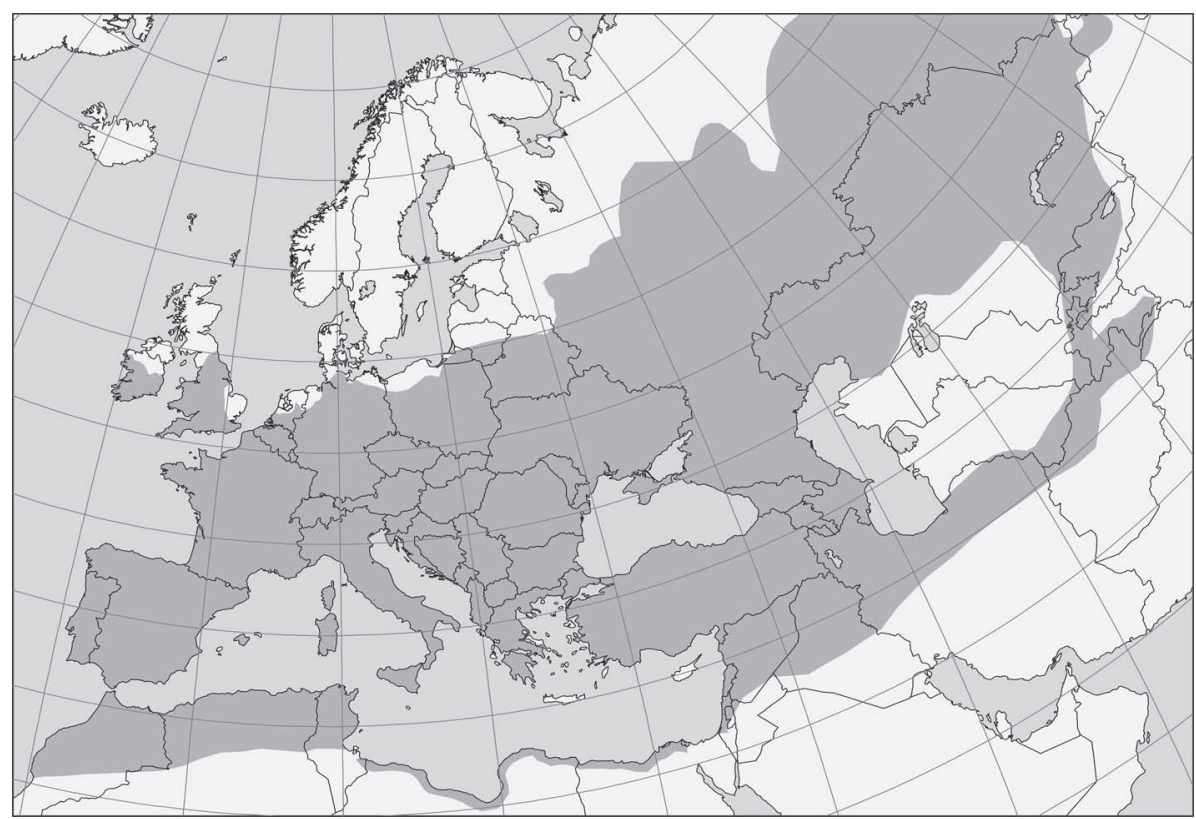

Fig. 28.- Distribución espontanea del chopo (Populus nigra) y potencial distribución de Chrysopa nigricostata, adaptado de EUFORGEN (2009), www.euforgen.org.

Fig. 28.- Spontaneous distribution of the Black Poplar (Populus nigra) and potential distribution of Chrysopa nigricostata, adapted from EUFORGEN (2009), www.euforgen.org.

con una porción triangular en su base relativamente esclerificada y una porción bilobulada caudal, particularmente esclerificada en su margen caudal. Internamente entre las gonapófisis laterales se dispone una estructura transversal estrecha y fuertemente pilosa.

Discusión: Es curioso que Chrysopa nigricostata, siendo una especie relativamente citada, esté tan escasamente representada. Hölzel (1998) llamaba la atención sobre este hecho e indicaba que no había nuevas imágenes en 150 años desde su descripción original aportada por Brauer (1850), por lo que resulta aún más interesante aportar ahora estos nuevos datos.

Algunos caracteres, tanto de su genitalia masculina (origen y aspecto del arceso/pseudopene, forma del gonarco y del entoprocesos, terguito $9^{\circ}$-ectoprocto y $8^{\circ}-9^{\circ}$ esternitos bien diferenciados e individualizados, llamativos apodemas entre el $8^{\circ}$ y $9^{\circ}$ esternitos, y especialmente a ambos lados del $9^{\circ}$ esternito, la complejidad del gonosaco y la morfología de las setas caudales sobre el $9^{\circ}$ esternito) (Figs. 1-9), como de la genitalia femenina (aspecto de la espermateca), resultan caracteres genitales bien definitorios en esta especie, que por su genitalia se asemeja a $C$. pallens (con quien podría estar relacionada) por la presencia de gonocoristae en la genitalia masculina (Figs. 1, 2) (Principi, 1949).

Por otra parte, en lo que respecta a la morfología y coloración externa y alar, la llamativa coloración diferencial amarillo intenso de la vena costal de ambas alas en la región mediana, cubital y anal (muy conspicua y próxima a la línea media dorsal con las alas en posición de reposo, al menos en los ejemplares ibéricos e italianos estudiados) o la coloración tan marcadamente distinta (negro-verde) de sus venas longitudinales y venillas transversales (Fig. 10) la hacen muy particular, al margen de la pigmentación tegumentaria y cefálica, y de la robusta e hirsuta setación del pronoto (Figs. 13, 14), que son caracteres conspícuos, aunque menos interesantes a la hora de diferenciarla de otras especies (como hasta ahora se ha hecho).

Hemos anotado que en la bibliografía se apunta cierta similitud entre esta especie y Chrysopa viridana, y esta especie se distingue fácilmente de ella por caracteres de coloración y morfología externa: en esta última, su color general verde manzana pálido, su cabeza blancuzca pálida, el color pardo miel de sus manchas laterales en el clípeo-labro, la tonalidad rojiza de esta zona, su línea dorsal amarilla-blanquecina, la ausencia de manchas pardas y rígidas setas negras en su pronoto, y el particular robusto delineado de su venación y su distinta coloración, la diferencian fácilmente. Más adelante volveremos sobre estas diferencias en la discusión de Cunctochrysa cosmia.

La potencial confusión entre esta especie y alguna de las pertenecientes al género Pseudomallada, y en particular con P. flavifrons (Brauer, 1850), se resuelve por la mancha oscura que las especies de este género poseen sobre la membrana alar en la base del campo costal en todas sus alas, elemento que no está presente en las especies del género Chrysopa, por lo que 
es fácilmente diferenciable, aun así hemos hallado alguna determinación incorrecta (ver material de P. flavifrons).

Otros elementos sobre su morfología externa (especialmente para ejemplares de antigua recolección, bien decolorados o bien conservados en alcohol), que contribuyan a diferenciarlas, se anotarán más adelante tras la redescripción de Cunctochrysa cosmia. También hallamos significativas diferencias en la biología y plantas soporte entre estas especies que anotamos a continuación.

Biología: Como hemos indicado, son proporcionalmente escasos, y a veces poco precisos o contradictorios, los datos existentes sobre la biología de esta especie (Pantaleoni, 1982). Mayoritariamente ha sido referida como una especie rara, infrecuente, comúnmente recolectada a la luz, y de biología poco conocida, al menos en Europa, habiendo sido recolectada a la luz y citada en bosques de caducifolios (Quercus), de coníferas (Pinus), en cultivo de frutales, olivos, chopos y bosques de galería/riveras, parques y zonas urbanas, riveras o zonas arenosas y de vegetación baja, y ha sido citada desde ser una especie vinculada a medios rivereños húmedos, a ser característica de zonas muy secas, esteparias y térmicas (ver información anteriormente citada y en Aspöck et al., 1980, 2001; Pantaleoni, 1982; Canard et al., 1984; Kovrigina, 1985; Volkovich, 1998; McEwen et al., 2001 , etc.). Reiteramos que de estos dispares datos parece sugerirse o deducirse más de alguna probable confusión en las identificaciones (muy probablemente entre Chrysopa nigricostata y Cunctochrysa cosmia).

Como C. nigricostata (o bajo sus sinonimias) ha sido citada sobre chopo (Salicaceae: Populus nigra L.): Brauer (1850, 1857), Schneider (1851), Heyden (1896), Hölzel (1965), Ohm \& Remane (1968), aunque otros autores no la asocian con estos árboles (Szentkirályi, 2001). Sin duda a esta salicácea deben corresponder las citas correctas verdaderamente asignables a esta especie, mientras que muchas de las otras citas de esta especie sobre otros sustratos vegetales (especialmente coníferas) muy probablemente pertenezcan, en realidad, a Cunctochrysa cosmia (Navás, 1918) n. comb. u otras especies (ver material estudiado de este género o de $C$. viridana), y esta vinculación con este árbol la hemos constatado en el material observado en Emilia Romagna (Italia), tanto en imagos, como en larvas, alguna de ellas recolectada en agalla de Pemphigus spyrotecae, Passerini, 1860 (Homoptera, Aphidoidea), también sobre chopo.

Este conocido árbol, nativo de Europa, sudeste y centro de Asia, y ribera mediterránea y noroeste de África (Fig. 28), está asociado a cursos de agua, pero no es espontáneo en zonas particularmente húmedas, e incluso a veces es característico de medios térmicos y esteparios (Wood, 1994; Vanden Broeck et al., 2002; Vanden Broeck, 2003), y sin duda debe acompañar a $C$. nigricostata en su amplia presunta distribución (Fig. 28), y así queda constatado en la distribución general citada para esta especie y en algunas localidades/países ahora citadas en el material estudiado (Tayikistán, Pamir) o en el de alguna de sus anteriormente citadas sinonimias (Kirguistán, Turkestán), zonas que coinciden con la distribución potencial de este árbol (Fig. 28).

Sobre otros datos citados de su biología también se desprenden contradicciones y, sin duda, posibles confusiones en la correcta identificación de ciertos ejemplares. Aunque puntualmente ha sido citada en zonas costeras, generalmente ha sido citada como orófila, incluso marcadamente alpina (c. 500-1000 m en Centroeuropa, hasta $1800 \mathrm{~m}$ en el sur de Europa y hasta $3000 \mathrm{~m}$ en Próximo Oriente), y se le adjudican dos probables generaciones anuales y una fenología de sus imagos entre V-IX (Aspöck et al., 1980, 2001; Pantaleoni, 1982; Volkovich, 1998). También en este caso, son probablemente descartables las citas en zonas montanas y/o alpinas (al menos en Europa), y muy probablemente muchos de estos datos también se correspondan con C. cosmia.

Sus estadios preimaginales son fragmentariamente conocidos (Brauer 1850; anotado por Gepp, 1983, 1989 y Hölzel, 1998) y, como hemos indicado, nosotros hemos hallado y observado ejemplares (adultos y larvas) sobre chopo (Populus nigra) en Italia.

Con respecto a los nuevos ejemplares ibéricos ahora citados, parecen fuertemente asociados a medios xéricos, térmicos y gipsícolas. Todos los ejemplares se han recolectado a la luz en estos medios esteparios y secos con vegetación xerófila que ahora citaremos, donde no descartamos la existencia de chopos en vaguadas con mayor humedad endorreica o en los lindes de cultivos de arroz existentes. Por ello que no puede anotarse ningún dato sobre su posible planta sustrato, aunque ahora citamos las especies vegetales características del medio donde ha sido hallada.

Todos los nuevos ejemplares ibéricos ahora citados han sido recolectados (a la luz) entre 280-380 m, dentro del Parque Natural y Reserva de la Biosfera de las Bardenas Reales. En este espacio protegido se distinguen tres zonas: El Plano, situado al norte, dedicado a la agricultura en sus zonas llanas y en cuyas laderas la vegetación natural está principalmente compuesta de coscojas (Quercus coccifera), romerales (Rosmarinus officinalis), ontinares (Artemisia herba-alba) y repoblaciones puntuales y dispersas de pinares (Pinus halepensis); la Bardena Negra, situada al sur, con un relieve tabular caracterizado por sus mesetas de distintas alturas y su red de barrancos con fondos muy estrechos, siendo la zona de mayor cobertura vegetal del Parque Natural, y presentando por un lado extensos campos de cultivo cerealista y por otro coscojares (Quercus coccifera) y pinares (Pinus halepensis) rodeando dichos campos; y por último la Bardena Blanca, situada en el centro del Parque, con zonas llanas cultivadas atravesadas por 
Tabla 1.- Diferencias en la morfología externa entre Chrysopa nigricostata y Cunctochrysa cosmia: a/: alas anteriores, /a: alas posteriores.

Table 1.-Morphological external diferences between Chrysopa nigricostata y Cunctochrysa cosmia: A/: forewings, /A: hindwings.

\begin{tabular}{lll}
\hline & Chrysopa nigricostata & Cunctochrysa cosmia \\
\hline Pedicelo & verde externamente & pardo externamente \\
Setas del pronoto & cortas, robustas y negras & largas, suaves y pardas \\
Manchas del pronoto & dos circulares a cada lado & dos bandas longitudinales oscuras \\
A/A vena costal & amarilla en región M, Cu y A & verde en todo su recorrido \\
A/A SR & verde & pardo en su base \\
A/ CUa y Cup & verdes & pardas \\
A/ venas RA-PsM & todas negras & verdes las que conectan con gradiformes \\
A/ horquillas marginales & negras & verdes \\
A/ costal en ángulo anal & muy ensanchado & apenas ensanchado \\
A/ membr. en ángulo anal & con mancha oscura & sin mancha oscura \\
/A venas PsM-PsCu & verdes & pardas \\
/A venas M-A & verdes & pardas \\
/A A y A & verdes en su base & pardas \\
Setas del abdomen & cortas, robustas y negras & largas, suaves y pardas \\
\hline
\end{tabular}

barrancos en cuyo fondo existen cerros testigo, con suelos yesosos y margo-arcillosos, y flora de aspecto estepizado, con ontillares (Artemisia herba-alba), sisallares (Salsola vermiculata y Atriplex halimus) y espartales (Lygeum spartum), creando estas formaciones vegetales zonas de acumulación de sales que carecen prácticamente de vegetación. En esta última zona es donde hemos encontrado esta especie y se corresponde con el medio estepario anteriormente citado para ella y se ajustan con los medios en los que parece habitar la especie que tratamos (zonas esteparias de mediana altura). Más información sobre este particular paraje se puede encontrar en Rivas Goday, 1948; Neuman, 1960; Galvez Cañero, 1967; Geiger, 1973; Ursua, 1985; Meaza, 1987, 1989; GonzalezBernaldez, 1989; Elósegui y Ursúa, 1990; Iriarte, 1992; Suárez Cardona et al., 1992; Delgado et al., 1995; Iriarte y Meaza, 1996; Creus Novau, 1998; Aizpuru Oyarbide \& Catalán Rodríguez, 2000; Desir \& Marín, 2007; Marín \& Desir, 2008; y en la web: http://www.bardenasreales.es/reserva_h.htm.

El material ibérico estudiado ha sído recolectado entre los meses de mayo y agosto (con máximo en julio), en altitudes que oscilan entre 225-930 m (como elemento de ayuda en su diferenciación con Cunctochrysa cosmia, ésta ha sido recolectada en la Península Ibérica entre 670-2100 m). También otros datos de biología pueden ayudarnos a diferenciar esta especie de otras que poseen ciertas semejanzas en su morfología externa y que anteriormente hemos anotado en la discusión de su morfología externa. Chrysopa nigricostata parece, según hemos anotado, vinculada/circunscrita a chopos, mientras que veremos que Cunctochrysa cosmia está fuertemente vinculada a coníferas, mayoritariamente a pinos. Por el contrario, Chrysopa viridana es una especie más generalista y posee una muy extensa amplitud de hábitat, habiéndose citado en la península sobre más de 28 sustratos vegetales distintos, con cierta preferencia sobre quercíneas (Quercus spp.) esclerófilas en medios mediterráneos (Monserrat \& Marín, 1994) y marcescentes/caducifolias en otras zonas (Italia).

Como dato complementario a su biología, podemos indicar respecto a la especie que ahora tratamos (Chrysopa nigricostata), que el contenido del tubo digestivo en alguno de los ejemplares ibéricos analizados $(\mathrm{n}=5)$ contenía diversos granos de polen, algún trozo de tegumento artropodiano y multitud de setas y escamas que sugieren un carácter depredador en sus imagos, hecho anotado para las especies de este género (Brooks \& Barnard, 1990). Uno de los ejemplares que hemos estudiado de Tayikistán (ð) contenía similares elementos.

Material estudiado: ESPAÑA: Burgos, Burgos, 14.VII.1900, 1 +, leg.? (MCNB) (determinada por L. Navás como Chr. nigricostata v. marginata Nav.). Madrid, Alpedrete, 30.VII.1975, 1 + a la luz, P. Monserrat [citada como Chrysopa nigricostata por Monserrat (1977a) y en este caso no asignable a Cunctochrysa cosmia], / Chr. nigricostata Brau. v. marginata Nav. (Chamartín) 12 Agosto 1903 / Typus / 78-1892 MZB / 1 \& (MCNB), Ciudad Universitaria, V.1973, 1 ðૈ, A. González, Madrid, VI.1900, 1 ㅇ, leg.? (MCNB) (determinada por Navás como Chr. nigricostata v. marginata Nav.). Navarra, Ablitas, 1.VI.2012, $1 \hat{\partial}, 1$ + recolectados a la luz, Arguedas, 17.VII.2012, $2 \hat{\partial} \hat{\jmath}, 13$ 우 recolectados a la luz [citados como Chrysopa nigricostata por Monserrat et al. (2013)]. Zaragoza, / Ch. nigricostata Br. v. ataresi Nav. Navas S.J. det. / 
Typus / Veruela (Z.) 1.VIII.14 (1914) / 78-1891 MZB / 1 ㅇ, leg.? (MCNB), Zaragoza, V.1907, 1 ô, leg.? (MCNB) (determinado por Navás como Chr. nigricostata v. marginata Nav.), 21.VII.13 (1913), 1 + , leg.? (MCNB) (determinada por Navás como Chr. nigricostata v. marginata Nav.). Como material complementario y comparativo hemos estudiado 1 recolectado en ITALIA: Emilia Romagna, Ferrara, Lido delle Nazioni, $44^{\circ} 44^{\prime} 45.55^{\prime \prime} \mathrm{N} 12^{\circ} 14^{\prime} 43.72^{\prime \prime}, 3$ o ô $^{\prime}$, 15.VI.1990, 1 ô, y varias larvas, R. Pantaleoni (RP), y 1 ठิ y 1 q recolectados en TAYIKISTÁN: Gorno-Badakhshan, Pamir, $38^{\circ} 23^{\prime} 15.67^{\prime} \mathrm{N} 73^{\circ} 05^{\prime} 05^{\prime \prime}$ E, 4600 m, 25.VII.1980, A.V. Zakharenko det., leg. Los datos de morfología y pigmentación de estos ejemplares corroboran las identificaciones del material ibérico ahora citado.

\section{Chrysopa nierembergi Navás, 1908}

Especie ibérica muy poco citada, de biología muy poco conocida y de posición taxonómica aún por corroborar. Está citada en la península de España: Alicante, Almería, Castellón, Granada, Guadalajara, Madrid, Málaga, Tarragona, Teruel y Zaragoza, donde se ha citado entre $\mathrm{V}$ y IX, en altitudes que oscilan entre 10 y $1410 \mathrm{~m}$.

Material estudiado: ESPAÑA: Almería, San José, Playa de Mónsul, 28.VI.2011, 1 ㅇ a la luz. Granada, La Herradura, Punta de la Mona, 26.VII.2010, 1 + a la luz.

\section{Género Pseudomallada Tsukaguchi, 1995}

Recientemente la Comisión Internacional de Nomenclatura Biológica (Opinion 2254, Case 3399), en su boletín de 2010, 67(3): 261-262, ha validado este género anteriormente relacionado con otros géneros como Anisochrysa, Mallada o Dichochrysa. Desde Monserrat \& Díaz Aranda (2012) mantenemos pues el nombre de este taxón en la nomenclatura de las especies de este género. El género Mallada Navás (1925b:24) es masculino (dedicado a Lucas Mallada) y, consecuentemente, Pseudomallada sigue siendo masculino. Ahora anotaremos dos nuevas combinaciones correspondientes a especies canarias.

\section{Pseudomallada prasinus (Burmeister, 1839)}

Especie paleártica, marcadamente eurioica. En la península y Baleares (Mallorca, Menorca, Ibiza) está ampliamente citada entre III y $\mathrm{X}$, en altitudes que oscilan entre 10 y $2454 \mathrm{~m}$.

Recientemente algunas especies o variedades/ subespecies previamente sinonimizadas con la especie que tratamos o, hasta ahora, sin interés taxonómico frente a ella, han sido consideradas como especies válidas: $P$. abdominalis (Brauer, 1856) y P. mariana (Navás, 1905) (Pantaleoni, 1988, 1990; Duelli, 1989; Hölzel, 1998; Aspöck et al., 2001; Duelli et al., 2002; Canard et al., 2010), por lo que, aceptadas estas opiniones, el abundante material ibérico de $P$. prasinus debería revisarse, máxime sabiendo que $P$. mariana (y sus variedades) se describieron de España (Barcelona, Montserrat), y son muy abundantes las citas antiguas dadas bajo diversas denominaciones: Chrysopa mariana Navás, 1905, Cintameva mariana (Navás, 1905), Mallada marianus (Navás, 1905), al margen de las variedades C. mariana chlorocephala Navás, 1907, C. mariana scalaris Navás, 1909 o C. mariana stictocera Navás, 1907.
Por el contrario, sobre las citas ibéricas de $P$. abdominalis (Brauer, 1856) parece haber, de momento, menor problemática, ya que, según comentaron Monserrat \& Triviño (2013), esta especie centroeuropea fue erróneamente citada de España por Navás (1901) en base a material de Madrid y Zaragoza, y posteriormente (Navás, 1903) asignaba estos ejemplares a $P$. ibericus (Navás, 1903) primero, y más tarde (Navás, 1908) a $P$. ventralis (Curtis, 1834), por ello estas citas no merecerían ser consideradas, pero habría que dilucidar la identidad de las abundantes citas dadas por este autor como Chrysopa prasina abdominalis Brauer, $1856 \mathrm{y}$, como hemos anotado, revisar el abundante material disponible citado de $P$. prasinus en la península y Baleares. Es muy probable que $P$. abdominalis y $P$. mariana sean especies válidas, y que una u otra especie (o ambas) habiten en la fauna ahora considerada. No en vano, Monserrat \& Díaz Aranda (2012), al estudiar los estadios larvarios de diferentes poblaciones ibéricas de $P$. prasinus, encuentran sorprendentes diferencias, sea en el tipo de puestas o en la morfología de sus larvas, hecho que sugiere y parece corroborar esta cuestión.

Mantenemos pues el tema a la espera de revisar el abundante material ibero-balear existente en muy diversas colecciones.

Material estudiado: ESPAÑA: Almería, Cuevas de Sorbas, 15.IV.2011, 2 우 sobre Salsola oppositifolia. Badajoz, Santa María de los Barros, 19.VI.2012, 1 o sobre Quercus rotundifolia. Baleares, Ibiza, Santa Eulalia, 16.VII.2010, 2 우 a la luz. Cádiz Pinsapar de Grazalema, 22.VI.2012, 1 क sobre Q. rotundifolia. Ciudad Real, Navas de Estena, 7.VII.2012, 2 to sobre Q. ilex. Cuenca, Puerto Cabrejas, 27.VI.2009, 2 우 sobre Q. rotundifolia, 1 o sobre $Q$. faginea, 12.VII.2009, 1 ऊ ex 1., capturada el 27.VI.2009 sobre Q. faginea, pupó el 2.VII.2009, Verdelpino de Cuenca, El Chantre, 27.VI.2009, 1 9 sobre Populus alba. Granada, Albondón, 5.VII.2010, 1 §, 1 o sobre Q. rotundifolia, Cádiar, 5.VII.2010, 1 q sobre $Q$. rotundifolia, Cáñar, 6.V.2011, 2 ठิ $\widehat{O}, 4$ 우 sobre $Q$. rotundifolia, 1 ㅇ sobre Castanea sativa, 27.VI.2011, 3 싱, 3 우 sobre $Q$. pyrenaica, 18.VII.2011, $1 \hat{\delta}, 2$ 오 sobre $Q$. pyrenaica, 6

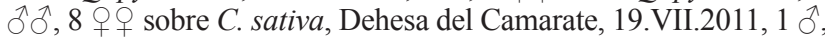
1 \& sobre $Q$. pyrenaica, Dúdar, VII-VIII.2005, 1 ㅇ, A. Tinaut, El Dornajo, 1.IX.2010, 1 O, 1 q sobre Q. rotundifolia, 10.VII.2012,

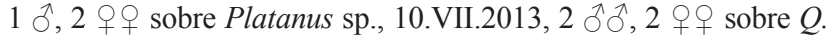
rotundifolia, El Rescate, 3.VIII.2010, 1 $\widehat{\partial}, 2$ 우 9 sobre Olea europea, 23.VIII.2010, 1 ô, 1 q sobre O. europea, 8.VIII.2011, 1 ㅇ

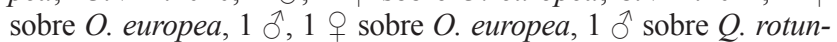
difolia, Ferreira, 8.V.2011, 7 ऊ̂े, 3 우 sobre Q. rotundifolia, Haza del Lino, 9.IX.2008, 1 +, A. Castro, Huétor de Santillán, 8.V.2011,

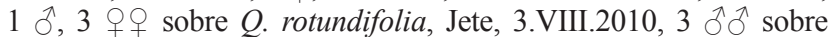
O. europea, 23.VIII.2010, 2 우 sobre O. europea, 8.VIII.2011, 1 ते sobre O. europea, 8.VIII.2011, 2 우 sobre O. europea, La Herradura, Cerro Gordo, 6.VIII.2011, 1 స, 2 우 우 a la luz, 27.VIII.2011, 1 a la luz, La Herradura, Las Cuevas, 27.VII-12.

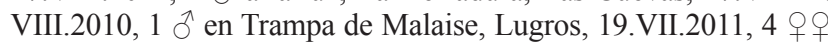
sobre Q. pyrenaica, Majadillas, 3.VIII.2010, 1 + sobre Pistacea sp., 23.VIII.2010, 1 त, 1 o sobre Nerium holeander, 8.VIII.2011, 1 우 sobre Pistacea sp., 21.VIII.2011, 1 oे sobre N. holeander, Otivar, 3.VIII.2010, 3 ठे के sobre O. europea, 23.VIII.2010, $1 \hat{\partial}, 2$ 우 sobre O. europea, 8.VIII.2011, 1 ô sobre O. europea, 21.VIII.2011,

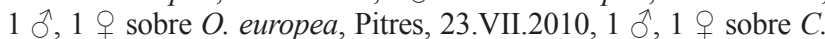
sativa, 2 우 sobre Q. rotundifolia, Puerto de la Ragua, 8.V.2011,

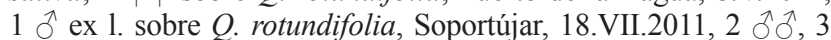
우 sobre Q. pyrenaica. Huelva, La Nava, 23.V.2012, 1 ô sobre $Q$. 
Tabla 2.- Alas anteriores: Número de venillas gradiformes externas (A) e internas (B); número de venillas trasversales del campo subcostal bajo el pterostigma (C).

Table 2.- Forewings: Number of outer gradate cross veins $(A)$ and inner gradate cross veins $(B)$; number of transverse veins in subcostal field under the pterostigma (C).

\begin{tabular}{|c|c|c|c|c|c|c|c|c|c|c|}
\hline $\mathbf{A}$ & 4 & 5 & 6 & 7 & 8 & 9 & 10 & & n & $\bar{X}$ \\
\hline Ch. nigricostata & & & 2 & 16 & 14 & 2 & 1 & & 18 & 7,33 \\
\hline Cu. cosmia & 1 & 6 & 21 & 20 & 1 & & & & 25 & 6,16 \\
\hline Ch. viridana & 5 & 9 & 17 & 8 & 1 & & & & 20 & 5,77 \\
\hline B & 2 & 3 & 4 & 5 & 6 & 7 & 8 & 9 & $\mathbf{n}$ & $\bar{X}$ \\
\hline Ch. nigricostata & & & & 1 & 8 & 10 & 15 & 2 & 18 & 7,25 \\
\hline Cu. cosmia & & 6 & 20 & 22 & 4 & & & & 26 & 4,46 \\
\hline Ch. viridana & 8 & 29 & 3 & & & & & & 20 & 2,87 \\
\hline $\mathrm{C}$ & 3 & 4 & 5 & 6 & 7 & 8 & 9 & & n & $\bar{X}$ \\
\hline Ch. nigricostata & & 1 & 9 & 13 & 10 & 2 & 1 & & 18 & 6,16 \\
\hline Cu. cosmia & 2 & 10 & 15 & 8 & 1 & & & & 18 & 4,88 \\
\hline
\end{tabular}

rotundifolia, Puerto Blanco, 19.VI.2012, 1 ô sobre Eucaliptus sp. León, León, Azucarera, 30.VII-10.VIII.2007, 3 ふふふ, 3 우우, M. C. Delgado (UL), 12-26.IX.2007, 10 $\widehat{\jmath}, 9$ 우, M. C. Delgado (UL). Madrid, Ciudad Universitaria, 18.IX.2012, 1 q a la luz, Chinchón, El Salitral, 20.VI.2009, 1 ㅇ a la luz, San Fernando de Henares,

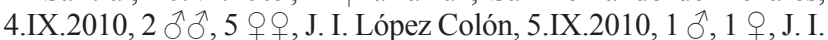
López Colón, 24.VII.2011, 2 우, J. I. López Colón, 24.VIII.2011, 1 Ф, J. I. López Colón. Málaga, Algarrobo, 5.VIII.2010, 1 đ, 3 우 sobre Ceratonia siliqua, 25.VIII.2010, 1 ๙ sobre O. europea, 10.VIII.2011, 1 ते sobre C. siliqua, 30.VIII.2011, 1 ते sobre $O$. europea, Benamocarra, 5.VIII.2010, 2 취, 3 우우 sobre $O$. europea, 25.VIII.2010, 1 ते sobre O. europea, 25.VIII.2010, 1 $\delta$ sobre Pinus halepensis, 10.VIII.2011, 2 ồ $\hat{\jmath}, 3$ 우 sobre O. europea, 30.VIII.2011, 1 đo sobre O. europea, Sayalonga 5.VIII.2010, $5 \hat{\partial} \sigma^{\lambda}$ sobre $O$. europea, 25.VIII.2010, 1 ते sobre $O$. europea, 10.VIII.2011, 1 ô sobre $O$. europea, 25.VIII.2010, 1 ô sobre $O$. europea, Coín, Sa . Alpujata, 23.VII.2012, 1 q a la luz, O.Gavira, 16.VIII.2012, 3 ठิ $\widehat{~}$ a la luz, O Gavira.

\section{Pseudomallada venosus (Rambur, 1842)}

Especie eremial, conocida de la Región Paleártica Occidental (S. O. de Europa, N. de África y Oriente próximo hasta Asia central). En la península y Baleares es conocida de medios mediterráneos y está fuertemente asociada a medios térmicos y xéricos, con cierta preferencia por las coníferas y con cierta frecuencia ha sido visualizada sobre la superficie de rocas. Está citada entre IV y IX, en altitudes que oscilan entre 10 y $3000 \mathrm{~m}$.

Material estudiado: ESPAÑA: Almería, Gérgal, 29.VI.2011, 1 ㅇ a la luz, Retamar, Rambla del Retamar, 14.VI.2012, 1 + a la luz, 12.VII.2012, 7 우 a la luz, Tabernas, Rambla Oasis, 7.VII.2013, $1 \hat{\jmath}$ sobre hierba, Tabernas, Rambla Roja, 19.VII.2011, $3 \hat{\delta} \hat{\sigma}, 6$

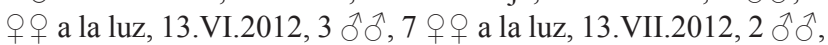
2 우 a la luz, 14.IX.2013, 1 ㅇ a la luz. Granada, Calahonda, 8.VII.2013, 2 우 우 sobre Pinus halepensis, La Herradura, Cerro Gordo, 6.VIII.2010, 1 ㅇ a la luz, 17.VIII.2013, 1 ते a la luz, La Herradura, Punta de la Mona, 3.VIII.2010, 1 q a la luz, 4.IV.2012, 1 a la luz. Madrid, Alcalá de Henares, 26.VII.1985, 1 q a la luz, Chinchón, El Salitral, 20.VI.2009, 1 đิ a la luz.

\section{Pseudomallada genei (Rambur, 1842)}

Especie holomediterránea. Ampliamente conocida de la península y Baleares asociada a medios térmicos sobre una amplia gama de sustratos, con cierta aparente preferencia por las coníferas. Está citada entre III y IX, en altitudes que oscilan entre 10 y $1750 \mathrm{~m}$.

Material estudiado: ESPAÑA: Almería, Agua Amarga,

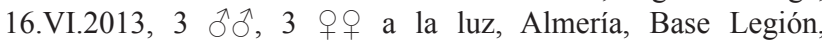
17.VII.2011, 1 + a la luz, 31.III.2013, 1 ㅇ, Almoladeras, 6.VII.2013, 1 ô, 4 우 sobre Ziziphus lotus, El Pozo del Fraile, 5.VII.2013, 1 q sobre Olea europea, El Toyo, Rambla del Agua, 6.V.2011, 2 우 sobre Atriplex halinus, Gérgal, 29.VI.2011, 11

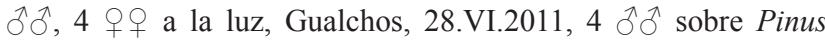
halepensis, Las Negras, 29.VI.2011, 2 ठึ, 1 o sobre O. europea, Níjar, 29.VI.2011, 1 ઈ,, 3 우 sobre P. halepensis, Punta Entina Sabinar, 15.IX.2013, 1 a la luz, Retamar, Rambla del

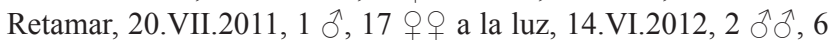

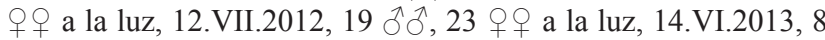

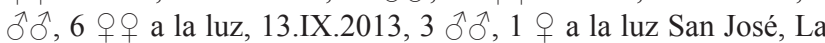
Torta, 5.VII.2013, 1 ô, 1 q sobre O. europea, San José, Playa de Mónsul, 7.V.2011, 1 ô sobre Chamaerops humilis, 28.VI.2011, $3 \hat{\delta} \widehat{\partial}, 10$ 우 a la luz, 19.VII.2011, 1 ô, 1 a la luz, Tabernas, 29.VI.2011, 1 + sobre Tamarix gallica, 18.VII.2011, 1 q sobre $T$. gallica, Tabernas, Rambla Roja, 19.VII.2011, 24 ठํ, 21 q $ᄋ$ a la luz, 13.VI.2013, 1 $\hat{\sigma}$ a la luz, 7.VII.2013, $3 \hat{\jmath} \widehat{\jmath}, 4$ 웅 a la luz,

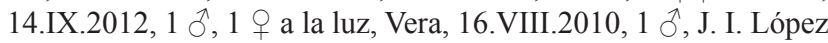
Colón, Vícar, 14.IX.2013, 2 우 a la luz. Granada, Calahonda, 8.VII.2013, 1 \& sobre P. halepensis, La Herradura, Cerro Gordo,

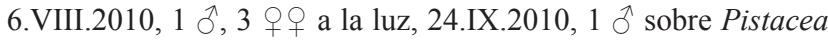
lentiscus, 17.VIII.2013, 1 §े a la luz, La Herradura, Punta de la Mona, 19.IX.2013, 1 o a la luz, Los Tablones, 6.V.2011, 1 q sobre P. halepensis. Huelva, Matalascañas, 24.V.2012, 1 ㅇ sobre Juniperus phoenicea, 1 ㅇ sobre P. pinea, Punta Umbría, 23.V.2012, 1 + a la luz, 20.VI.2012, 1 + sobre $P$. pinea.

\section{Pseudomallada flavifrons (Brauer, 1850)}

Especie holomediterránea expansiva, conocida desde Canarias a Georgia e Irán. Marcadamente eurioica y generalmente asociada a medios mediterráneos. 
Ampliamente citada en la península y Baleares. Está citada entre III y XI, en altitudes que oscilan entre 10 y $2200 \mathrm{~m}$.

Material estudiado: ESPAÑA: Almería, El Toyo, Rambla del Agua, 6.V.2011, 2 우 of sobre A. halinus, Gérgal, 29.VI.2011, 1 đo a la luz, La Rambla Honda, 7.V.2011, 2 đ̊ ồ sobre Olea europea, Níjar, 29.VI.2011, 1 o sobre O. europea, Tabernas, Rambla Roja, 19.VII.2011, 1 ô, 2 우 a la luz, 13.VII.2012, $1 \hat{\delta}$ a la luz, Turrillas, 13.VI.2012, $1 \hat{\delta}$ sobre Quercus rotundifolia. Badajoz, Río Ardila, 23.V.2012, 2 đิ ồ sobre Ulmus minor. Baleares, Ibiza, Santa Eulalia, 16.VII.2010, 1 a la luz, Menorca, Poblat de Torralba, 25.VII.2008, 1 đ̋, 2 우 우 sobre $O$. europea. Barcelona, Cabrils, Can Tolrá, 25.VII.1996, 2 § $\widehat{\jmath}, 2$ 우

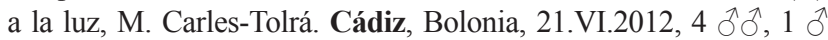
sobre Pistacea lentiscus, 1 q sobre O. europea, Bonanza, 24.V.2012, 1 it sobre Juniperus phoenicea, Chiclana, 25.V.2012, 1 o sobre P. lentiscus, Facinas, 20.VI.2012, 1 a la luz, La Marchenilla, 25.V.2012, 1 ㅇ sobre Eucaliptus sp., Las Cañillas, 21.VI.2012, 1 ô sobre P. lentiscus, Pinsapar de Grazalema, 26.V.2012, 1 q ex 1. sobre Q. rotundifolia, 22.VI.2012, 3 $\widehat{\jmath}, 5$ 우 0 sobre Abies pinsapo, 1 ㄱ, 2 우우 sobre Q. rotundifolia. Cuenca, Uña, 27.VI.2009, 1 우

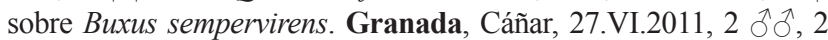
우오 sobre Q. pyrenaica, 18.VII.2011, 1 ㅇ sobre $Q$. pyrenaica, 1 우 sobre Castanea sativa, Dehesa del Camarate, 19.VII.2011, 1 đ sobre Q. rotundifolia, Hoya de la Mora, 30.VI.2011, 1 q sobre Pinus sylvestris, La Herradura, Cerrogordo, 7.VIII.2010, 1 q sobre P. lentiscus, 24.IX.2010, 1 q sobre P. lentiscus, 21.IV.2011, 1 ภ, 2 우우 sobre P. lentiscus, 2.VIII.2011, 2 우 a la luz, 27.VIII.2011, 1 ㅇ a la luz, La Herradura, Punta de la Mona, 12.VIII.2010, 1 ㅇ a la luz, 15.VI.2013, 1 q a la luz, 19.IX.2013, 1 q a la luz, 1.XI.2013, 3 우 a la luz, Pitres, 23.VII.2010, 1 ㅇ sobre $Q$. rotundifolia, Vélez de Benaudalla, 5.V.2011, 1 ð̊, 2 우 sobre hierba, 1 ㅇ sobre Eucaliptus sp. Guipúzcoa, Ataun, Aia, Aralar P.N., Urkillaga, 8-15.VI.2011, 1 ㅇ, 15-28.VII.2011, 1 우 , 15-28.VII.2011, 1 ô, 3 우우 sobre $Q$. ilex ilex, S. Pagola. Huelva, Matalascañas, 20.VI.2012, 1 q sobre $P$. pinea. Jaén, Jándula, X.1932, 1 ㅇ, F. Escalera (identificada como Chrysopa tenella Schneider, 1851=Cunctochrysa albolineata $)$ (MNCN). León, León, Azucarera, 12-26.IX.2007, 2 đ̂े, 1 우, M. C. Delgado (UL). Madrid, Alpedrete, 13.IX.1974, 1 옹 Chinchón,

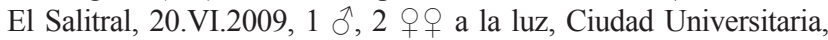
7.XI.2012, 1 + a la luz, El Escorial, Abantos 4.VII.2012, 2 우 sobre P. sylvestris, El Escorial, Abantos, Arboreto L. Ceballos, 21.VI.2008, 1 స ex.1., sobre Q. robur, 1.VIII-12.IX.2008, 1 \& en Trampa de Malaise, San Fernando de Henares, 22.IX.2010, 1 + , 29.IX.2010,

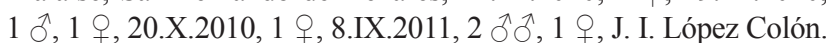
Pontevedra, Pereiro, 20.IX.2009, 1 $\delta, 1$ \& sobre $Q$. robur. Teruel, Saldón, 7.VII.2010, 2 우 sobre P. pinaster.

\section{Pseudomallada granadensis (Pictet, 1865)}

Especie atlantomediterránea. De biología muy poco conocida, en la península está asociada a medios térmicos de carácter mediterráneo. Está citada entre IV y $X$, en altitudes que oscilan entre 55 y $1750 \mathrm{~m}$.

Material estudiado: ESPAÑA: Granada, El Dornajo, 10.VII.2013, 1 \& sobre Quercus rotundifolia. Huelva, La Corte, 23.V.2012, 1 q sobre Q. rotundifolia. Salamanca, Berruecopardo, 31.V.2009, 1 sobre Q. pyrenaica. Teruel, Saldón, 7.VII.2010, 1 ô sobre Pinus pinaster.

\section{Pseudomallada picteti (McLachlan, 1880)}

Especie eurioica atlantomediterránea. Ampliamente conocida de la península y Baleares, asociada a medios mediterráneos. Está citada entre III y XII, en altitudes que oscilan entre 10 y $2000 \mathrm{~m}$.

Material estudiado: ESPAÑA: Almería, El toyo, Rambla del Agua, 29.VI.2011, 1 đ sobre Atriplex halinus, La Rambla Honda, 7.V.2011, 2 우 7 우 sobre O. europea, Tabernas, Rambla Roja, 13.VI.2012, 2 ô $\hat{\delta}$ a la luz. Baleares, Ibiza, Es Cavallet, 17.VII.2010, 1 o sobre Juniperus phoenicea, Menorca, Torre d'en Galmés, 27.VII.2008, $2 \widehat{\partial} \hat{O}, 1$ + sobre O. europaea. Cádiz, Pedro Valiente, Playa de los Lances, 21.VI.2012, 1 + sobre Pinus pinea, Pinsapar de Grazalema, 22.VI.2012, 3 우 sobre Abies pinsapo. Granada, Gualchos,

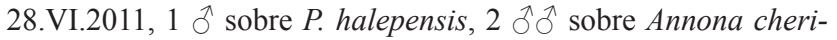
mola, Huétor de Santillán, 8.V.2011, 1 đิ sobre Quercus rotundifolia, La Herradura, Punta de la Mona, 27.VIII.2011, 1 ㅇ a la luz, 4.IX.2011, 1 ㅇ a la luz, 8.XII.2011, 1 \& a la luz, 22.III.2013, 1 o

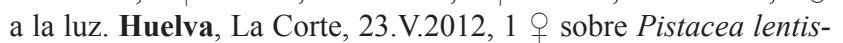
cus, Punta Umbría, 20.VI.2012, 1 đ sobre $P$. pinea. Málaga, Coín, $\mathrm{S}^{\mathrm{a}}$. Alpujata, 3.V.2013, 2 đ̄ $\widehat{\text { s }}$ sobre Q. rotundifolia, Estepona, $\mathrm{S}^{\mathrm{a}}$. Bermeja, Río Padrón, 12.VI.2013, 1 đ, 1 q sobre Salix pedicellata, Las Asomadillas, 25.V.2012, 2 우 sobre P. lentiscus.

Pseudomallada subcostalis (McLachlan, 1882) n. comb.

Especie conocida de las Islas Canarias (Tenerife, Gran Canaria y La Gomera). De carácter eurioico. Merced a la información proporcionada por Arp Kruithof, y que está expuesta en el foro que anotamos: http://www. flickr.com/photos/35142635@N05/5571534489/ in/pool-44933587@N00/; http://www.flickr.com/ photos/35142635@N05/5571534489/in/pool1536553@N20; http://www.arthropodafotos.de/dbsp. php?lang $=$ eng $\& s c=0 \&$ ta $=t$ t50_neu_0_chr\&sci $=$ Dichochrysa\&scisp=subcostalis han aparecido interesantes citas de esta especie que ha sido fotografiada en Fuerteventura y Lanzarote, y que consideramos interesante anunciar, a la espera de que la recolecta de ejemplares confirme la identificación que ahora anotamos.

Como hemos indicado, el género Dichochrysa Yang, 1991, en el que ha sido incluida más recientemente esta especie (Aspöck et al., 2001; Ohm \& Báez, 2004; Báez \& Oromí, 2010) ha sido desestimado por la Comisión Internacional de Nomenclatura Zoológica [Opinión 2254 (Caso 3399), Boletín de Nomenclatura Zoológica 67: (3) septiembre 2010, p 261-262]. El nombre aceptado actualmente es Pseudomallada Tsukaguchi, 1995. El género Mallada Navás, 1925 es masculino, y consecuentemente también debe serlo Pseudomallada. Por ello se establece y propone esta nueva combinación.

Material estudiado o citado en las citadas webs: ESPAÑa: Islas Canarias, Fuerteventura, Costa Calma, 8.III.2006, 1 , , M. Friedrich. Gran Canaria, Marzagán, 17.V.1985, 1 \&, G. Ortega (MCNT). Lanzarote, Los Claveles, Playa Blanca, 16.III.2011, 1 §, S. Rae. Tenerife, Bajamar, 3.II.1980, 1 †, M. Báez (MCNT), Puerto de la Cruz, 24.III.2009, 1 ㅇ, S. Krejcik.

\section{Pseudomallada subcubitalis (Navás, 1901)}

Especie atlanto-mediterránea. Ampliamente conocida de la península, marcadamente asociada a Tamarix spp. Está citada entre IV y X, y en altitudes que oscilan entre 10 y $2200 \mathrm{~m}$. 


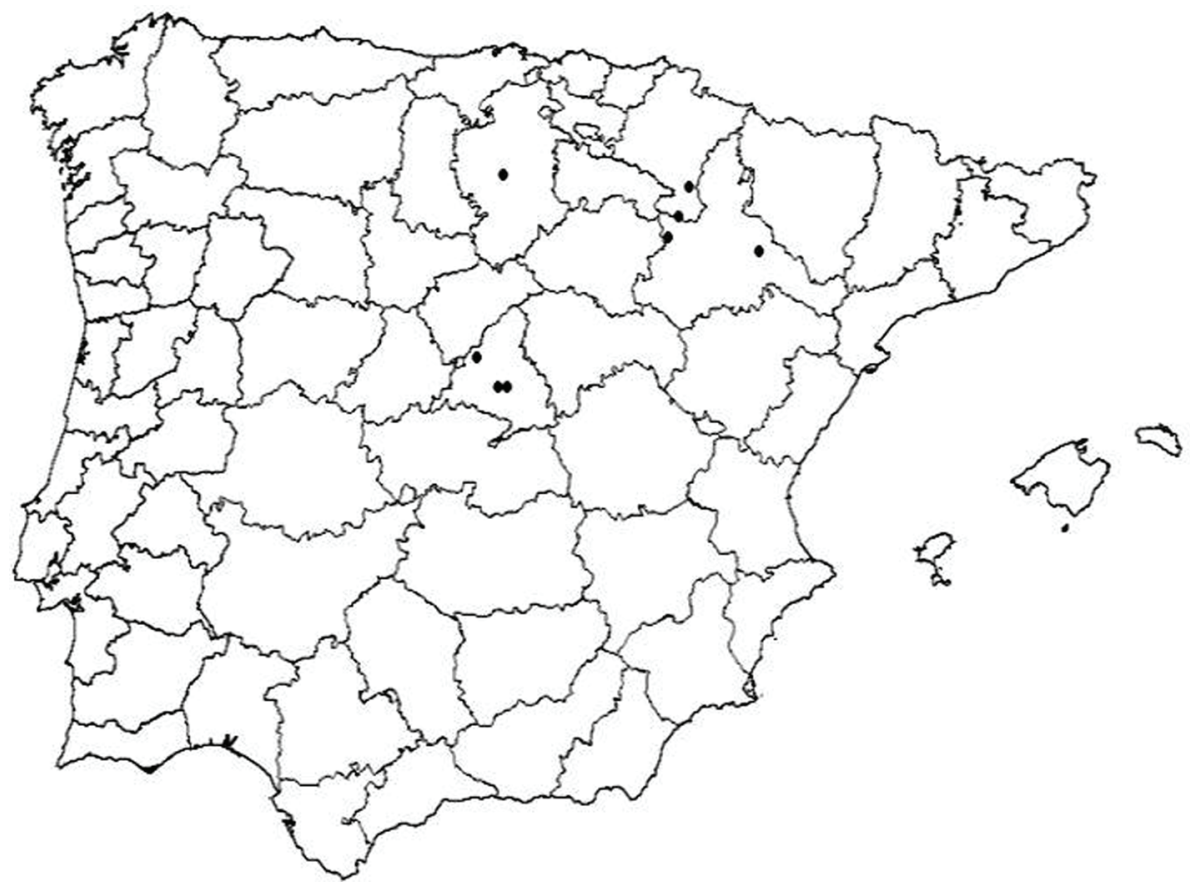

Fig. 29.- Distribución de Chrysopa nigricostata Brauer, 1850 en la Península lbérica.

Fig. 29.- Distribution of Chrysopa nigricostata Brauer, 1850 in the Iberian Peninsula.

Material estudiado: ESPAÑA: Almería, Amoladeras, 6.VII.2013, 2 우우 sobre sobre Tamarix gallica, Cueva de las Medinas, 20.VII.2011, 1 ô sobre T. gallica, Gérgal, 8.V.2011, 2 우 sobre Tamarix sp., Punta Entina Sabinar, 15.IX.2013, 1 구 sobre T. gallica, Tabernas, 7.V.2011, 2 ऊ̂े, 1 q sobre Tamarix sp., 29.VI.2011, 1 đิ sobre T. gallica, Tabernas, Rambla Roja, 19.VII.2011, 1 ㅇ a la luz. Granada, Albondón, 5.VII.2010, 1 오 sobre Quercus rotundifolia, Cáñar, 18.VII.2011, 1 đ, 1 + sobre $Q$.

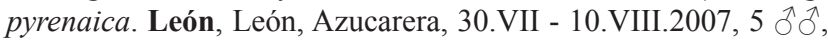
5 우오, M. C. Delgado (UL). Madrid, Cercedilla, Cerro Colgado, 19.VIII.2013, 1 9, C. Ornosa, Chinchón, El Salitral, 20.VI.2009, 1 ¿ a la luz, San Fernando de Henares, 29.V.2011, 1 đ, J. I. López Colón. Málaga, El Madroñal, Embalse del Río Guadaiza, 13.VI.2013, 1 + sobre T. gallica. Murcia, Playa de las Moreras, 19.VIII.2011, 2 q 0 sobre T. gallica.

Pseudomallada fortunatus (McLachlan, 1882) n. comb.

Especie canaria conocida de La Palma, ElHierro, Gran Canaria y Tenerife. Como citábamos anteriormente, merced a la información expuesta por Arp Kruithof en el foro que anotamos: http://www.arthropodafotos.de/ dbsp.php?lang $=$ eng \& sc $=0 \&$ ta $=$ t_50_neu_0_chr\&sci $=$ Dichochrysa\&scisp=fortunata, ha aparecido una interesante cita de esta especie que ha sido fotografiada en Fuerteventura y que consideramos interesante anunciar, a la espera de que la recolecta de ejemplares confirme la identificación que ahora anotamos.

Como anteriormente mencionábamos, el género Dichochrysa Yang, 1991, en el que más recientemente ha sido incluida esta especie (Aspöck et al., 2001; Ohm \& Báez, 2004; Báez \& Oromí, 2010) ha sido desestimado por la Comisión Internacional de Nomenclatura Zoológica [Opinión 2254 (Caso 3399),
Boletín de Nomenclatura Zoológica 67(3) septiembre 2010, pp. 261-262]. El nombre aceptado actualmente es Pseudomallada Tsukaguchi, 1995. El género Mallada Navás, 1925 es masculino, y consecuentemente también debe serlo Pseudomallada. Por ello se establece y propone esta nueva combinación.

Material citado en la web: ESPAÑA: Islas Canarias, Fuerteventura, Parque Natural de Jandia, 15.III.2011, 1 ㅇ, M. Friedrich.

\section{Pseudomallada ibericus (Navás, 1903)}

Especie mediterránea occidental. En la península está mayoritariamente asociada a medios mediterráneos con cierta preferencia por las coníferas. Está citada entre III y X, en altitudes que oscilan entre 10 y $1900 \mathrm{~m}$.

Material estudiado: ESPAÑA: Almería, El Toyo, Rambla del Agua, 6.V.2011, 1 ठै sobre Tamarix sp., Gérgal, 8.V.2011, 1 § sobre Tamarix sp., 29.VI.2011, 1 đa la luz, La Rambla Honda, 7.V.2011, 1 + sobre Olea europea, 1 ㅇ sobre Atriplex halinus, Níjar, 15.IV.2011, 2 우 sobre Salsola sp., 7.V.2011, 1 ठ, 1 ๆ sobre Ceratonia siliqua, 29.VI.2011, 2 우 sobre O. europea, Tabernas, 7.V.2011, 1 ㅇ sobre Tamarix sp., 1 ô, 1 ㅇ sobre Salsola oppositifolia, 29.VI.2011, 1 ते sobre Tamarix gallica, Tabernas, Rambla Roja, 19.VII.2011, 1 ô, 4

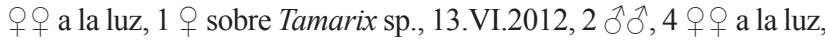
13.VII.2012, 3 우 a la luz, 15.VI.2013, 2 우 a la luz, 7.VII.2013, 1

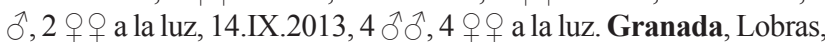
6.V.2011, 1 ㅇ sobre Quercus rotundifolia. Huelva, Matalascañas, 24.V.2012, 1 के, 1 क sobre Juniperus phoenicea, 1 के sobre Pinus

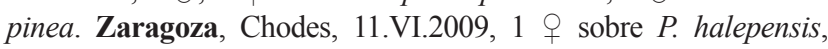
Granja de San Pedro, 11.VI.2009, 1 \& sobre Ulmus sp.

Pseudomallada alarconi (Navás, 1915)

Especie atlantomediterránea. Marcadamente estenotópica y fuertemente asociada a enebros y sabinas 
en medios mediterráneos continentales. Es una especie muy poco citada en la península (Albacete, Granada, Guadalajara, Jaén, Madrid, Murcia y Teruel). Está citada entre V y IX, en altitudes que oscilan entre 420 y $1410 \mathrm{~m}$.

Material estudiado: ESPAÑA: Guadalajara, Molina de Aragón, 22.VII.2001, 1 ठิ sobre Juniperus sabina, J.L. Sánchez.

Atlantochrysa atlantica (McLachlan, 1882).

Especie macaronésica, conocida de Canarias (Gran Canaria, El Hierro, La Gomera, La Palma y Tenerife) y Madeira. Asociada a medios húmedos de Laurisilva.

Material estudiado: ESPAÑA: Islas Canarias, Gran Canaria, La Mina (Barranco de), 17.III.1902, 1 $\delta$, Eaton (NHM). Tenerife, Barranco del Agua, 13.VII.2005, 1 o sobre Myrica faya, 1 o sobre Viburnum rigidum, 13.VII.2007, 1 Oे, 1 q sobre Apollonias barbujana, 13.VII.2008, 1 §, 2 우 sobre V. rigidum, E. Fernández, Monte del Agua, 16.XI.2000, 1 §ૈ, E. R. Guerrero (MCNT).

\section{Brinckochrysa nachoi Monserrat, 1977}

Especie conocida del sur de España (Cádiz, Cáceres), Francia e Italia (Cerdeña). Frecuentemente hallada sobre eucaliptos. Está citada entre V y VIII, en altitudes que oscilan entre 40 y $400 \mathrm{~m}$.

Material estudiado: ESPAÑA: Cádiz, Algodonales, 26.V.2012, 1 q sobre Eucaliptus globulus.

\section{Género Chrysoperla Steinman, 1964}

Como se anotó en la introducción, la situación taxonómica de algunas especies del género Chrysoperla de la Región Holártica, Paleártica Occidental, y de las europeas en particular, dista mucho de estar resuelta desde que se descubrió la existencia de un complejo de numerosas especies crípticas, reproductivamente aisladas por diferentes tipos de cantos de apareamiento (Tauber \& Tauber, 1973; Henry, 1985, 1989, 1991, 1993, 1994; Henry \& Wells, 1990a, b; Cianchi \& Bullini, 1992; Henry et al., 2001, 2002, 2003, 2013; Thierry et al., 2013, etc.), sin que, en muchos casos, exista una clara y definitiva diferenciación morfológica que permita la identificación de los ejemplares por los métodos tradicionales (Henry et al., 2001; Canard \& Thierry, 2007). Esto ha creado una situación taxonómica y nomenclatorial especialmente compleja en el grupo de Chrysoperla carnea s.l. que ahora tratamos, con vivas discusiones, contribuciones e incluso nuevas formas y especies siguen describiéndose (Henry, 1989, 1991, 1993, 1994; Brooks \& Barnard, 1990; Henry \& Wells, 1990a, b; Wells \& Henry, 1992; Thierry \& Adams, 1992; Thierry et al., 1992, 1996, 1997, 1998; Henry et al., 1993, 2001, 2002, 2003; Brooks, 1994; Ventura et al., 2002; Fernández, 2003; Lourenço et al., 2005; Monserrat \& Díaz-Aranda, 2012, etc.).

Ante esta situación se aportan nuevos datos de varias especies ibéricas y baleares, cuyos ejemplares podrían identificarse con los caracteres de morfología y genitalia anotados por algunos autores que tratan de resolver esta interesante cuestión (Brooks, 1994; Plant \& Schembri, 1996; Thierry et al., 1998; Henry et al., 2001; Mazel et al., 2006; Canard \& Thierry, 2013, etc.), sin tener en cuenta los fenotipos de sonidos que, lógicamente, no pueden considerarse en ejemplares montados o conservados en alcohol.

\section{Chrysoperla mutata (McLachlan, 1898)}

Especie holomediterránea expansiva conocida desde el norte de África (Marruecos, Argelia, Túnez, Libia, Mauritania, Egipto, Sudán), Sur de Europa (Chipre, Grecia insular, sur y centro de España), Anatolia, Israel y Jordania, hasta la Península Arábica, Pakistán, Irán, Irak y norte de India. De biología poco conocida, está asociada a medios térmicos. En la Península Ibérica está muy escasamente citada (Almería, Ávila, Granada, Jaén, Madrid y Valencia), sobre Eucaliptus globulus, Olea europea, Ceratonia siliqua y Quercus rotundifolia. Está citada entre V y X, en altitudes que oscilan entre 270 y $1390 \mathrm{~m}$.

Material estudiado: ESPAÑA: Almería, Níjar, 7.V.2011, 1 ㅇ sobre Ceratonia siliqua.

\section{Chrysoperla lucasina (Lacroix, 1912)}

Especie paleártica occidental, conocida desde Canarias a Chipre y del norte de África a Escocia, probablemente eurioica. En la península está ampliamente citada y corroboramos su presencia en Baleares (Monserrat, 2005), y citamos nuevos datos inéditos para Menorca. Está citada entre I y X, en altitudes que oscilan entre 10 y $2800 \mathrm{~m}$.

Material estudiado: ESPAÑa: Almería, Atochares,

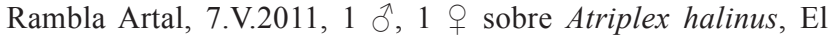
Toyo, Rambla del Agua, 6.V.2011, 1 q sobre A. halinus, Gérgal, 29.VI.2011, 1 § a la luz, La Rambla Honda, 7.V.2011, 1 శึ sobre Olea europea, Níjar, 7.V.2011, 1 ○ sobre Ceratonia siliqua, Rambla de Torregarcía, 14.VI.2012, 1 ô errante, San José, Los Genoveses, 7.V.2011, 1 ㅇ sobre Eucaliptus sp., San José, Playa de Mónsul, 7.V.2011, 1 q sobre Chamaerops humilis, 28.VI.2011, 1 ふै, 7 우 a la luz, 14.VI.2012, 1 ㅇ sobre C. humi-

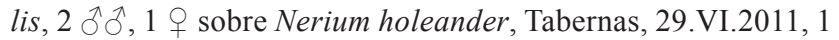
ô sobre Tamarix gallica, Tabernas, Rambla Roja, 13.VI.2012, 2 우 a la luz. Badajoz, Río Ardila, 23.V.2012, 1 ๙ิ sobre Ulmus minor, Río Sillo, 19.VI.2012, 1 đ sobre Quercus rotundifolia, Valverde de Burguillos, 23.V.2012, 1 sobre Q. rotundifolia. Baleares, Menorca, Binisafua, 20.V.1998, 1 +, D. Vellido (DV), 27.V.1998, 1 q, D. Vellido (DV), Ciutadella, 26.IX.1997, 1 9, D. Ventura (DV), 22.V.1998, 1 ㅇ, G. Chust (DV), Far de Favàritx, 27.IX.1997, 1 +, G. Chust (DV), Platja d'Esgrau, 24.V.1998, 1 , G. Chust (DV), Sa Roca, El Toro, 28.IX.1997, 1 ㅇ, D. Ventura (DV), 25.V.1998, 2 ऊิरे, D. Vellido (DV), Son Bou, 26.V.1998, 1 q, G. Chust (DV), Torre d'en Galmés, 27.VII.2008, 1 o sobre O. europaea, Torret, 24-25.IX.1997, 1

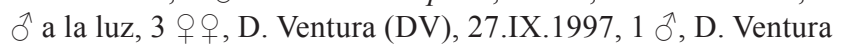
(DV), 20.V.1998, 1 ㅇ, D. Ventura (DV). Cádiz, Algodonales, 26.V.2012, 1 o, 1 क sobre Pistacea lentiscus, Barbate, 24.V.2012, 1 우 a la luz, Chiclana, 25.V.2012, 2 우 sobre $P$. lentiscus, Facinas, 25.V.2012, 1 ઈ, 1 q a la luz, Parque Natural del Estrecho, 21.VI.2012, 1 ㅇ sobre ornamental. Cuenca, Puerto Cabrejas, 27.VI.2009, $2 \hat{\jmath} \hat{\sigma}$ sobre Q. rotundifolia, $4 \hat{\jmath} \hat{\sigma}$ 


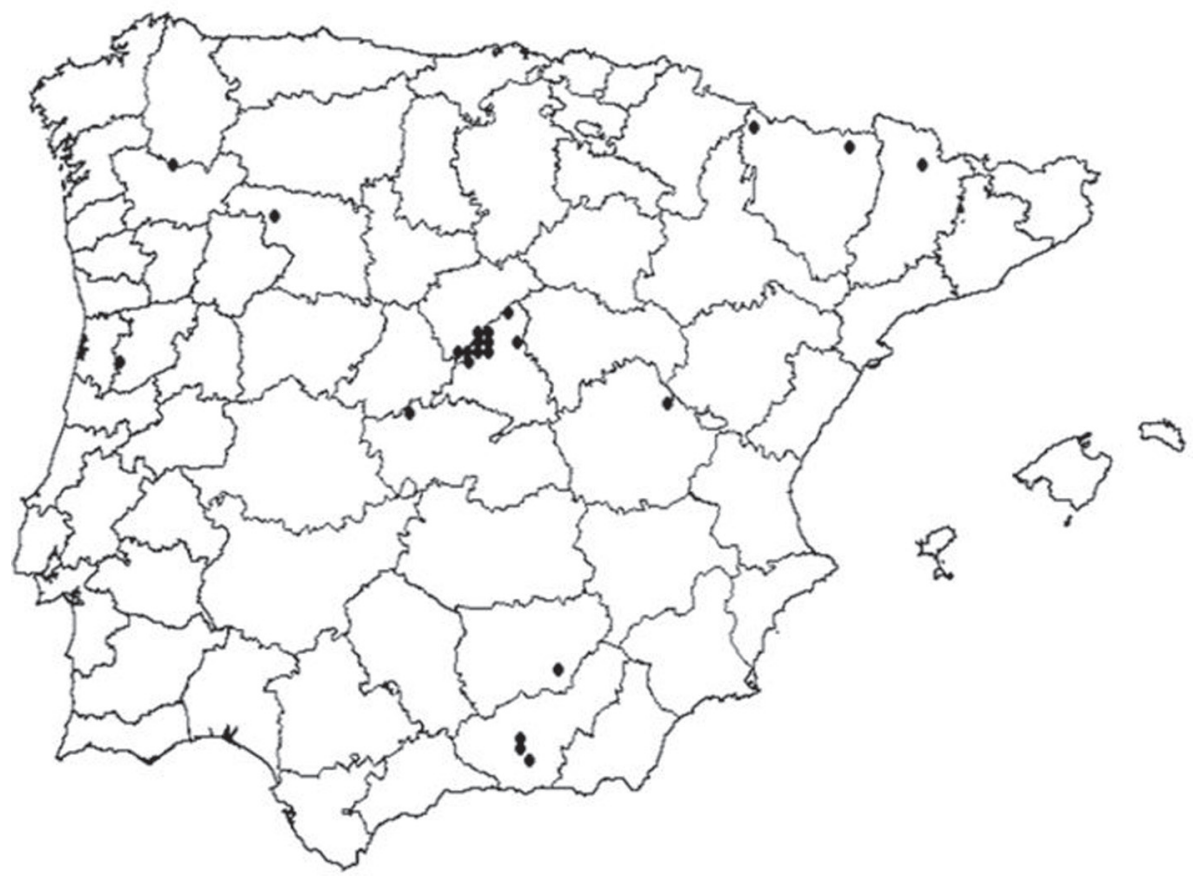

Fig. 30.- Distribución de Cunctochrysa cosmia (Navás, 1918) n. comb. en la Península lbérica.

Fig. 30.- Distribution of Cunctochrysa cosmia (Navás, 1918) n. comb. in the lberian Peninsula.

sobre Q. faginea, 1 ते sobre Pinus nigra, Uña, 27.VI.2009, 1 ㅇ sobre Buxus sempervirens, 1 ㅇ sobre Juniperus oxycedrus,

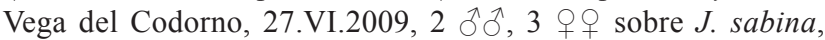
Verdelpino de Cuenca, El Chantre, 27.VI.2009, 1 ô sobre $J$. oxycedrus. Granada, Cáñar, 27.VI.2011, 4 $\widehat{\jmath}, 1$ ㅇ sobre $Q$. pyrenaica, 18.VII.2011, 1 §े, 2 우 sobre $Q$. pyrenaica, 1 ठे, 1 + sobre Castanea sativa, 1 + sobre P. sylvestris, Cerro Gordo, Cantarriján, 12.VI.2012, 1 q sobre $P$. halepensis, Dehesa del Camarate, 19.VII.2011, 1 đ, 1 \& sobre Q. pyrenaica, El

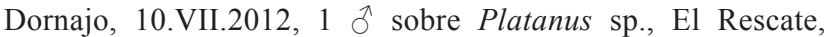
3.VIII.2010, 1 गे, 2 우 sobre O. europea, 23.VIII.2010, 1 o, 1 ㅇ sobre O. europea, Gualchos, 28.VI.2011, 1 ㅇ sobre

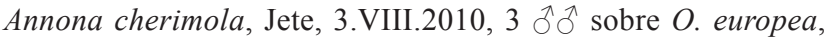
23.VIII.2010, 2 우 sobre O. europea, La Herradura, Punta de la Mona, 11.VIII.2011, 1 § a la luz, 4.IX.2011, 1 ô a la luz, Majadillas, 3.VIII.2010, 1 sobre Pistacea sp., 23.VIII.2010, $1 \hat{\delta}, 1$ ㅇ sobre $N$. holeander, Otivar, 3.VIII.2010, $3 \hat{\jmath} \hat{\jmath}$ sobre O. europea, 23.VIII.2010, 1 §, 2 우 sobre O. europea, Vélez de Benaudalla, 5.V.2011, 1 đ sobre Nicotiana glauca. Huelva, Puerto Blanco, 19.VI.2012, 2 ôे sobre Eucaliptus sp., Punta

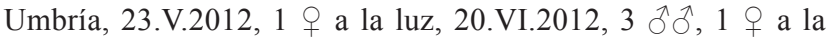
luz. León, León, Azucarera, 30.VII-10.VIII.2007, 2 $\widehat{\jmath}, 2$ 우우,

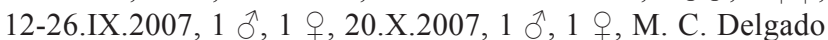
(UL). Madrid, Chinchón, El Salitral, 20.VI.2009, 3 ổ a la luz, Fuentidueña de Tajo, 28.VI.2009, 1 ㅊ, 2 우 우 sobre $Q$. ilex, Rascafría, 6.VII.2009, 1 ô sobre Q. pyrenaica, San Fernando de Henares, 11.I.2009, 1 ㅇ, J.I López-Colón. Málaga, Algarrobo, 5.VIII.2010, 3 우 우 sobre $C$. siliqua, 25.VIII.2010, 1 ฟ sobre $O$. europea, Benamocarra, 5.VIII.2010, $2 \hat{\partial} \hat{\delta}, 3$ 우 sobre O. europea, 25.VIII.2010, 1 § sobre O. europea, Frigiliana, 5.VIII.2010,

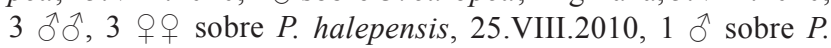
halepensis, Navahermosa, 26.V.2012, 1 q sobre O. europea, Sayalonga 5.VIII.2010, 3 ồ sobre O. europea, 25.VIII.2010, 1 I sobre O. europea, Torrox, 5.VIII.2010, 3 q $q$ sobre P. halepensis, 25.VIII.2010, 1 đ̋ sobre P. halepensis, Vélez Málaga,
5.VIII.2010, 3 के के sobre P. halepensis, 25.VIII.2010, 1 के sobre P. halepensis. Orense, Allariz, 22.IX.2009, 1 ㅅ, 2 우우 sobre Q. pyrenaica, Vilavella, 22.IX.2009, 2 우 sobre Q. pyrenaica. Pontevedra, Fontán, 21.IX.2009, 2 $\widehat{\delta}, 2$ 우 sobre Q. robur, Pereiro, 20.IX.2009, $2 \hat{\delta} \hat{\partial}, 2$ 우 sobre Q. robur. Salamanca, Berruecopardo, 31.V.2009, 1 ㅇ sobre Q. pyrenaica. Zamora, Otero de Sanabria, 22.IX.2009, 1 + sobre Q. pyrenaica, Puebla de Sanabria, 22.IX.2009, 1 q en interior de vivienda.

\section{Chrysoperla mediterranea (Hölzel, 1972)}

Especie circunmediterránea expansiva. En la península y Baleares (Mallorca, Formentera, y ahora la mencionamos de Ibiza) está ampliamente citada. Es una especie marcadamente termófila en medios mediterráneos, y está fuertemente asociada a coníferas, especialmente a Pinus halepensis. Está citada entre I y XII, en altitudes que oscilan entre 10 y 2000 m.

Material estudiado: ESPAÑA: Almería, San José, Los Genoveses, 4.V.2011, 1 ð sobre Pinus sylvestris. Baleares, Ibiza, Es Cavallet, 17.VII.2010, 1 ㅇ sobre Juniperus phoenicea, Santa

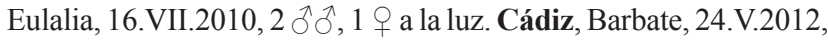
1 ภ, 1 ㅇ a la luz, Pinsapar de Grazalema, 22.VI.2012, 1 § sobre Abies pinsapo, Playa de los Lances, 21.VI.2012, 1 त sobre $P$. pinea.

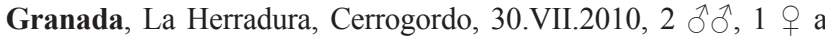
la luz, 6.VIII.2010, 5 우 sobre $P$. halepensis, $1 \hat{\delta}, 4$ 우 a la luz, 6.VIII.2011, 1 q a la luz, 27.VIII.2011, 1 q a la luz, La Herradura, Punta de la Mona, 26.VII.2010, 1 q a la luz, 3.VIII.2010, 2 ठิ

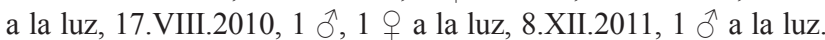
Huelva, Matalascañas, 20.VI.2012, 1 q sobre P. pinea. Madrid, Alcorcón, 4.XII.2011, 1 त a la luz. Málaga, Benamocarra, 30.VIII.2011, 1 ô sobre P. halepensis, Torrox, 5.VIII.2010, 3 우 sobre $P$. halepensis, 25.VIII.2010, 1 đ sobre P. halepensis, Vélez

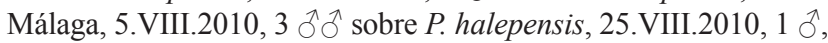
1 q sobre P. halepensis. 
Chrysoperla pallida Henry, Brooks, Duelli \& Johnson, 2002

Especie conocida del Reino Unido, España, Francia, Suiza, Italia, Grecia, Alemania y Hungría. Aún poco citada y de biología poco conocida. En España sólo se ha citado de las provincias de Madrid, Guipúzcoa, Granada y Navarra, ampliando ahora significativamente su distribución. Está citada entre V y XI, en altitudes que oscilan entre 10 y $2050 \mathrm{~m}$.

Material estudiado: ESPAÑA: Almería, El Toyo, Rambla del Agua, 6.V.2011, 1 \& sobre Tamarix sp., San José, Playa de Mónsul, 20.VII.2011, 1 ऊิ a la luz. Asturias, Luarca, 2.VII.2011, 1 ô, 1 + sobre Quercus robur. Badajoz, Fregenal de la Sierra, 19.VI.2012, 1 đ̊ sobre $Q$. rotundifolia. Cádiz, Facinas, 25.V.2012, 1 오 a la luz. Ciudad Real, Navas de Estena, 7.VII.2012, 1 ㄱ, 3 우우 sobre Q. ilex. Cuenca, Puerto Cabrejas, 27.VI.2009, 1 o sobre Q. faginea, Vega del Codorno, 27.VI.2009, 1 ㅇ sobre Juniperus sabina. Granada, Albondón, 5.VII.2010, 1 ㅇ sobre $Q$.

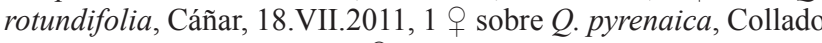
de la Sabina, 10.VII.2012, 1 ㅇ sobre Pinus sylvestris, Dehesa del Camarate, 19.VII.2011, 1 q sobre Q. pyrenaica, La Herradura, Cerrogordo, 1.VIII.2010, 1 ㅇ sobre Pistacea lentiscus, 21.V.2011, 1 đิ sobre P. lentiscus, La Herradura, Las Cuevas, 27.VII-12. VIII.2010, 1 ऊ en Trampa de Malaise, La Herradura, Punta de la Mona, 3.VIII.2010, $1 \hat{\jmath}, 3$ 우 a la luz, 10.VIII.2010, 1 ô a la luz, 12.VIII.2010, 3 के a la luz, 17.VIII.2010, $1 \hat{\delta}, 1$ ㅇ a la luz, 11.VII.2012, 1 우 a la luz, 1.XI.2013, 3 $\widehat{\partial}$ a la luz, Soportújar, 27.VI.2011, 1 a la luz. Guadalajara, Brihuega, 27.VII.2010, 1 a la luz. Huelva, La Nava, 23.V.2012, 1 q sobre Q. rotundifolia, Matalascañas, 24.V.2012, 2 우 sobre $P$. pinea, 1 우 sobre Nerium oleander, Puerto Blanco, 19.VI.2012, 2 우 sobre Eucaliptus sp., Punta Umbría, 23.V.2012, 1 a la luz. Madrid, Chinchón, El Salitral, 20.VI.2009, 1 ㅇ a la luz, Fuentidueña de Tajo, 28.VI.2009, 1 क sobre $Q$. ilex, Montarco, Rivasvaciamadrid, 12.VIII.2007, 1 đે, J. I. López-Colón. Málaga, Las Asomadillas, 25.V.2012, 1 ô sobre P. lentiscus.

Género Cunctochrysa Hölzel, 1970

El género Cunctochrysa Hölzel, 1970 comprende en la actualidad 8 especies descritas de la Región Paleártica, sur de África y Nepal (Brooks \& Barnard, 1990; Aspöck et al., 2001).

En Europa el género está representado por tres especies: C. albolineata (Killington, 1935), ampliamente distribuida en la Región Paleártica, desde Portugal a Corea; C. baetica (Hölzel, 1972), especie holomediterránea distribuida desde el sur de Europa, Marruecos y Túnez a Anatolia (ambas están presentes en la Península Ibérica y de ellas ahora se anotarán nuevos datos); y una tercera especie, C. bellifontensis Leraut, 1988, descrita de Francia, citada en Gran Bretaña y Bélgica (Leraut, 1988; Plant, 1993; San Martin, 2004; Canard et al., 2010, 2014) y referida de "toda Europa" por Leraut (2003), que ha sido propuesta como sinónima de C. albolineata por Aspöck et al. (2001), y cuyo estatus, según nuestro punto de vista, estaba aún por definir correctamente.

Los estadios larvarios de C. albolineata y $C$. baetica fueron descritos por Díaz-Aranda \& Monserrat (1994) y Monserrat \& Díaz-Aranda (2012), y ahora anotamos algún dato sobre la larva de $C$. cosmia $(=C$. bellifontensis).
A diferencia de lo que normalmente ocurre con las especies de otros géneros europeos de esta familia, las diferencias de morfología externa entre $C$. albolineata, C. baetica y C. bellifontensis son más sutiles y menos relevantes que en otros géneros, $y$ las de genitalia masculina se nos antojan engorrosas, subjetivas, y poco claras y definitorias (Hölzel, 1972a; Aspöck et al., 1980; Leraut, 1988, 2003; Plant, 1993), y por ello son especies fácilmente confundibles (Duelli, 1989; Aspöck et al., 2001). No así los nichos y hábitats que las tres especies europeas ocupan, que veremos más adelante al tratar conjuntamente la biología de las tres especies ahora tratadas. Esta cuestión no solo afecta a la problemática diferenciación de estas tres especies entre sí, sino que incluso afecta a especies de otros géneros, como quizás es el caso de Chrysopa viridana, y en especial de Chrysopa nigricostata, especies con las que, como hemos indicado, poseen numerosas similitudes en su morfología externa, particularmente con esta última.

Pues bien, tratando de profundizar y de contribuir a resolver esta cuestión, hemos comprobado que estos elementos planteados afectan a alguna de las sinonimias anteriormente propuestas y aceptadas para alguna de las especies anteriormente mencionada (Chrysopa nigricostata), y que, como hemos anotado, consideramos incorrecta, con lo que alguna de ellas merece ser revalidada como especie válida (Chrysopa cosmia) ya que, en realidad y como hemos referido con anterioridad, pertenece al género Cunctochrysa: Cunctochrysa cosmia (Navás, 1918) n. comb., especie que ahora revalidamos, y no es la primera vez que esto ocurre, y ejemplos hemos citado al referirnos a Pseudomallada prasinus. Por el contrario, una de esas tres especies del género Cunctochrysa citadas (C. bellifontensis), debe ser propuesta como sinónima posterior de Cunctochrysa cosmia (Navás, 1918) n. comb.

En lo que concierne a la fauna ibérica, y por lo anteriormente anotado para Chrysopa nigricostata (de la que Cunctochrysa cosmia no debe considerarse sinónima), han de corregirse las numerosas citas anteriormente dadas en relación a este grupo de especies. Ya hemos anotado las correspondientes a Chrysopa nigricostata, y ahora lo haremos con las citas que afectan a especies del género Cunctochrysa.

Debido a la similitud morfológica entre estas especies, no es de extrañar que sean numerosas las identificaciones erróneas que sobre ellas se hayan dado, y así lo hemos comprobado con material que ahora hemos estudiado (ver material de Chrysopa nigricostata, Chrysopa viridana, Pseudomallada flavifrons, Cunctochrysa albolineata o C. cosmia), y sobre todo, y como hemos indicado, sería muy aconsejable que se revisaran adecuadamente las sinonimias propuestas para estas especies, en particular las de Chrysopa nigricostata (Hölzel, 1973; Aspöck 
et al., 1980, 2001), hecho que incluso podría afectar a la prioridad en el uso del nombre de algunos taxa sinonimizados (ver Aspöck et al., 1980, 2001) respecto a otros nombres de especies habitualmente utilizados (Cunctochrysa albolineata). Tratemos pues de resolver esta cuestión reconsiderando a Cunctochrysa cosmia (Navás, 1918) n. comb. como especie válida.

\section{Cunctochrysa cosmia (Navás, 1918) especie revali- dada, n. comb.}

Esta especie fue descrita por Navás (1918) dentro del género Chrysopa a partir de un único ejemplar recolectado sobre pinos, el 9 de agosto de 1917 en Hecho (Huesca), siendo escasas las referencias posteriores existentes sobre ella (Navás, 1917, 1924a, 1925a, 1931), exclusivamente circunscritas a este único dato del pirineo aragonés, y sin que se hubieran recolectado o aportado nuevos ejemplares.

Posteriormente Hölzel (1973), tras estudiar el ejemplar tipo, propone a esta especie como sinónima posterior de Chrysopa nigricostata Brauer, 1850, y así ha sido desde entonces considerada (Aspöck et al., 1980, 2001; Brooks \& Barnard, 1990; Monserrat \& Díaz Aranda, 2012; Monserrat \& Triviño, 2013). De esta sinonimia derivan algunas referencias (ahora erróneas) de Chrysopa nigricostata en la Península Ibérica, según hemos indicado anteriormente.

Aunque la mayor parte de las especies ibéricas de esta familia con situación taxonómica problemática habían sido recientemente resueltas por Monserrat (2011), aún quedaba alguna cuestión por resolver. Pues bien, revisando el material de L. Navás existente en el Museu de Ciències Naturals de Barcelona, y tratando de dilucidar la identidad real de esta especie (C. cosmia), hemos llegado a la conclusión de que se trata de una especie válida y de que los numerosos ejemplares que anteriormente habíamos asignado por su morfología externa a Chrysopa nigricostata (ver relación más adelante el material estudiado) pertenecen en realidad a esta especie. No en vano, y como anteriormente hemos mencionado, Monserrat \& Díaz-Aranda (2012), ya citaban que, sorprendentemente, las larvas cultivadas de alguno de estos ejemplares se correspondían con la morfología larvaria de Cunctochrysa sp., y no de Chrysopa sp., y por ello, estos autores ya citaban la existencia de una posible tercera especie ibérica de este género, entonces aún no dilucidada, y ahora sabemos que, mayoritariamente, los ejemplares ibéricos anteriormente estudiados por nosotros se corresponden con Chrysopa cosmia Navás, 1918=Cunctochrysa cosmia (Navás, 1918) n. comb., aunque hubieran sido citados como Chrysopa nigricostata.

Pues bien, no solo hemos comprobado que el ejemplar tipo de Chrysopa cosmia Navás, 1918, depositado en el citado museo (Fig. 22-23), no debe ser considerado como sinónimo posterior de Chrysopa nigricostata (Fig. 1-15), sino que pertenece a una especie distinta y válida del género Cunctochrysa (Fig. 16-21), y que prácticamente todos los ejemplares ibéricos que hasta ahora habíamos citado como pertenecientes a Chrysopa nigricostata: Monserrat, 1977a: 20, 107, 108, 1978b: 178, 1980: 186, 1984a: 37, 1984b: 156, 1996: 14, 2008: 181, 2013: 291; Díaz Aranda et al., 1986: 1139; Díaz Aranda \& Monserrat, 1988a: 223, 1988b: 220; Monserrat \& Díaz-Aranda, 1989a: 256 part.; Monserrat \& Rodrigo, 1992: 127; Canard et al., 1992: 96; Monserrat \& Marín, 1994: 122; Marín \& Monserrat, 1995: 116; Monserrat \& Triviño, 2013: 75, part.), deben asignarse a la especie que ahora tratamos, referencias que ahora se anotan y cuyo material, entonces incorrectamente identificado, ahora se corrige y se anota en el material estudiado, y sugerimos que la cita dada por (Hölzel \& Ohm, 1972) en Portugal (ya citada en este país como C. nigricostata por Monserrat, 2008), por su ubicación y la altitud de la localidad $(850 \mathrm{~m})$, también debe pertenecer a la especie que tratamos. Por otra parte, los datos de morfología del ejemplar tipo de C. cosmia (Fig. 22-23) y del abundante material ahora asignado a esta especie (Fig. 16-21) son coincidentes con los correspondientes a Cunctochrysa bellifontensis Leraut, 1988, proponiendo pues estos nuevos datos:

\section{Cunctochrysa cosmia (Navás, 1918) especie revali-} dada, n. comb.

Chrysopa cosmia Navás, 1918: 19

= Chrysopa nigricostata Brauer, 1850: autores part.

= Cunctochrysa bellifontensis Leraut, 1988: 230 n. sin.

Con el fin de individualizar adecuadamente la morfología de esta revalidada especie, y de aportar datos diferenciales en relación a las otras dos especies europeas de este género anteriormente citadas (C. albolineata y $C$. baetica), procedemos a su redescripción, recopilando después otros elementos complementarios distintivos en base a la diferente biología de estas tres especies (distribución, hábitats y plantas preferentes). Tras ello aportamos una clave de identificación para las tres especies europeas/ibéricas del género y el correspondiente mapa de la distribución real en la Península Ibérica de Cunctochrysa cosmia (Fig. 30), corrigiendo y actualizando lo recientemente anotado para ellas por Monserrat \& Triviño (2013). También aportaremos otros elementos que nos permitan diferenciar mejor estas tres especies de otras especies con similar morfología externa (Chrysopa viridana y en especial Chrysopa nigricostata).

Morfología eXterna: Cabeza verde pálido con dos manchas oscuras en el clípeo y en las genas, más oscura la segunda (Fig. 18), vértex verde (Fig. 17). Antenas con escapo verde pálido, pedicelo verde, algo pardo en su cara externa (Fig. 17), flagelo pardo pálido, progresivamente más oscuro hacia el final. 
Palpos labiales y maxilares pardo pálidos, estos más oscuros en la cara externa (Fig. 18).

Tórax con una banda amarilla sobre la línea media, zonas laterales verde parduzcas y entre ambas una zona verde pálida (Figs. 17, 19, 20). Pronoto con setas negras en la mitad externa, meso- y metanoto apenas con setas (Figs. 19, 20). Patas verdes pálidas, porción distal de la tibia pardo, y tarsos pardos pálido, último tarsómero algo más oscuro. Uñas pardas dilatadas y acodadas en la base. Alas iridiscentes (Fig. 16), las anteriores con vena costal verde en todo su recorrido. Venas longitudinales verdes. Órgano timpánico poco desarrollado, y de color verde. Sector del radio pardo en su región basal, mediana posterior parda en su base, pseudocubital verde, cubital anterior y cubital posterior parduzcas. Venas trasversales del campo costal todas pardo oscuras, venas gradadas internas y externas pardas, venas entre unas y otras verdes, venilla trasversal basal del campo subcostal pardo oscura y las del campo subestigmático verdes. Venas trasversales entre el radio y su sector pardas, venas trasversales entre el sector del radio y pseudomediana pardas las basales y verdes las que conectan con las gradiformes, venas trasversales entre el sector del radio y las gradadas pardas las tres basales, verdes y pardas en los extremos las más distales, y verdes las que conectan con las gradiformes, venas entre gradadas externas y/o horquillas marginales verdes, horquillas marginales verdosas, venas trasversales entre mediana posterior y pseudocubital pardas, trasversales entre pseudomediana y pseudocubital pardas. Trasversales entre pseudocubital y margen posterior pardas. Trasversales del campo cubital, medial y anal pardas. Anales 1 y 2 verdes en su base, y anal 3 verde (Fig. 16).

Alas posteriores (Fig. 16) con vena costal verde en todo su recorrido. Venas longitudinales verdes, venas trasversales del campo costal pardas, pálidas las pterostigmáticas. Venas gradadas internas y externas pardas, venas entre unas y otras verdes. Sector del radio pardo en su origen. Venas trasversales entre el radio y su sector pardas. Trasversales entre sector del radio y pseudomediana pardas las más basales y verdes las asociadas a las gradiformes, venas trasversales entre mediana posterior 2 y costal verdes, venas entre gradadas externas y/o horquillas marginales verdes, y horquillas marginales verdes. Cubital anterior y posterior verdes. Trasversales entre pseudomediana y pseudocubital pardas, trasversales entre mediana posterior 2 y cubital anterior pardas, trasversales entre campo medial y anal pardas. Anales 1 y 2 pardas (Fig. 16).

Abdomen con tergos portando una banda dorsal amarilla levemente marginada de verde a ambos lados, con setas pálidas (Fig. 21). Región pleural parda verdosa a oscuro-negruzca formando dos bandas llamativas a lo largo del abdomen. Esternitos verde amarillentos, los basales con una banda parda en el tercio caudal y setas pardas pálidas (Fig. 21). La genitalia masculina de los ejemplares estudiados coincide con la anotada por Leraut (1988).

Salvo algunos elementos de pigmentación decolorados por el paso del tiempo, la morfología descrita es coincidente con la que ofrece el ejemplar tipo (Figs. 22, 23).

Discusión: Como hemos indicado, las diferencias en la genitalia masculina en las especies de este género no nos parecen significativas (Hölzel, 1972a; Aspöck et al., 1980; Leraut, 1988), por lo que otros caracteres de morfología externa y de biología son más interesantes para diferenciarlas. Tampoco se consideran los caracteres morfológicos de las uñas y la setación de la vena costal que anotan Leraut $(1988,2003)$ y Plant (1993), elementos que nos parecen algo magnificados, y preferimos recurrir a otros caracteres más accesibles que utilizamos en la siguiente clave:

\section{Clave de las especies europeas/ibéricas del género Cunctochrysa:}

1. Alas anteriores con todas las venas trasversales del campo costal completamente oscuras (Fig.16). Pedicelo levemente oscuro en su región externa (Fig.17). Pronoto con una banda media blanco-amarillenta marginada a cada lado de verde primero y verdosa negruzco intenso más externamente (Fig. 19). Abdomen con región pleural pardo verdoso oscuro, formando dos bandas llamativas negruzcas a lo largo del abdomen (Fig. 21)................... cosmia

- Alas anteriores con la primera vena trasversal del campo costal pálida o, si es oscura, sólo son completamente oscuras las restantes en sus extremos distales en su contacto con vena costal y subcostal. Pedicelo verde, no más oscuro en su región externa. Pronoto con pequeñas manchas circulares oscuras, pero sin que la banda media blanco-verdosa esté marginada a cada lado de verde negruzco intenso. Abdomen con región pleural pardo verdosa, sin formar dos bandas llamativas negruzcas a lo largo del abdomen.....

2. Alas anteriores con la primera vena trasversal del campo costal pálida y las restantes oscuras en toda su extensión o solo en sus extremos. Pronoto con dos manchas circulares oscuras sobre el tercio posterior mucho mayores y más intensas que las dos situadas sobre el margen anterior. Banda media dorsal marcadamente blanquecina................................................. albolineata Alas anteriores con la primera vena trasversal del campo costal oscura y las restantes oscuras solo en sus extremos. Pronoto con dos manchas circulares oscuras sobre el tercio posterior similares en tamaño e intensidad a las dos situadas sobre el margen anterior. Banda media dorsal amarillenta blanquecina...

C. baetica

Biología: Como datos complementarios a la identificación de estas tres especies pueden resultar muy útiles algunos elementos de su respectiva biología, sean las preferencias de sustrato vegetal o el entorno ambiental y altitudinal en el que estas tres especies se segregan. 
La biología de Cunctochrysa albolineata es bien conocida, y es una especie asociada a zonas boscosas $\mathrm{y}$ planifolios en medios mayoritariamente húmedos y eurosiberianos, mientras que $C$. baetica, de la que se tienen muchos menos datos, está asociada a zonas boscosas abiertas y a planifolios en medios mayoritariamente secos y mediterráneos (Killington, 1937; Aspöck et al., 1980, 2001; Canard et al., 1984; Pantaleoni, 1990; Monserrat \& Marín, 1994, 2001; McEwen et al., 2001). Respecto a la tercera especie (C. cosmia), hasta ahora de biología casi desconocida (un ejemplar recolectado sobre pino a $840 \mathrm{~m}$ ), y a partir de los nuevos datos ahora anotados se desprende y corrobora que es una especie de tendencia marcadamente orófila y está intensamente asociada a coníferas, particularmente a pinos (significativamente sobre Pinus sylvestris y en menor medida sobre $P$. pinaster y $P$. nigra), preferencia que se refleja desde la descripción original (Navás, 1918) al abundante material ibérico ahora citado.

En la Península Ibérica Cunctochrysa albolineata ha sido recolectada entre los 170-1650 m, con una fenología que comprende los meses de junio a septiembre, también en esta zona marcadamente asociada a los medios eurosiberianos citados, y lógicamente con una distribución mayoritaria en su mitad septentrional. Cunctochrysa baetica ha sido recolectada entre los 10-1350 m, con una fenología que comprende los meses de abril a septiembre, claramente asociada a medios mediterráneos, y por ello con una distribución mayoritaria en su mitad meridional. Por último, $\mathrm{y}$ en función de los datos ahora rectificados y anotados, Cunctochrysa cosmia ha sido recolectada entre los 670-2100 m, con una fenología que comprende los meses de abril y septiembre (con máximos en julioagosto), incuestionablemente asociada a coníferas: salvo el material recolectado a la luz, prácticamente todo el material ahora citado se ha recolectado sobre Pinus sylvestris, tanto larvas como imagos, algunos sobre $P$. nigra y $P$. pinaster, y apenas una docena de ejemplares en bosques de quercíneas: Quercus pyrenaica, $Q$. robur y Q. rotundifolia (mayoritariamente próximos a pinares repoblados), y con una distribución hasta ahora conocida en su mitad septentrional (Fig. 30).

De esta última especie, y en función de los nuevos datos ahora aportados, indiquemos que también sus fases larvarias han sido halladas sobre pinos, y que poseen el tórax blanquecino, y entre los ejemplares recolectados y tras practicar el capullo de pupación a finales de verano (septiembre-octubre), podemos asegurar su capacidad de sortear los fríos meses de invierno dentro de él en fase de larva-prepupa, y pasar a fase de pupa en la siguiente primavera, en la que emergen los imagos (abril-mayo-junio) (este hecho ya fue detectado por Principi, 1977 para Cunctochrysa albolineata). A partir de los nuevos datos es de suponer la existencia de dos generaciones (primavera y verano) en su fenología. Lógicamente, sobre su especie sinónima ahora propuesta (C. bellifontensis) también se ha citado como de tendencia orófila y fuertemente asociada a coníferas, particularmente a Pinus (Eglin, 1941; Séméria, 1978; Leraut, 1988, 2003; Plant, 1993). También en relación a la biología de esta especie, debemos anotar que los imagos desprenden un fuerte olor desagradable, semejante al de las especies del género Chrysopa (este hecho ya fue detectado por Principi, 1977 para Cunctochrysa albolineata).

Como anteriormente hemos indicado, y al margen de las diferencias anotadas entre las tres especies citadas del género Cunctochrysa, existen dos especies europeas del género Chrysopa: Chrysopa viridana y en especial Chrysopa nigricostata (ya hemos anotado ciertas diferencias que ayudan a la identificación de estas dos especies), que poseen una morfología externa relativamente similar a alguna de las especies tratadas y, de hecho, ya hemos anotado algunos errores de identificación dentro del material ahora estudiado. Para facilitar la diferenciación, y simplemente basándonos en las características de morfología externa, comentemos sobre ellas que su pigmentación general verde manzana-azulado, cabeza más pálida con manchas rojizas en su margen externo, y el color y marcada textura de la venación de Chrysopa viridana la hace fácilmente distinguible de Chrysopa nigricostata y de Cunctochrysa cosmia, y es entre estas dos especies donde vamos a encontrar una mayor dificultad, ya que son muy similares. Aportamos algunas características distintivas que comparativamente pueden observarse en las láminas correspondientes a las figuras 10-15 y 16-21 (repárese especialmente en la coloración de la venación de las alas y en la setación del pronoto), y que se resumen en las Tablas 1 y 2 :

Junto a estas características anotamos algunos otros datos comparativos que ayuden a diferenciarlas, especialmente en aquellos ejemplares decolorados o conservados en alcohol (Tabla 2).

Sobre la envergadura alar de ambas especies, las medidas son poco significativas. Longitud del ala anterior de $C$. nigricostata: 10,30-15,60 mm, $\bar{X}$ : 12,305 mm (n=10). C. cosmia: $10,70-13,50 \mathrm{~mm}, \bar{X}$ : 12,03 $\mathrm{mm}(\mathrm{n}=11)$ (Tipo de C. cosmia: ala anterior 12 $\mathrm{mm}$, ala posterior $11 \mathrm{~mm}$ ).

También podemos añadir que, habitualmente, en las alas anteriores de Cunctochrysa cosmia, la última venilla trasversal más basal de la serie gradada interna contacta directamente con la vena pseudomediana, hecho constatado en el ejemplar tipo y el abundante material ahora estudiado (Figs. 16, 22), mientras que en Chrysopa nigricostata, con mucha frecuencia es la ultima vena entre el Sr y la pseudomediana la que directamente contacta con ella (Fig. 10), hecho ya ilustrado en la descripción original de esta especie (Brauer, 1850).

Como complemento a su identificación, y sobre su biología en la Península Ibérica, solo recordar que Chrysopa nigricostata está fuertemente asociada a medios esteparios y xéricos, de baja y media cota y 
a chopos, mientras que Cunctochrysa cosmia es una especie marcadamente montana y está fuertemente asociada a pinos, y prácticamente todo el material ibérico ahora citado de esta especie se ha recolectado sobre $P$. sylvestris, tanto larvas como imagos.

En lo que respecta a la fauna ibero-balear, ya hemos anotado anteriormente la generalizada confusión en la identificación de ejemplares que con anterioridad habíamos mayoritariamente referido como pertenecientes a Chrysopa nigricostata, y que ahora rectificamos y recogemos entre el material estudiado de Cunctochrysa cosmia. Su distribución actualizada en la Península Ibérica se anota en la figura 30. Puede observarse su marcada tendencia orófila, que genera su disyunta distribución (Pirineos, Sierra de la Culebra, Sistema Central, Montes de Toledo, Serranía de Cuenca, Sierra de Cazorla y Sierra Nevada en España y Serra da Estrêla en Portugal).

También a nivel general, y como hemos anotado anteriormente al hablar de la posible generalizada confusión entre Chrysopa nigricostata y Cunctochrysa cosmia, incidimos en que es muy probable que ambas especies se ncuentren mezcladas en su identificación en la multitud de citas europeas existentes para la primera de ellas. De forma general reiteremos que, muy probablemente, las citas dadas en zonas esteparias de mediana o baja cota, y especialmente las dadas sobre Populus spp., pertenezcan realmente a Chrysopa nigricostata, mientras que las citas dadas en zonas elevadas y especialmente las dadas sobre Pinus spp. y otras coníferas, pertenezcan, en realidad, a Cunctochrysa cosmia.

Material estudiado: ESPAÑA: Cuenca, Valdemeca, 13.VII.2009, 1 ㅇ a la luz, P. Almagro. Granada, Collado de la Sabina, 10.VII.2013, 1 + sobre Pinus sylvestris, Fuente de la Cortichuela, 3.VII.1986, 1 ते sobre P. sylvestris, Monachil, 3.VII.1986, 1 o sobre P. nigra, Pto. del Trevenque, 3.VII.1986, 1 P sobre P. sylvestris. Huesca, / Hecho (H.) 9.VIII.17 (1917) / Chrysopa cosmia Nav. Navás S. J. det. / Typus / 78-1888 MZB / Chrysopa nigricostata Brauer det. H. Hölzel 1972 / 1 \& (MCNB), San Juan de Plan, 17.VIII.1982, 1 ô sobre Quercus rotundifolia. Jaén, Cazorla, Camino Agracea, 2.VIII.1991, 1 a la luz, J. L. Yela. Lérida, Rubió, 15.VII.2009, 1 ㅇ sobre P. sylvestris. Madrid, Abantos, Fuente del Cervunal, 24.VII.2007, 1 त, $2 \hat{\delta} \sigma^{\lambda}$ (RP), 3 우우, 1 우 (RP) sobre P. sylvestris, 30.VII.2007, 1 त sobre P. sylvestris, Alpedrete, 15.VII.1975, 1 , 12.VIII.1975, 1 ○, 31.VIII.1975, 1 ㅇ, 5.IX.1975, 1 ㅇ, 15.IX.1975, 2 우, 30.VII.1976, 1 운, 17.VIII.1976, 1 ㅇ , 19.VIII.1976, 1 § (RP), 2 우, 27.VIII.1979, 5 오, 3.IX.1980, 1 으 (RP), todos a la luz, Barranca de Navacerrada, 18.V.1976, $1 \hat{\sigma}$ ex larva recolectada sobre $P$. sylvestris, pupó el 18.IX.1975, 13.V.1976, 1 + ex larva recolectada sobre $P$. sylvestris el 4.X.1975, pupó el 7.X.1975, Cercedilla, El Regidor, 6.VIII.1975, 1 ㅇ sobre P. sylvestris, 21.IV.1976, 1 q ex larva recolectada sobre P. sylvestris el 20 IX.1975, 1.V.1976. 1 ô ex larva recolectada sobre P. sylvestris el 20.IX.1975, Cercedilla, Las Dehesas, 18.VIII.1975, 1 o sobre P. sylvestris, El Escorial, Abantos, 4.VII.2012, 1 \& sobre

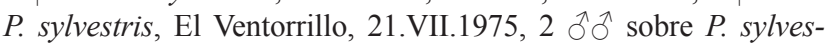
tris, 4.VIII.1975, 2 우우 sobre P. sylvestris, 4-11.VIII.1989, 1 우 en trampa de Malaise, Nieves \& Rey, La Jarosa, 7.VI.1976, 1 ๙ sobre P. pinaster, La Pedriza, 16.VI.1976, 1 ô sobre P. pinaster,
R. Outerelo, Navacerrada, 10.IX.1975, 2 우 sobre P. sylvestris, 19.IX.1975, 2 우, Navalpinganillo, 20.VIII.1975, 1 , , Pradera del Navalhorno, 4.VIII.1975, 1 , 2 우 $ᄋ$, Puerto de Cotos, 16.VIII.1975, 1 ㅇ sobre P. sylvestris, Puerto de la Fuenfría, 12.VII.1975, 1 $\sigma^{\lambda}$ sobre P. sylvestris, V.1976, 1 त ex larva recolectada sobre $P$. sylvestris el 27.VIII.1975, pupó el 1.IX.1975, 12.VII.1976, 1 đิ sobre P. sylvestris, Puerto de los Leones, 16.VII.1975, 1 §, 1 우 sobre P. sylvestris, Puerto de la Morcuera, 27.VI.1975, 1 o, Puerto de Navacerrada, 17.VII.1975, 1 ก sobre P. sylvestris, Rascafría, El Paular, Los Hoyones, 6.VI.1976, 1 đ ex larva recolectada el 19.IX.1975, Tablada, 16.VII.1975, 1 đ sobre P. sylvestris. Orense, Caxide, 30.VI.1977, 1 \& sobre Q. robur. Segovia, La Granja, 4.VIII.1975, 1 \&, San Rafael, 23.IV.1976, 1 ठ ex larva recolectada sobre P. sylvestris el 2.X.1975, pupó el 23.X.1975, Sierra Calva, 26.VIII.1975, 1 f. Toledo, Navamorcuende, 19.IX.1975, 1 ㅇ sobre P. sylvestris, 22.VII.1978, 1 Oૈ, 3 우, sobre P. sylvestris. Zamora, San Pedro de las Herrerías, 27.VIII.1977, 1 q sobre P. sylvestris. Como material complementario hemos estudiado: RUMANÍA: Alba, Sohodolu, 46 $16^{\prime} 38.85^{\prime \prime N} 2^{\circ} 00^{\prime} 35.08^{\prime}$ E, $840 \mathrm{~m}$, 24.VII.1976, $1 \hat{\jmath}$, B. Kis (identificada como Chrysopa albolineata Killington, 1935, det. Dr. Béla Kis). No se ha podido reestudiar de nuevo el ejemplar citado como Chrysopa nigricostata en Portugal, Santarém, Tomar por Monserrat (2008), y no podemos por ahora aseverar si la determinación era correcta (cosa que es probable por la escasa altutud de la localidad, o si, con el nuevo criterio que hemos expuesto, pertenezca a la especie que tratamos.

\section{Cunctochrysa albolineata (Killington, 1935)}

Especie paleártica. Aparentemente eurioica y con marcada preferencia a planifolios en zonas húmedas. En la península se circunscribe a su región eurosiberiana y zonas montanas de centro. Está citada entre VI y IX, en altitudes que oscilan entre 170 y $1650 \mathrm{~m}$.

Material estudiado: ESPAÑA: Asturias, La Viliella, Muniellos, 6.VII.2002, 1 ô sobre Corylus avellana, R. Ocharán. León, León, Azucarera, 13.IX.2007, 1 ㅇ, M. C. Delgado (UL). Madrid, Cerdedilla, Estación Alpina, VII.1931, 1 †, J. Hernández (MNCN). Como material complementario hemos estudiado: AUSTRIA: Niederösterreich, Wachau, Dürnstein, 48.24N/15.32E, $200 \mathrm{~m}, 25-27 . V I .1976,3$ ㅊํㅇ, 3 우우 a la luz, H.Aspöck et al. (identificados como C. nigricostata Brauer, 1850, det. H.Rausch).

\section{Cunctochrysa baetica (Hölzel, 1972)}

Especie holomediterránea. En la península sustituye mayoritariamente a la especie anterior y está asociada a medios más térmicos de carácter mediterráneo. Está citada entre IV y IX, en altitudes que oscilan entre 10 y $1350 \mathrm{~m}$.

Material estudiado: ESPAÑA: Almería, Turrillas, 13.VI.2012, 1 q sobre Ulex sp. Cádiz, Pedro Valiente, Playa de los Lances, 21.VI.2012, 1 ô sobre Pistacea lentiscus. Granada, Cáñar, 27.VI.2011, 1 ㅇ sobre Quercus rotundifolia, Dúdar, VIIVIII.2005, 1 \&,A. Tinaut, La Herradura, Cerro Gordo, 2.VIII.2011, 1 a la luz. Madrid, Chinchón, El Salitral, 20.VI.2009, $1 \delta$ a la luz, San Fernando de Henares, 4.IX.2010, 1 q, 22.IX.2010, 1 ${ }^{\wedge}$, 9.IX.2011, 1 q, 11.IX.2011, 1 ठ̊ , J. I. López Colón.

\section{Rexa lordina Navás, 1919}

Especie mediterránea occidental. Conocida de España oriental y meridional, Portugal, Francia meridional, Córcega, Italia (Lazio, Cerdeña), Croacia, Marruecos y Argelia. Muy localizada, habitualmente 
poco frecuente, aunque a veces puntualmente abundante, y muy escasamente citada (Cáceres, Gerona, Granada, Huesca, Jaén, Málaga y Murcia en España, y en los distritos de Vila Real y Faro en Portugal). Asociada a medios térmicos mediterráneos (mayoritariamente sobre Oleaceae) y de fenología marcadamente primaveral (abril-junio). Está citada entre IV y VI, en altitudes que oscilan entre 50 y $1870 \mathrm{~m}$.

Material estudiado: ESPAÑA: Málaga, Las Asomadillas, 25.V.2012, 1 ठิ sobre Olea europea.

Suarius walsinghami walsinghami Navás, 1914

Especie eremial, conocida del tercio norte africano (Marruecos, Argelia, Túnez, Egipto, Mauritania y Sudán) y de Israel, Arabia Saudí, Yemen y Sinaí. En Europa está limitada al S. E. de la Península Ibérica (Almería, Granada y Málaga). Siempre asociada a medios térmicos y xéricos. Está citada entre VI y IX, en altitudes que oscilan entre 30 y $1750 \mathrm{~m}$.

Material estudiado: ESPAÑA: Almería, Tabernas, Rambla Roja, 19.VII.2011, $9 \hat{\delta} \widehat{\delta}, 18$ 우 a la luz, 13.VI.2012, $8 \hat{\delta}, 5$

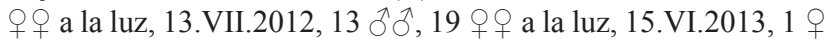

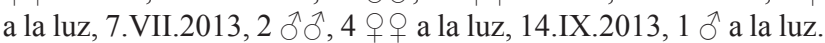
Granada, Pinos Puente, Moclín, 27.VII.2010, 1 §ึ, 10.VIII.2010, $1 \AA$, 7.IX.2010, 1 \% , capturados con trampas McPhail utilizando como atrayente fosfato amónico $5 \%+$ Bórax $1 \%$ sobre Olea europea, M. Porcel.

\section{Suarius tigridis (Morton, 1921)}

Especie eremial, conocida del norte africano (Marruecos, Argelia, Túnez, Egipto), Israel, Irak, Kuwait y Bahrein. En Europa está limitada al S. E. árido de la Península Ibérica (Almería). Siempre asociada a medios térmicos y xéricos. Está citada entre VI y IX, en altitudes que oscilan entre 10 y $360 \mathrm{~m}$.

Material estudiado: ESPANA: Almería, Tabernas, Rambla Roja, 19.VII.2011, 1 ઈิ a la luz, 13.VI.2012, 2 우우 a la luz, 13.VII.2012, $6 \widehat{\jmath}, 16$ 우 a la luz, 15.VI.2013, 1 ㅇ a la luz, 7.VII.2013, $4 \hat{\delta} \hat{\jmath}, 1$ a la luz, 14.IX.2013, 1 q a la luz.

Suarius iberiensis Hölzel, 1974

Especie endémica del S. E. árido y zonas subdesérticas del centro de la Península Ibérica (Almería, Madrid, Murcia, Navarra y Toledo). Asociada a Salsola spp. (Chenopodiaceae) y Ammi majus (Umbelliferae) en medios térmicos, xéricos, gipsícolas y/o halófilos. Está citada entre V y IX, en altitudes que oscilan entre 240 y $670 \mathrm{~m}$.

Material estudiado: ESPAÑA: Almería, Tabernas, Rambla Roja, 13.VI.2012, 2 우 a la luz, 13.VII.2012, 2 §ోô, 10 우우 a la

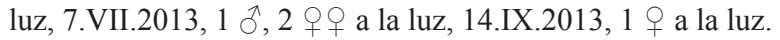

\section{Agradecimientos}

Esta contribución forma parte del Proyecto coordinado de I+D+i Fauna Ibérica (Neuroptera) CGL2010-22267-C07-05. Deseamos agradecer a los museos e instituciones citadas el habernos permitido estudiar ejemplares de sus colecciones, y a los autores y compañeros citados en el material estudiado por el envío de ejemplares de sus colecciones particulares o de sus centros de investigación. También deseamos manifestar nuestro sincero agradecimiento a las autoridades de las diferentes Comunidades Autónomas por facilitarnos los correspondientes permisos de muestreos para la toma de datos en los espacios protegidos visitados, a Víctor Triviño y Miguel Ángel Dionisio por su ayuda en los últimos muestreos realizados, a Arp Kruithof por su valiosa información, y a Eduardo Ruiz por su ayuda en la realización y tratamiento de las imágenes. También agradecemos a David Papenberg por su ayuda en la traducción de algunos textos.

\section{Referencias}

Adams, P. A., 1975. Status of the genera Ungla and Mallada Navás (Neuroptera: Chrysopidae). Psyche, 82: 167-173. http://dx.doi.org/10.1155/1975/62979.

Aizpuru Oyarbide, I. \& Catalán Rodríguez, P., 2000. Aportación al conocimiento de la flora y vegetación de los yesos de Navarra. Actas Congreso de Botánica. Instituto de Estudios Turolenses, Excma. Diputación Provincial de Teruel: 653-663.

Aspöck, H., Aspöck, U. \& Hölzel, H., 1980. Die Neuropteren Europas. 2 vols. Goecke and Evers. Krefeld. T. I: 495 pp., T. II: 355 pp.

Aspöck, H., Hölzel, H. \& Aspöck, U., 2001. Kommentierter Katalog der Neuropterida (Insecta: Raphidioptera, Megaloptera, Neuroptera) der Westpaläarktis. Denisia, 2: 1-606.

Báez, M. \& Oromí, P., 2010. Lista de especies silvestres de Canarias (hongos, plantas y animales terrestres). In: M. Arechavaleta Hernández, et al. (Coords.). Gobierno de Canarias. La Laguna. 579 pp. (Planipennia, pp. 253-254).

Bakker, H. A., 1943. Over Nederlandsche Neuropteroidea en Mecoptera. Tijdschrift voor Entomologie, 86: xxxiv-xxxviii.

Brauer, F., 1850. Beschreibung und Beobachtung der österreichischen Arten der Gattung Chrysopa. Naturwissenschaftliche Abhandlungen, 4 (4): 1-12, 2 láminas.

Brauer, F., 1856. Rückblick auf die im Jahre 1850 beschriebenen österreischischen Arten der Gattung Chrysopa Leach nebst Beschreibung der Ch. tricolor n. sp. Verhandlungen der Zoologisch-Botanischen Gesellschaft in Wien, 6: 703-708.

Brauer, F., 1857. Chrysopa tricolor, vergleichen mit der Beschreibung von Chrysopa gracilis Heyden und stenoptila Schn. Verhandlungen der ZoologischBotanischen Gesellschaft in Wien, 7: 201.

Brauer, F., 1876. Die Neuropteren Europas und insbesondere österreichs mit Rücksicht auf ihre geographische Verbreitung. Festschrift zum 25 Jährigen Bestehen der kaiserlich-königlichen zoologisch-botanischen Gesellschaft in Wien: 263-300.

Brooks, S. J., 1994. A taxonomic review of the common green lacewing genus Chrysoperla (Neuroptera: Chrysopidae). Bulletin of the British Museum of Natural History, Entomology, 63(2): 137-210.

Brooks, S. J. \& Barnard, P. C., 1990. The green lacewings of the world: a generic review (Neuroptera: Chrysopidae). Bulletin of the British Museum of Natural History, Entomology, 59: 117-286.

Bullini, L. \& Cianchi, R., 1984. Electrophoretic studies of gene-enzyme systems in chrysopid lacewings. In: M. Canard, Y, Séméria \& T. R. New (eds.). Biology of Chrysopidae. W. Junk. The Hague: 48-56. 
Bullini, L., Principi, M. M. \& Cianchi, R., 1984. Eletrophoretic studies in the genus Chrysopa (s.1.), Evolutionary and Phylogenetic Inferences. In: J. Gepp, H. Aspöck \& H. Hölzel (eds.). Progress in World's Neuropterology. Proceedings of the 1st International Symposium on Neuropterology, Graz: 57-59.

Bullini, L., Principi, M.M., Cianchi, R. \& Pantaleoni, R., 1983. Nuovi dati sulla tassonomia biochimica delle crisope italiane (Neuroptera, Chrysopidae). Atti XIII Congresso Nazionale Italiano di Entomologia: 479-483.

Cadena, P., Ángel, L., Gómez, A. \& González, R., 2007. Diferenciación morfológica y molecular de especies de crisópidos (Neuroptera: Chrysopidae). Revista Colombiana de Entomología, 33: 171-177.

Canard, M., 2001. Natural food and feeding habits of lacewings. In: P. McEwen, T. R. New \& A. E. Whittington, Lacewings in the Crop Environment. Cambridge University Press. Cambridge: 116-129.

Canard, M., Danflous, S., Giacomino, M., Thierry, D. \& Villenave-Chasset, J., 2014. Trosième complement à la cartographie des Chrysopides de France (Neuroptera, Chrysopidae). Revue de l'Association Roussillonnaise d'Entomologie, 23(1): 2-11.

Canard, M., Grimal, A. \& Monserrat, V.J., 1992. A list of green and brown lacewings recently collected in the central Pyrennes (Insecta: Neuroptera: Chrysopidae, Hemerobiidae). Current Research in Neuropterology. Proceedings of the Fourth International Symposium on Neuropterology, Bagnères-de-Luchon: 95-97.

Canard, M., Kokubu, H. \& Duelli, P., 1990. Tracheal Trunks supplying air to the foregut and feeding habits in adults of European lacewing species. In: M. W. Mansell \& H. Aspöck (eds.). Advances in Neuropterology. Proceedings of the Third International Symposium on Neuropterology. South African Department of Agricultural Development. Pretoria: 277-286.

Canard, M., Séméria, Y. \& New, T. R. (Eds.), 1984. Biology of Chrysopidae. W. Junk. The Hague. 294 pp.

Canard, M. \& Thierry, D., 2007. A historical perspective on nomenclature within the genus Chrysoperla Steinman, 1964 in Europe: the carnea-complex (Neuroptera Chrysopidae). Annali del Museo Civico di Storia Naturale di Ferrara, [2005], 8: 173-179.

Canard, M. \& Thierry, D., 2013. Identification des Chrysoperla de France (Neuroptera: Chrysopidae). Revue de l'Association Roussillonnaise d'Entomologie, 22(2): 75-84.

Canard, M., Thierry, D., Whittington, A.E. \& Bozsik, A., 2010. The actual annual occurrence of the green lacewings of northwestern Europe (Neuroptera: Chrysopidae). Proceedings of the Tenth International Symposium on Neuropterology, Piran: 127-134.

Cianchi, R. \& Bullini, L., 1992. New data on sibling species in chrysopid lacewings: the Chrysoperla carnea (Stephens) and Mallada prasinus (Burmeister) complexes (Insecta: Neuroptera: Chrysopidae). In: M. Canard, H. Aspöck, and M. W. Mansell (eds.). Current Research in Neuropterology. Proceedings of the Fourth International Symposium on Neuropterology, Toulouse: 99-104.

Creus Novau, J., 1998. El clima de Los Monegros. In: C. Pedrocchi Renault (coordinador). Ecología de Los
Monegros. Instituto de Estudios Altoaragoneses y Centro de Desarrollo de Monegros. Huesca: 54-66.

Czechowska, W., 1986. Structure of neuropteran (Neuropteroidea) communities in urban green areas of Warsaw. Memorabilia Zoologica, 41: 187-214.

Delgado, I., Ochoa, M.J., Albiol, A., Luna, L. \& Muñoz, F., 1995. Descripción y evaluación de la fitomasa presente en áreas no cultivadas de la comarca de Monegros (Aragón). Pastos, 25(1): 87-97.

Desir, G. \& Marín, C., 2007. Factor controlling the erosion rates in a semi-arid zone (Bardenas Reales, NE Spain). Catena, 71(1): 31-40. http://dx.doi.org/10.1016/j. catena.2006.10.004.

Díaz Aranda, L. M. \& Monserrat, V. J., 1988a. Contribución al conocimiento de los neurópteros de Teruel (Insecta, Neuropteroidea). Boletín de la Asociación Española de Entomología, 12: 215-231.

Díaz Aranda, L. M. \& Monserrat, V. J., 1988b. Contribución al conocimiento de los Neurópteros de Granada (Insecta, Neuropteroiea). Actas III Congreso Ibérico de Entomología, Lisboa: 211-227.

Díaz Aranda, L. M. \& Monserrat, V. J., 1994. The larval stages of genus Cunctochrysa Hölzel, 1970 in Europe (Neuroptera, Chrysopidae). Deutsche Entomologische Zeitschrift, (N.F.), 41(1): 163-171. http://dx.doi. org/10.1002/mmnd.19940410117.

Díaz Aranda, L. M. \& Monserrat, V. J., 1995. Aphidophagous predator diagnosis: Key to Genera of European Chrysopid Larvae (Neur.: Chrysopidae). Entomophaga, 40(2): 169-181. http://dx.doi.org/10.1007/BF02373066.

Díaz Aranda, L. M., Monserrat, V. J. \& Marín, F., 1986. Contribución al conocimiento de los neurópteros de Guadalajara (Insecta, Neuropteroidea). Actas de las VIII Jornadas de la Asociación Española de Entomología, Sevilla: 1131-1144.

Díaz Aranda, L. M., Monserrat, V. J. \& Marín, F., 1994. Contribución al conocimiento de los neurópteros de Lérida (Insecta, Neuroptera). Zoologica Baetica, 5: 41-64.

Díaz Aranda, L. M., Monserrat, V. J. \& Tauber, C.A., 2001. Recognition of early stages of Chrysopidae. In: P. McEwen, T. R. New \& A. E. Whittington. Lacewings in the Crop Environment. Cambridge University Press. Cambridge: 60-81.

Duelli, P., 1989. Zwei für die Schweiz neue Florfliegenarten aus dem Wallis (Planipennia: Chrysopidae). Mitteilungen der schweizerischen entomologischen Gesellschaft, 62: 345-347.

Duelli, P., Henry, C. S. \& Mochizuki, A., 2014. The endemic Atlantochrysa atlantica (McLachlan) (Neuroptera: Chrysopidae) on Atlantic Islands: African or American origin? Journal of Natural History, published online. http://dx.doi.org/10.1080/00222933.2014.917211.

Duelli, P., Obrist, M. K. \& Flückiger, P. F., 2002. Forest edges are biodiversity hotspots. Acta Zoologica Academiae Scientiarum Hungaricae, 48(Suppl. 2): 75-87.

Eglin, W., 1941. Beitrag zur Kenntnis der Neuropteroidea des Wallis. Bulletin de la Murithienne, 58: 63-95.

Elósegui, J. \& Ursúa, C., 1990. Las Bardenas Reales. Departamento de Ordenación del Territorio, Vivienda y Medio Ambiente, Gobierno de Navarra. Pamplona. 63 pp. 
Evans, W. F., 1848. Monograph of the British Species of the genus Chrysopa. Transactions of the Entomological Society of London, 5(4): 77-79, pl. 9-10. http://dx.doi. org/10.1111/j.1365-2311.1848.tb02974.x.

Fernández, J., 2003. Noticia de nuevos táxones para la ciencia en el ámbito íbero-balear y macaronésico ( $7^{\mathrm{a}}$ parte). Graellsia, 59(1): 101-130. http://dx.doi.org/10.3989/ graellsia.2003.v59.i1.230.

Galvez Cañero, A., 1967. Mapa de las zonas áridas de España. Notas y comunicaciones del Instituto Geológico y Minero, 95: 7-10.

Geiger, F., 1973. El Sudeste español y los problemas de aridez. Revista de Geografía, 7: 166-209.

Geijskes, D. C., 1972. Over de Neuroptera-Fauna van Meijendel. Zoologische Bijdragen, 13: 43-58.

Gepp, J., 1983. Schlüssel zur Freilanddiagnose mitteleuropäischer Chrysopidenlarven (Neuroptera, Chrysopidae). Mitteilungen des Naturwissenschaftlichen Vereins für Steiermark, 113: 101-132, 8 lám.

Gepp, J., 1989. Zur Ökologischen Differenzierung der präemaginalen Stadien baumbewohnender Chrysopiden im Alpenraum (Planipennia: Chrysopidae). Sitzungsberichte der Österreicheschen Akademie der Wissenschaften, Mathematische-Naturwissenschaftliche Klasse, 197(1-4): 1-73.

González-Bernáldez, F., 1989. Ecosistemas áridos y endorreicos españoles. In: Zonas Áridas en España. Real Academia de Ciencias Exactas, Físicas y Naturales. Madrid: 223-238.

Hagen, H. A., 1858. Neuroptera. Synopsis of the British Planipennes. Entomologist's Annual, 1858: 17-33.

Haruyama, N., Mochizuki, A., Duelli, P., Naka, H. \& Nomura, M., 2008. Green lacewing phylogeny, based on three nuclear genes (Chrysopidae, Neuroptera). Systematic Entomology, 33(2): 275-288. http://dx.doi. org/10.1111/j.1365-3113.2008.00418.x.

Henry, C. S., 1985. The proliferation of cryptic species in Chrysoperla green lacewings through song divergence. The Florida Entomologist, 68(1): 18-38. http://dx.doi. org/10.2307/3494328.

Henry, C. S., 1989. The unique purring song of Chrysoperla comanche (Banks), a green lacewing of the rufilabris species group (Neuroptera: Chrysopidae). Proceedings of the Entomological Society of Washington, 91: 133-142.

Henry, C. S., 1991. The status of the P2-song morph, a North American green lacewing of the Chrysoperla carnea species group (Neuroptera, Chrysopidae). Canadian Journal of Zoology, 69(7): 1805-1813. http://dx. doi.org/10.1139/z91-249.

Henry, C. S., 1993. Chrysoperla johnsoni (Neuroptera: Chrysopidae): Acoustic evidence for full species status. Annals of the Entomological Society of America, 86: 14-25.

Henry, C. S., 1994. Singing and cryptic speciation in insects. Trends in Ecology and Evolution, 9(10): 388-392. http:// dx.doi.org/10.1016/0169-5347(94)90061-2.

Henry, C. S., Brooks, S. J., Duelli, P. \& Johnson, J. B., 2002. Discovering the true Chrysoperla carnea (Stephens) (Insecta: Neuroptera: Chrysopidae) using song analysis, morphology, and ecology. Annals of the Entomological Society of America, 95: 172-191.
Henry, C. S., Brooks, S. J., Duelli, P. \& Johnson, J. B., 2003. A lacewing with the wanderlust: the European song species "Maltese", Chrysoperla agilis sp. n. of the carnea group of Chrysoperla (Neuroptera: Chrysopidae). Systematic Entomology, 28(2): 131-148. http:// dx.doi.org/10.1046/j.1365-3113.2003.00208.x.

Henry, C. S., Brooks, S. J., Thierry, D., Duelli, P. \& Johnson, J. B., 2001. The common green lacewing (Chrysoperla carnea s. lat.) and the sibling species problem. In: P. McEwen, T. R. New \& A. E. Whittington, Lacewings in the Crop Environment. Cambridge University Press. Cambridge: 29-42.

Henry, C. S., Brooks, S. J., Thierry, D., Duelli, P., Johnson, J. B., Wells, M. \& Mochizuki, M. 2013. Obligatory duetting behaviour in the Chrysoperla carnea-group of cryptic species (Neuroptera: Chrysopidae): its role in shaping evolutionary history. Biological Reviews, 88: 787-808. http://dx.doi.org/10.1111/brv.12027.

Henry, C. S. \& Wells, M. M., 1990a. Geographical variation in the song of Chrysoperla plorabunda (Neuroptera: Chrysopidae) in North America. Annals of the Entomological Society of America, 83: 317-325.

Henry, C. S. \& Wells, M. M., 1990b. Sexual singing preceding copulation in Chrysoperla plorabunda green lacewings: observations in a semi-natural environment (Neuroptera: Chrysopidae). The Florida Entomologist, 73(2): 331-333. http://dx.doi. org/10.2307/3494818.

Henry, C. S., Wells, M. M. \& Pupedis, R. J., 1993. Hidden taxonomic diversity within Chrysoperla plorabunda (Neuroptera: Chrysopidae): Two new species based on courtship songs. Annals of the Entomological Society of America, 86: 1-13.

Heyden, L.V., 1896. Die Neuropteren-Fauna der weiteren Umgebung von Frankfurt am Main. Bericht der Senckenbergischen Naturforschenden Gesellschaft in Frankfurt am Main, 1896: 105-123.

Hölzel, H., 1964. Die Netzflügler Kärntens. Carinthia, 2: 97-156.

Hölzel, H., 1965. Bemerkungen zu Chrysopiden II. Chrysopa nigricostata $\mathrm{Br}$. (Neuroptera, Planipennia). Nachrichtenblatt der Bayerischen Entomologen, 14(7/8): 74-76.

Hölzel, H., 1972a. Eine neue Chrysopiden-Art aus Südeuropa - Anisochrysa (Cunctochrysa) baetica n. sp. (Planipennia, Chrysopidae). Entomologische Zeitschrift, 82: 217-221.

Hölzel, H., 1972b. Anisochrysa (Chrysoperla) mediterranea n. sp. eine neue europäische Chrysopiden-Spezies (Planipennia, Chrysopidae). Nachrichtenblatt der Bayerischen Entomologen, 21: 81-83.

Hölzel, H., 1973. Zur Revision von Typen europäischer Chrysopa-Arten. Revue suisse Zoologie, 80(1): 65-82.

Hölzel, H., 1974. Zwei neue Chrysopiden-Arten aus Südwesteuropa (Planipennia, Chrysopidae). Entomologische Zeitschrift, 84: 257-260.

Hölzel, H., 1998. Kommentare zu den von Friedrich Brauer in den Jahren 1850 und 1856 aus Österreich bescriebenen Chrysopa Species (Neuroptera: Chrysopidae). Stapfia, 55: 409-420. 
Hölzel, H. \& Ohm, P., 1972. Die Chrysopiden der Iberischen Halbinsel (Planipennia, Chrysopidae). Faunistisch-Ökologische Mitteilungen, 4: 127-145.

Iriarte, M. J., 1992. El entorno vegetal en las Bardenas Reales (Navarra) durante la prehistoria reciente. Cuadernos de Sección Historia, 20: 359-367.

Iriarte, M.J. \& Meaza, G., 1996. Las Bardenas Reales: evolución del paisaje vegetal desde mediados del segundo milenio antes de Cristo a la actualidad. In: P. Ramil, C. Fernández \& M. Rodríguez (Coord.). Biogeografia Pleistocena-Holocena de la Península Ibérica, vol. II. Universidad de Santiago. Santiago de Compostela: 137-147.

Killington, F. J., 1937. A monograph of the British Neuroptera. Vol. 2. Ray Society. London. 306 pp.

Kis, B., 1968. Nachträge zur Neuropterenfauna Rumämiens. Folia Entomologica Hungarica, 21(2): 45-50.

Kis, B., Nagler, C. \& Mândru, C., 1970. Insecta: Neuroptera (Planipennia). Fauna Republicii Socialiste România, 8(6): 1-343.

Kovrigina, A. M., 1985. Introduction to the ecology of Chrysopidae (Neuroptera) from Middle Volga region. Neuroptera International, 3: 143-144.

Lacroix, J. L., 1924a. Chasses entomologiques. II. Feuille des Jeunes Naturalistes, 45: 115-117.

Lacroix, J. L., 1924b. Note sur les genres Chrysocerca, Weele et Chrysotropia, Navas (Ins., Planipennes Chrysopides). Compte Rendu de l'Association Française pour l'Avancement des Sciences, 47: 571-574.

Leraut, P., 1988. Cunctochrysa bellifontensis n. sp.: une espèce de chrysope nouvelle pour la science découverte en forêt de Fontainebleau (Neur. Chrysopidae). Bulletin de l'Association des Naturalistes de la Vallée du Loing et du Massif de Fontainebleau, 64: 230-235.

Leraut, P., 2003. La guide entomologique. Delachaux \& Niestlé. Lonay. 527 pp.

Lourenço, P., Brito, C., Backeljau, T., Thierry, D. \& Ventura, M.A., 2005. Molecular systematics on the Chrysoperla carnea group (Neuroptera: Chrysopidae) in Europe. Journal of Zoological Systematics and Evolutionary Research, 44(2): 180-184. http://dx.doi.org/ 10.1111/j.1439-0469.2006.00352.x.

Marín, C. \& Desir, G., 2008. Procesos de formación de coladas de barro en Bardenas Reales (Navarra, España). In: J. Benavente \& F. J. Gracia (eds.). Trabajos de Geomorfología en España. Actas X Reunión Nacional de Geomorfología, Cádiz: 93-96.

Marín, F. \& Monserrat, V. J., 1990. Contribución al conocimiento de los neurópteros de Soria (Insecta, Neuropteroidea). Boletín de la Asociación Española de Entomología, 14: 219-230.

Marín, F. \& Monserrat, V. J., 1995. Contribución al conocimiento de los neurópteros de Zaragoza (Insecta, Neuropteroidea). Zapateri, 5: 109-126.

Mazel, R., Canard, M. \& Thierry, D., 2006. Clés synoptiques des Chrysopidae de France (Neuroptera). Revue de l'Association Roussillonnaise d'Entomologie, 15: 29-45.

McEwen, P., New, T. R. \& Whittington, A. E., 2001. Lacewings in the Crop Environment. Cambridge University Press. Cambridge. 546 pp.
Meaza, G., 1987. Las Bardenas de Navarra. La Llanada alavesa Oriental, La Sierra de Aizkorri. Didáctica de los paisajes naturales del País Vasco. Tomo 2, I.C.E. Editorial y Universidad del País Vasco. Lejona. $164 \mathrm{pp}$.

Meaza, G., 1989. Caracterización fitogeográfica de las Bardenas de Navarra. Lurralde: Investigación y Espacio, 12: 45-69.

Monserrat, V. J., 1977a. Neuroptera (Planipennia) de la Sierra del Guadarrama. Trabajos de la Cátedra de Entomología, Facultad de Biología, Universidad Complutense, 19: 1-202.

Monserrat, V. J., 1977b. Brinckochrysa nachoi n.sp., nuevo crisópido en la fauna europea (Insecta, Neuroptera: Chrysopidae). Vie et Milieu, 27C: 267-277.

Monserrat, V. J., 1978a. Sobre los Neurópteros de las Islas Canarias I: Anisochrysa (Atlantochrysa) atlantica (McLachlan, 1882) (Plan., Chrysopidae). Boletín de la Asociación Española de Entomología, 1: 151-159.

Monserrat, V. J., 1978b. Contribución al conocimiento de los Neurópteros de Orense (Neu. Planipennia). Boletín de la Asociación Española de Entomología, 2: 169-184.

Monserrat, V. J., 1980. Contribución al conocimiento de los Neurópteros de Toledo. Graellsia, [1978], 34: 177-193.

Monserrat, V. J., 1982. Sobre los Neurópteros de las Islas Canarias III: Chrysopa flaviceps (Brullé, 1838) (Neur., Plan., Chrysopidae). Boletín de la Asociación Española de Entomología, 6: 113-119.

Monserrat, V. J., 1984a. Contribución al conocimiento de los neurópteros de Huesca (Neur., Planipennia). Pirineos, 121: 29-50.

Monserrat, V. J., 1984b. Contribución al conocimiento de los neurópteros de Zamora (Neur. Planipennia). Miscellania zoológica, 8: 153-163.

Monserrat, V. J., 1985. Contribución al conocimiento de los neurópteros de Lugo (Neur., Planipennia). Trabajos Compostelanos de Biología, 12: 87-98.

Monserrat, V. J., 1986. Sobre los Neurópteros ibéricos (IV) (Neur.). Boletín de la Asociación Española de Entomología, 10: 95-105.

Monserrat, V. J., 1987. Contribución al conocimiento de los Neurópteros de Almería (Neur., Planipennia). Graellsia, [1986], 42: 131-147.

Monserrat, V. J., 1996. Lista de los neurópteros de Aragón (Megaloptera, Raphidioptera, Planipennia). Catalogus entomofauna Aragonesa, 11: 11-17.

Monserrat, V. J., 2005. Catálogo de los Neurópteros de Baleares con nuevos datos sobre su fauna (Insecta, Neuroptera). Bolletí de la Societat d'Història Natural de les Balears, 48: 71-85.

Monserrat, V. J., 2008. Nuevos datos sobre algunas especies de crisópidos (Insecta: Neuroptera, Chrysopidae). Heteropterus Revista de Entomología, 8(1): 171-196.

Monserrat, V. J., 2010. Nuevas o interesantes citas de neurópteros en la Península Ibérica (Insecta: Neuroptera). Heteropterus Revista de Entomología, 10(1): 19-34.

Monserrat, V. J., 2011. Sobre algunas especies de neurópteros de la Península Ibérica y de las Islas Canarias de posición taxonómica problemática o con citas dudosas 
o cuestionables (Insecta, Neuroptera: Megaloptera, Planipennia). Boletín de la Sociedad Entomológica Aragonesa, 49: 153-178.

Monserrat, V. J., 2013. Los neurópteros (Insecta, Neuroptera) de Sierra Nevada. In: F. Ruano, J. M., Tierno de Figueroa \& A. Tinaut (eds.). Los insectos de Sierra Nevada. 200 años de historia. Vol. 1. Asociación Española de Entomología. Santa Fe: 283-309.

Monserrat, V. J. \& Díaz-Aranda, L. M., 1987. Contribución al conocimiento de los neurópteros de Cuenca (Neuropteroidea, Raphidioptera, Planipennia). Boletín de la Asociacion Española de Entomología, 11: 171-189.

Monserrat, V. J. \& Díaz-Aranda, L. M., 1988. Contribución al conocimiento de los neurópteros de Castellón (Insecta, Neuropteroidea, Planipennia). Mediterránea (Serie Estudios Biológicos), 10: 87-95.

Monserrat, V. J. \& Díaz-Aranda, L. M., 1989a. Nuevos datos sobre los crisópidos ibéricos (Neuroptera, Planipennia: Chrysopidae). Boletín de la Asociación Española de Entomología, 13: 251-267.

Monserrat, V. J. \& Díaz-Aranda, L. M., 1989b. Suarius walsinghami Navás, 1914, nuevo crisópido para la fauna europea (Neuroptera: Chrysopidae). Nouvelle Revue d'Entomologie (N.S.), 6(4): 407-411.

Monserrat, V. J. \& Díaz-Aranda, L. M., 1989c. Contribución al conocimiento de los neurópteros de Castellón (Insecta, Neuropteroidea, Planipennia). Mediterránea (Serie Estudios Biológicos), 11: 47-57.

Monserrat, V. J. \& Díaz-Aranda, L. M., 2012. Los estadios larvarios de los Crisópidos ibéricos (Insecta, Neuroptera, Chrysopidae), nuevos elementos sobre la morfología larvaria aplicables a la sistemática de la familia. Graellsia, 68(1): 31-158. http://dx.doi.org/10.3989/ graellsia.2012.v68.055.

Monserrat, V. J. \& Marín, F., 1994. Plant substrate specificity of Iberian Chrysopidae (Insecta: Neuroptera). Acta Oecologica, 15(2): 119-131.

Monserrat, V. J. \& Marín, F., 2001. Comparative plant substrate specificity of Iberian Hemerobiidae, Coniopterygidae and Chrysopidae. In: P. McEwen, T. R. New \& A. E. Whittington (eds.). Lacewings in the Crop Environment. Cambridge University Press. Cambridge: 424-434.

Monserrat, V. J., Marín, F. \& Díaz-Aranda, L. M., 1994. Contribución al conocimiento de los neurópteros de Lérida (Insecta, Neuroptera). Zoologica Baetica, 5: 41-64.

Monserrat, V. J., Oswald, J. D., Tauber, C. A. \& Díaz-Aranda, L. M., 2001. Recognition of larval Neuroptera. In: P. McEwen, T. R. New \& A. E. Whittington (eds.). Lacewings in the Crop Environment. Cambridge University Press. Cambridge: 43-81.

Monserrat, V. J. \& Rodrigo, F., 1992. Nuevas citas sobre los crisópidos ibéricos (Insecta, Neuroptera: Chrysopidae). Zoologica Baetica, 3: 123-138.

Monserrat, V. J. \& Triviño, V., 2013. Atlas de los neurópteros de la Península Ibérica e Islas Baleares (Insecta, Neuroptera: Megaloptera, Raphidioptera, Planipennia) / Atlas of the Iberian and Balearic lacewings (Insecta, Neuroptera: Megaloptera, Raphidioptera, Planipennia). Monografías de la Sociedad Entomológica Aragonesa, vol. 13. Zaragoza. 154 pp., 136 mapas.
Monserrat, V. J., Triviño, V. \& Acevedo, F., 2013. Contribución al conocimiento de los neurópteros de Navarra (Insecta, Neuroptera), Heteropterus Revista de Entomología, 13(1): 41-58.

Navás, L., 1901. Notas neuropterológicas. III. El género Chrysopa en España. Butlletí de la Institució Catalana d'Historia Natural, (1), 1: 23-28.

Navás, L., 1904. Notas zoológicas. I. Las Chrysopas (Insectos Neurópteros) de Chamartín de la Rosa (Madrid). Boletín de la Sociedad Aragonesa de Ciencias Naturales, 3: 115-122.

Navás, L., 1905. Catálogo descriptivo de los insectos Neurópteros de los alrededores de Madrid. Revista de la Real Academia de Ciencias Exactas Fisicas y Naturales de Madrid, 2: 521-574.

Navás, L., 1908. Neurópteros de España y Portugal. Brotéria (Serie Zoológica), 7: 5-133.

Navás, L., 1914a. Neurópteros del Moncayo (Zaragoza). Boletín de la Sociedad Aragonesa de Ciencias Naturales, 13: 207-218.

Navás, L., 1914b. Les Chrysopides (Ins. Névr.) du Musée de Londres. Annales de la Société scientifique de Bruxelles, 38: 73-114.

Navás L., 1914c. Neuroptera asiatica 3 series. Revue russe d'entomologie, 14: 6-13.

Navás, L., 1915. Crisòpids d'Europa (Ins. Neur.). Arxius de l'Institut d'Estudis Catalans, Secció de Ciencies, Barcelona, 3(2): 1-99.

Navás, L., 1917. Comunicaciones entomológicas. 2. Excursiones entomológicas por Aragón y Navarra. Revista de la Academia de Ciencias de Zaragoza, 2: 81-91.

Navás, L., 1918. Insecta nova. IV Series. Memorie della Pontificia Accademia delle Scienze Nuovi Lincei, 4: 13-23.

Navás, L., 1924a. Entomologia de Catalunya. Neuròpters. Fasc. I. Neuròpters propis. Fauna de Catalunya. Publicacions de L'Institut de Estudis Catalans, Seccio de Ciencias. Barcelona. 271 pp.

Navás, L., 1924b. Mis excursiones entomológicas del verano de 1924. Brotéria, 21(3): 115-150.

Navás, L., 1925a. Sinopsis de los Neurópteros (Ins.) de la Península Ibérica. Memorias de la Sociedad Ibérica de Ciencias Naturales, 4: 1-150.

Navás, L., 1925b. Neurópteros del Museo de Berlin. Revista de la Academia de Ciencias exactas, físicas, químicas y naturales de Zaragoza, 9: 20-34.

Navás, L., 1931. Entomología del Pirineo. Publicaciones de la Academia de Ciencias de Zaragoza, 1931-1932: 233-246.

Naville, A. \& Beaumont, J. de, 1933. Recherches sur les chromosomes des Névroptères. Archives d'Anatomie Microscopique, 29: 199-243.

Naville, A. \& Beaumont, J. de, 1936. Recherches sur les chromosomes des Névroptères (2ème partie). Archives d'Anatomie Microscopique 32: 271-302.

Neuman, H., 1960. El clima del sudeste de España. Estudios Geográficos, 21: 171-209.

New, T. R., 1984. The need for taxonomic revision in Chrysopidae. In: M. Canard, Y. Séméria \& T. R. New (eds.). Biology of Chrysopidae. W. Junk. The Hague: 37-42. 
Ohm, P. \& Báez, M., 2004. Lista de especies silvestres de Canarias (Hongas, Plantas y Animales Terrestres). In: I. Izquierdo Zamora, J. L. Martín Esquivel, N. Zurita Pérez \& M. Arechavaleta Hernández (eds.). Gobierno de Canarias. La Laguna. 500 pp. (Planipennia, pp. 207-208).

Ohm, P. \& Remane, R., 1968. Die Neuropterenfauna Hessen und einiger angrenzender Gabiete (zur Verbreitung der Neuropteren in Mitteleuropa). Faunistish-Ökologische Mitteilungen, 3(6): 209-228.

Pantaleoni, R. A., 1982. Neuroptera Planipennia del comprensorio della Valli di Comacchio: indagine ecologica. Bollettino dell'Istituto di Entomologià della Università degli Studi di Bologna, 37: 1-73.

Pantaleoni, R. A., 1988. La Neurotterofauna dell'Appennino romagnolo. Atti XV Congresso Nazionale Italiano di Entomologia, L’Aquila: 633-640.

Pantaleoni, R. A., 1990. I Neurotteri (Neuropteroidea) della Valle del Bidente-Ronco (Appennino Romagnolo). Bollettino dell'Istituto di Entomologià "Guido Grandi" della Università di Bologna, 44: 89-142.

Plant, C. W., 1993. Cunctochrysa bellifontensis n. sp.: Leraut, 1988 (Neuroptera: Chrysopidae), a lacewing new to Britain, with a note on its identification. Entomologist's Gazette, 44: 41-44.

Plant, C. W. \& Schembri, S., 1996. A review of the Neuropteroidea of the Mediterranean islands of Malta, Gozo and Comino (the Maltese Islands) (Neuroptera: Coniopterygidae, Hemerobiidae, Chrysopidae, Myrmeleontidae). Entomofauna, 17(2): 25-36.

Pongrácz, S., 1912. Magyarország Chrysopái alak-és rendszertani tekintetben. Állattani Közlemények, 11(4): 161-221.

Pongrácz, S., 1913. Ujabb adatok Magyarország Neuroptera-faunájához. Rovartani Lapok, 20(9-10): 175-186.

Popov, A., 1993. Raphidiopteren und Neuropteren aus Bulgarien in den Sammlungen des Nationalmuseums in Prag. Historia Naturalis bulgarica, 4: 16-28.

Principi, M. M., 1946. Contributi allo studio dei "neurotteri" italiani. IV. Nothochrysa italica Rossi. Bollettino dell'Istituto di Entomologià della Università degli Studi di Bologna, 15: 85-102.

Principi, M. M., 1949. Contributi allo studio dei Neurotteri Italiani. VIII. Morfologia, anatomia e funzionamento degli apparati genitali nel gen. Chrysopa Leach (Chrysopa septempunctata Wesm. e C. formosa Brauer). Bollettino dell'Istituto di Entomologià della Università degli Studi di Bologna, 17: 316-362.

Principi, M. M., 1954. Contributi allo studio dei Neurotteri Italiani. XI. Chrysopa viridana Schn. Bollettino dell'Istituto di Entomologià della Università degli Studi di Bologna, 20: 359-376.

Principi, M. M., 1956. Contributi allo studio dei Neurotteri Italiani. XIII. Studio morfologico, etologico e sistematico di un gruppo omogeneo di specie del Gen. Chrysopa Leach (C. flavifrons Brauer, prasina Burm. e clathrata Schn.). Bollettino dell'Istituto di Entomologià della Università degli Studi di Bologna, 21: 319-410.

Principi, M. M., 1977. Contributi allo studio dei Neurotteri Italiani. XXI. La morfologia addominale ed il suo valore per la discriminazione generica nell' ambito delle
Chrysopinae. Bollettino dell'Istituto di Entomologià della Università degli Studi di Bologna, 31: 325-360.

Principi, M. M. \& Canard, M., 1984. Feeding habits. In: M. Canard, Y. Séméria \& T. R. New (eds.). Biology of Chrysopidae. W. Junk. The Hague: 76-92.

Rivas Goday, S., 1948. La aridez e higrocontinentalidad en las provincias de España y su relación con las comunidades vegetales climáticas (clímax). Anales del Jardín Botánico de Madrid, 7: 501-510.

San Martin, G., 2004. Clé de détermination des Chrysopidae de Belgique. Jeunes \& Nature. Wavre. 42 pp.

Schneider, W. G., 1851. Symbolae ad monographiam generis Chrysopae Leach. Hirt. Vratislaviae. 178 pp. 60 plates.

Schoch, G., 1885. Zusätze und Berichtigungen zur Fauna Neuropterorum helvetica. Neuroptera Helvetiae, 1886: 89-94.

Séméria, Y., 1978. Observations sur l'autoécologie et la synécologie des principales espèces de Chrysopinae (Neuroptera, Planipennia) du Sud-Est de la France, des genres Italochrysa Principi et Chrysopa Leach. Bulletin of Ecology, 9: 231-251.

Séméria, Y., 1984a. Some caryotypes in Chrysopidae. In: M. Canard, Y. Séméria \& T. R. New (eds.). Biology of Chrysopidae. W. Junk. The Hague: 42-48.

Séméria, Y., 1984b. Savannah: Mediterranean climates. In: M. Canard, Y. Séméria \& T. R. New (eds.). Biology of Chrysopidae. W. Junk. The Hague: 167-180.

Sengonca, C., 1980. Türkiye Chrysopidae (Neuroptera) faunasi üzerinde Sistematik ve taksonomik arastirmalar. Zirai Micadele ve Zirai Karantina Genel Müdürlügü. Ankara. 138 pp.

Steinmann, H., 1964. The Chrysopa Species (Neuroptera) of Hungary. Annales Historico-Naturales Musei Nationalis Hungarici, 56: 257-266.

Stephens, J.F., 1836. Illustrations of Brithish Entomology, or a synopsis of indigenous insects: containing their generic and specific distinctions; with an account of their metamorphoses, times of appearance, localities, food, economy ... Mandibulata. Vol. 6. Baldwin and Cradock. London. 240 pp., 28-34 pl.

Suárez Cardona, F., Sáinz Ollero, H., Santos Martínez, T. \& González Bernáldez, F., 1992. Las estepas ibéricas [Monografias]. Ministerio de Obras Públicas y Transportes. Madrid. $160 \mathrm{pp}$.

Szentkirályi, F., 2001. Lacewings in vegetables, forest, and other crops. In: P. McEwen, T. R. New \& A. E. Whittington, Lacewings in the Crop Environment. Cambridge University Press. Cambridge: 239-291.

Tauber, C. A. \& Tauber, M. J., 1973. Diversification and secondary intergradation of two Chrysopa carnea strains (Neuroptera: Chrysopidae). Canadian Entomologist, 105(9): 1153-1167. http://dx.doi.org/10.4039/ Ent1051153-9.

Thierry, D. \& Adams, P. A., 1992. Round table discussion on the Chrysoperla carnea complex (Insecta: Neuroptera: Chrysopidae). In: M. Canard, H. Aspöck \& M. W. Mansell (eds.). Current Research in Neuropterology. Proceedings of the Fourth International Symposium on Neuropterology, Toulouse: 367-377. 
Thierry, D., Canard, M., Ventura, M., Lourenço, P. \& Lodé, T., 2013. Is Chrysoperla agilis Henry et al., 2003 (Neuroptera: Chrysopidae) a shadow species as an outcome of common green lacewings' character displacement in Europe? Açoreana, Suplemento 9: 73-82.

Thierry, D., Cloupeau, R. \& Jarry, M., 1992. La chrysope commune Chrysoperla carnea (Stephens) sensu lato dans le centre de la France: mise en évidence d'un complexe d'espèces (Insecta: Neuroptera: Chrysopidae). In: M. Canard, H. Aspöck \& M. W. Mansell (eds.). Current Research in Neuropterology. Proceedings of the Fourth International Symposium on Neuropterology, Toulouse: 379-392.

Thierry, D., Cloupeau, R. \& Jarry, M., 1996. Distribution of the sibling species of the common green lacewing Chrysoperla carnea (Stephens) in Europe (Insecta: Neuroptera: Chrysopidae). In: M. Canard, H. Aspöck \& M. W. Mansell (eds.). Pure and Applied Research in Neuropterology. Proceedings of the 5th International Symposium on Neuropterology, Toulouse: 233-240.

Thierry, D., Cloupeau, R., Jarry, M. \& Canard, M., 1998. Discrimination of the West-Palaearctic Chrysoperla Steinmann species of the carnea Stephens group by means of claw morphology (Neuroptera, Chrysopidae). Acta Zoologica Fennica, 209: 255-262.

Thierry, D., Ribodeau, M., Foussard, F. \& Jarry, M., 1997. Allozyme polymorphism in a natural population of Chrysoperla carnea sensu lato (Neuroptera: Chrysopidae): A contribution to the status of the constitutive taxons in western Europe. European Journal of Entomology, 94: 311-316.

Ursúa, C., 1985. Las Bardenas Reales. Perfil ecológico y botánico. Gorosti, 2: 49-54.

Vanden Broeck, A., 2003. Euforgen Technical Guidelines for genetic conservation and use for European black poplar (Populus nigra). International Plant Genetic Resources Institute. Rome. 6 pp.
Vanden Broeck, A.H., Storme, V., Cox, K., Quataert, P., Ivens, B., Hostyn, V., Halfmaerten, D., Boerjan, W. \& Van Slycken, J., 2002. Mating system of $P$. nigra in a mixed poplar stand composed of $P$. nigra, $P$. deltoides and P. euramericana. In: B. C. Van Dam \& B. Sandor (eds.). Genetic Diversity in River Populations of European Black Poplar Implications for Riparian Eco-system Management. Csiszár Nyomda. Budapest: 53-60.

Ventura, M. A., Thierry, D. \& Coderre, D., 2002. Origins and composition of the "Chrysoperla carnea complex" (Neuroptera: Chrysopidae) in the Azores and Madeira Islands. Proceedings IV Symposium on Fauna \& Flora of the Atlantic Islands, Praia: 135-141.

Vidal y López, M., 1943. Catálogo provisional de Neurópteros de la región levantina. Graellsia, 1(6): 13-24.

Volkovich, T.A., 1998. Environmental control of seasonal cycles in green lacewings (Neuroptera: Chrysopidae) from the forest-speppe zone of Russia. Acta Zoologica Fennica, 209: 263-275.

Walker, F., 1853. List of specimens of Neuropterous insects in the collection of the British Museum (Sialidae-Nemopteridae). Notes from the Leyden Museum, 2: 193-476.

Wells, M. M. \& Henry, C. S., 1992. The role of courtship songs in reproductive isolation among populations of green lacewings of the genus Chrysoperla (Neuroptera: Chrysopidae). Evolution, 46(1): 31-42. http://dx.doi. org/10.2307/2409802.

Wood, C. D., 1994. A Most Dangerous Tree: The Lombardy Poplar in Landscape Gardening. Arnoldia, 54 (1): 24-30.

\section{Enlaces citados}

Euforgen: www.euforgen.org

Foro Insectos: http://insektenfotos.de/forum/thread.php? threadid $=59557$

Las Bardenas Reales: http://www.bardenasreales.es/ reserva h.htm 
Apéndice 1.- Coordenadas UTM y altitud de las localidades ibero-baleares y canarias citadas.

Appendix 1.- UTM coordinates and altitude of the Iberian-Balearic and Canary locations cited.

\section{ESPAÑA:}

Almería

Agua Amarga, 30SWF98, $30 \mathrm{~m}$

Almería, Base Legión, 30SWF58, $165 \mathrm{~m}$

Almerimar, 30SWF16, $20 \mathrm{~m}$

Amoladeras, 30SWF67, $30 \mathrm{~m}$

Atochares, Rambla Artal, 30SWF78, $206 \mathrm{~m}$

Cueva de las Medinas, 30SWF67, $100 \mathrm{~m}$

Cuevas de Sorbas, 30SWG70, $430 \mathrm{~m}$

El Pozo de los Frailes, 30SWF77, $40 \mathrm{~m}$

El Toyo, Rambla del Agua, 30SWF67, $15 \mathrm{~m}$

Gérgal, 30SWG40, $860 \mathrm{~m}$

Las Negras, 30SWF88, $20 \mathrm{~m}$

Níjar, 30SWF79, $271 \mathrm{~m}$

La Rambla Honda, 30SWF79, 597 m

Punta Entina-Sabinar, 30SWF26, $10 \mathrm{~m}$

Rambla de Torregarcía, 30SWF67, $10 \mathrm{~m}$

Retamar, 30SWF67, 27 m

Retamar, Rambla del Retamar, 30SWF67, 36 m

San José, La Torta, 30SWF76, 30 m

San José, Los Genoveses, 30SWF76, $10 \mathrm{~m}$

San José, Playa de Mónsul, 30SWF76, 12 m

Tabernas, 30SWF50, $400 \mathrm{~m}$

Tabernas, Rambla Oasis, 30SWF59, $350 \mathrm{~m}$

Tabernas, Rambla Roja, 30SWF50, $450 \mathrm{~m}$

Turrillas, 30SWF69, $1000 \mathrm{~m}$

Vera, 30SXG02, $80 \mathrm{~m}$

Vícar, 30SWF37, $310 \mathrm{~m}$

\section{Asturias}

Luarca, 29TPJ92, $30 \mathrm{~m}$

La Viliella, Muniellos, 29TPH88, $850 \mathrm{~m}$

\section{Badajoz}

Fregenal de la Sierra, 29SQC02, $724 \mathrm{~m}$

Río Ardila, 29SQC13, $340 \mathrm{~m}$

Río Sillo, 29SQC01, 405 m

Santa María de los Barros, 29AQC07, 500 m

Valverde de Burguillos, 29SQC14, 425 m

Barcelona

Cabrils, 31TDF49, $148 \mathrm{~m}$

Cabrils, Can Tolrá, 31TDF49, $200 \mathrm{~m}$

Baleares, Ibiza

Es Cavallet, 31SCD60, $10 \mathrm{~m}$

Santa Eulalia, 31SCD71, $80 \mathrm{~m}$

Baleares, Menorca

Binisafua, 31SFE00, $20 \mathrm{~m}$

Ciutadella, 31SEE72, $25 \mathrm{~m}$

Far de Favàritx, 31SFE02, $10 \mathrm{~m}$

Platja d'Esgrau, 31SFE02, $14 \mathrm{~m}$

Poblat de Torralba, 31SEE72, $72 \mathrm{~m}$

Sa Roca, El Toro, 31SEE92, $221 \mathrm{~m}$

Son Bou, 31SEE91, $65 \mathrm{~m}$

Torre d'en Galmés, 31SEE91, 105 m

Torret, 31SFE01, $62 \mathrm{~m}$

Burgos

Burgos, 30TVM48, $900 \mathrm{~m}$

Cádiz

Algodonales, 30STF88, $350 \mathrm{~m}$

Barbate, 30STF31, $65 \mathrm{~m}$

Bolonia, 30STE59, $10 \mathrm{~m}$

Bonanza, 29SQA38, $10 \mathrm{~m}$
Chiclana, 29SQA53, $30 \mathrm{~m}$

Estación de la Almoraima, 30STF81, 45 m

Facinas, 30STF50, $95 \mathrm{~m}$

La Marchenilla, 30STE79, $155 \mathrm{~m}$

Parque Natural del Estrecho, 30STE68, $85 \mathrm{~m}$

Pedro Valiente, Playa de los Lances, 30STE69, $10 \mathrm{~m}$

Pinsapar de Grazalema, 30STF87, 770 m

Playa de los Lances, 30STE69, $10 \mathrm{~m}$

Puerto del Boyar, 30STF87, 1100 m

Ciudad Real

Navas de Estena, 30SUJ69, 675 m

\section{Cuenca}

Puerto Cabrejas, 30TWK53, $1150 \mathrm{~m}$

Uña, 30TWK87, 1142 m

Valdemeca, 30TXK05, $1320 \mathrm{~m}$

Vega del Codorno, 30TWK97, $1480 \mathrm{~m}$

Verdelpino de Cuenca, El Chantre, 30TWK34, 948 m

\section{Gerona}

Molló, 31TDG58, 1070 m

\section{Granada}

Albondón, 30SVF87, $1076 \mathrm{~m}$

Cádiar, 30SVF88, $1000 \mathrm{~m}$

Calahonda, 30SVF66, $10 \mathrm{~m}$

Cáñar, 30SVF68, 1353 m

Cerro Gordo, Cantarriján, 30SVF36, 10 m

Collado de la Sabina, 30SVG60, $2050 \mathrm{~m}$

Dehesa del Camarate, 30SVG71, 1689 m

Dúdar, 30SVG51, $900 \mathrm{~m}$

El Dornajo, 30SVG50, 807 m. $1750 \mathrm{~m}$

El Rescate, 30SVF37, $850 \mathrm{~m}$

Ferreira, 30SVG95, $1356 \mathrm{~m}$

Fuente de la Cortichuela, 30SVG50, $1900 \mathrm{~m}$

Gualchos, 30SVF66, $30 \mathrm{~m}$

Haza del Lino, 30SVF77, $1240 \mathrm{~m}$

Hoya de la Mora, 30SVG60, $2200 \mathrm{~m}$

Huétor de Santillán, 30SVG52, $1083 \mathrm{~m}$

Jete, 30SVF47, $360 \mathrm{~m}$

La Herradura, Cerro Gordo, 30SVF36, 75 m

La Herradura, Punta de la Mona, 30SVF36, $100 \mathrm{~m}$

La Herradura, Las Cuevas, 30SVF36, $100 \mathrm{~m}$

Lobras, 30SVF88, $822 \mathrm{~m}$

Los Tablones, 30SVF56, $300 \mathrm{~m}$

Lugros, 30SVG71, $1600 \mathrm{~m}$

Majadillas, 30SVG70, $2454 \mathrm{~m}$

Monachil, 30SVG51, $900 \mathrm{~m}$

Otivar, 30SVF37, $215 \mathrm{~m}$

Pinos Puente, Moclín, 30SVG33, $700 \mathrm{~m}$

Pitres, 30SVF78, $1333 \mathrm{~m}$

Puerto de la Ragua, 30SWF09, $1254 \mathrm{~m}$

Puerto del Trevenque, 30SVG50, $2000 \mathrm{~m}$

Soportújar, 30SVF69, $1550 \mathrm{~m}$

Vélez de Benaudalla, 30SVF54, 156 m

\section{Guadalajara}

Brihuega, 30TWL11, $905 \mathrm{~m}$

Molina de Aragón, 30TWL92, 1100 m

Guipúzcoa

Ataun, Aia, Aralar P.N. Urkillaga, 30TWN68, 614 m

Huelva

La Corte, 29SPB99, $520 \mathrm{~m}$

La Nava, 29SPC90, $330 \mathrm{~m}$ 
Matalascañas, 29SQA19, $30 \mathrm{~m}$

Patrás, 20SQB08, $400 \mathrm{~m}$

Puerto Blanco, 29SPB95, $275 \mathrm{~m}$

Punta Umbría, 29SPB81, 10 m

Huesca

Hecho, 30TXN83, $860 \mathrm{~m}$

San Juan de Plan, 31TBH81, 1390 m

Islas Canarias, Fuerteventura

Costa Calma, 28RES71, $40 \mathrm{~m}$

Jandia, 28RES60, $38 \mathrm{~m}$

Islas Canarias, Gran Canaria

Barranco de La Mina, 28RDS22, $100 \mathrm{~m}$

Marzagán, 28RDS59, $70 \mathrm{~m}$

Sardina, 28RDS31, $38 \mathrm{~m}$

Islas Canarias, Lanzarote

Los Claveles, Playa Blanca, 28RFS19, 17 m

Islas Canarias, Tenerife

Bajamar, 28RCS65, $50 \mathrm{~m}$

Barranco del Agua, 28RCS22, $120 \mathrm{~m}$

Cumbres de Arafo, 28RCS60, $1300 \mathrm{~m}$

Las Cañadas, 28RCS42, $220 \mathrm{~m}$

Monte del Agua, 28RCS64, $800 \mathrm{~m}$

Puerto de la Cruz, 28RCS44, 83 m

Jaén

Cazorla, Camino Agracea, 30SWH14, 815 m

Jándula, 30SVH13, 530 m

León

León, Azucarera, 30TTN81, 838 m

Lérida

Rubió, 31TCG59, 1700 m

Madrid

Abantos, Arboreto L. Ceballos, 30TVK09, 1319 m

Abantos, Fuente del Cerevunal, 30TVK09, 1650 m

Alcorcón, 30TVK36, $700 \mathrm{~m}$

Alcalá de Henares, 30TVK69, 688 m

Alpedrete, 30TVL10, $930 \mathrm{~m}$

Barranca de Navacerrada, 30TVL11, $1550 \mathrm{~m}$

Cerdedilla, Estación Alpina, 30TVL10, $1500 \mathrm{~m}$

Cercedilla, Los Dehesas, 30TVL01, $1300 \mathrm{~m}$

Cercedilla, El Regidor, 30TVL11, $1300 \mathrm{~m}$

Cercedilla, Cerro Colgado, 30TVL11, $1290 \mathrm{~m}$

Ciudad Universitaria, 30TVK37, $640 \mathrm{~m}$

Chamartín, 30TVK47, $620 \mathrm{~m}$

Chinchón, El Salitral, 30TVK 54, 560 m

El Escorial, Abantos, 30TVK09, $1730 \mathrm{~m}$

El Ventorrillo, 30TVL11, $1500 \mathrm{~m}$

Embalse de la Pedrezuela, 30TVL41, $900 \mathrm{~m}$

Fuentidueña de Tajo, 30TVK84, $695 \mathrm{~m}$

La Jarosa, 30TVL20, $1100 \mathrm{~m}$

La Pedriza, 30TVL51, $950 \mathrm{~m}$

Montarco, Rivasvaciamadrid, 30TVK56, 633 m

Navacerrada, 30TVL14, $1313 \mathrm{~m}$

Navalpinganillo, 30TVL21, $1500 \mathrm{~m}$

Pradera de Navalhorno, 30TVL12, $1210 \mathrm{~m}$

Puerto de Cotos, 30TVL12, $1850 \mathrm{~m}$

Puerto de la Fuenfría, 30TVL11, 1800 m
Puerto de la Morcuera, 30TVL22, $1600 \mathrm{~m}$

Puerto de los Leones, 30TVL00, $1640 \mathrm{~m}$

Puerto de Navacerrada, 30TVL11, $1750 \mathrm{~m}$

Rascafría, El Paular, Los Hoyones, 30TVL25, 1163 m

San Fernando de Henares, 30TVK57, 559 m

Tablada, 30TVL0506, $1240 \mathrm{~m}$

\section{Málaga}

Algarrobo, 30SVF07, $289 \mathrm{~m}$

Benamocarra, 30SUF97, $140 \mathrm{~m}$

Coín, Sierra de la Alpujata, 30SUF45, $440 \mathrm{~m}$

El Madroñal, Embalse del Río Guadaiza, 30SUF24, 129 m

Estepona, Sa . Bermeja, Río Padrón, 30SUF03, 140 m

Frigiliana, 30SVF27, $790 \mathrm{~m}$

Las Asomadillas, 30STF73, $175 \mathrm{~m}$

Las Cañillas, 30STF74, $160 \mathrm{~m}$

Navahermosa, 30SUG31, $430 \mathrm{~m}$

Sayalonga, 30SVF08, $430 \mathrm{~m}$

Torrox, 30SVF16, $355 \mathrm{~m}$

Vélez Málaga, 30SVF07, 100 m

Murcia

Playa de las Moreras, 30SXG45, $10 \mathrm{~m}$

Navarra

Ablitas, 30TXM14, $380 \mathrm{~m}$

Arguedas, 30TXM27, $280 \mathrm{~m}$

\section{Orense}

Allariz, 29TNG97, $500 \mathrm{~m}$

Caxide, 29TNG66, $770 \mathrm{~m}$

Vilavella, 29TPG65, $1033 \mathrm{~m}$

\section{Pontevedra}

Fontán, 29TNH30, $194 \mathrm{~m}$

Pereiro, 29TNH71, $150 \mathrm{~m}$

Salamanca

Berruecopardo, 29TPF94, $720 \mathrm{~m}$

Segovia

La Granja, 30TVL12, $1190 \mathrm{~m}$

San Rafael, 30TUL90, $1250 \mathrm{~m}$

Sierra Calva, 30TVL44, $1440 \mathrm{~m}$

Tarragona

Arnes, 31TBF63, $500 \mathrm{~m}$

Teruel

Saldón, 30TXK36, 1430 m

Toledo

Navamorcuende, 30TUK44, 1310 m

Zamora

Otero de Sanabria, 29TQG05, $967 \mathrm{~m}$

Puebla de Sanabria, 29TPG95, $1050 \mathrm{~m}$

San Pedro de las Herrerías, 29TQG14, 920 m

Zaragoza

Chodes, 30TXL29, $455 \mathrm{~m}$

Granja de San Pedro, 30TXL29, 794 m

Perdiguera, 30TXM92, $480 \mathrm{~m}$.

Veruela, 30TXM02, $630 \mathrm{~m}$

\section{PORTUGAL:}

Guarda

Manteigas (Serra da Estrêla), 29TPE27, 940 m 